Aus der Klinik für Mund-, Kiefer- und Gesichtschirurgie

(Prof. Dr. med. Dr. med. dent. H. Schliephake)

im Zentrum Zahn-, Mund- und Kieferheilkunde

der Medizinischen Fakultät der Universität Göttingen

\title{
Experimentelle Untersuchung zur Alveolarkammaugmentation mit Trikalziumphosphat- Hydroxylapatit-Komposit eingebettet in eine Poloxamermatrix
}

\author{
INAUGURAL-DISSERTATION \\ zur Erlangung des Doktorgrades für Zahnheilkunde \\ der Medizinischen Fakultät der \\ Georg-August-Universität zu Göttingen
}

vorgelegt von

Mona Köwing, geb. Drewes

aus

Hannover

Göttingen 2014 
Dekan:

1. Berichterstatter:

2. Berichterstatter/in:
Prof. Dr. rer. nat. H. K. Kroemer

Prof. Dr. med. Dr. med. dent. H. Schliephake

Prof. Dr. med. N. Miosge

Tag der mündlichen Prüfung: 16.03.2015 


\section{Inhaltsverzeichnis}

1 EINLEITUNG 1

1.1 KNOCHENGEWEBE 2

1.2 KNOCHENERSATZMATERIALIEN

1.2.1 AUTOLOGER KNOCHENERSATZ

1.2.2 ALLOGENER KNOCHENERSATZ 8

1.2.3 XENOGENER KNOCHENERSATZ

1.2.4 PHYKOGENER KNOCHENERSATZ 9

1.2.5 AlLOPLASTISCHER KNOCHENERSATZ 11

1.3 GUIDED BONE REGENERATION (GBR) 12

1.4 DEgRadierbare POLYMERE

$\begin{array}{lll}1.5 & \text { Fragestellung } & 16\end{array}$

$\underline{2}$ MATERIAL UND METHODEN

$\begin{array}{lll}2.1 & \text { VERSUCHSÜBERSICHT } & 17\end{array}$

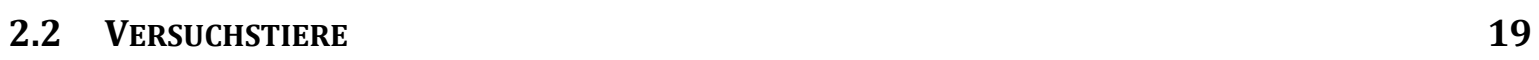

$\begin{array}{llr}2.3 & \text { POLOXAMER } 407 & 19\end{array}$

2.4 OPERATIVES VORGEHEN

2.5 AUFBEREITUNG DES KNOCHENMATERIALS

2.5.1 GeRÄTE UND MATERIALIEN 24

2.5.2 VORGEHENSWEISE 24

2.6 TRENN-DÜNNSCHLIFF-TEChNIK 25

2.6.1 GERÄTE UND MATERIALIEN 25

2.6.2 HeRSTELLUNG DER PRÄPARATE 25

2.7 FÄRBUNG $\quad 27$

2.7.1 REAGENZIEN Und CHEMIKALIEN FÜR DIE FÄRBUng DER HISTOLOGISCHEN PRÄPARATE 27

2.7.2 FÄrbUnG DER PRÄPARATE 28

2.8 HISTOMORPHOMETRIE $\quad 29$

2.8.1 GERÄTE UND SOFTWARE FÜR DIE HISTOMORPHOMETRIE 29

2.8.2 DigitalisieREN DER PRÄPARATE 30

2.8.3 MARKIERUNG DER FLÄCHEN MIT PHOTOSHOP 31

2.8.4 FLÄCHENMESSUNG MITTELS AXIOVISION

2.8.5 MESSUNG DER MAXIMALEN DEFEKTAUSDEHNUNG 36

$\begin{array}{lll}2.8 .6 & \text { STATISTISCHE AUSWERTUNG } & 37\end{array}$

$\underline{3} \quad \underline{\text { ERGEBNISSE }} \quad 39$ 
3.1 KLINISCHE HEILUNG 39

3.2 QUALITATIVE HISTOLOGISCHE UNTERSUCHUNG 39

3.3 HISTOMORPHOMETRISCHE UNTERSUCHUNG 46

3.3.1 REGENERIERTE KNOCHENFLÄCHE 46

3.3.2 KNOCHENERSATZMATERIAL IM REGENERATIONSBEREICH

3.3.3 FLÄCHENANTEIL DER KNÖCHERNEN REGENERATION 48

3.3.4 KNOCHENHÖHE IM VERGLEICH ZUR ORIGINALHÖHE 49

3.3.5 ERHALT DER AUGMENTIERTEN HÖHE UND BREITE 50

3.3.6 KNOCHENDICHTE 52

4 DISKUSSION $\quad 55$

4.1 DISKUSSION DER METHODE

4.2 DISKUSSION DER ERGEBNISSE

$\underline{5}$ ZUSAMMENFASSUNG $\quad 66$

$\underline{6}$ ABBILDUNGSVERZEICHNIS $\quad 67$

$\underline{7} \quad$ LITERATURVERZEICHNIS $\quad 69$

$8 \underline{8}$ ANHANG $\quad 85$ 


\section{Abkürzungsverzeichnis}

bone morphogenetic protein

Humanes Immundefizienz-Virus

Hydroxylapatit

Knochenersatzmaterial

koronare Herzerkrankung

platelet derived growth factor

plättchenreiches Plasma

Polyethylenglykol

receptor activator of nuclear factor kappa $B$

transforming growth factor beta

Trikalziumphosphat
BMP

HIV

HA

KEM

KHK

PDGF

PRP

PEG

RANK

TGF- $\beta$

TCP 


\section{$1 \quad$ Einleitung}

Nach Angaben der Deutschen Gesellschaft für Implantologie werden derzeit in Deutschland jährlich mehr als eine Million Implantate verkauft, mit weiterhin steigender Tendenz (2010). Obwohl heutzutage fest verankerter, implantatgetragener Zahnersatz für viele Patienten ein selbstverständlicher Wunsch ist, sind die indiviuduell vorliegenden anatomischen Gegebenheiten nicht immer als stabiles Implantatlager geeignet. Häufig liegt zum Beispiel durch ausgeprägte Atrophie des Alveolarfortsatzes, Trauma oder Entzündungen ein $\mathrm{zu}$ geringes Knochenangebot vor, das augmentative Maßnahmen erforderlich macht. Zur Augmentation wurden in der Vergangenheit verschiedenste Materialien und Methoden angewendet, wobei eine Transplantation körpereigenen Knochens weiterhin als Goldstandard gilt (LAURENCIN et al. 2006). Aufgrund der bestehenden Nachteile des autologen Knochens, wie zum Beispiel der zusätzlichen Entnahmeoperation mit möglichen Nervschädigungen, Gewebeschädigungen oder Narbenzügen, wird weiterhin nach Alternativen zum Eigenknochen gesucht. Besonders bei vertikalen Alveolarfortsatzaugmentationen ist der Einsatz von partikulärem Knochenersatzmaterial aufgrund mangelnder dreisimensionaler Formstabilität kritisch.

Ziel dieser Studie war es herauszufinden, inwieweit eine resorbierbare Poloxamermatrix bei einer vertikalen Alveolarkammaugmentation dazu beitragen kann, partikuläres Trikalziumphosphat-Hydroxylapatit-Komposit in der gewünschten Form zu stabilisieren, ohne dabei die knöcherne Regeneration zu stören. 


\subsection{Knochengewebe}

Knochengewebe ist ein besonders stabiles, auf seine Stütz- und Skelettfunktion spezialisiertes Gewebe, das außerdem Speicherort verschiedener Ionen und Ort der Hämatopoese ist.

Makroskopisch lassen sich am Knochen zwei verschiedene Strukturen unterscheiden: Kompakta und Spongiosa. Spongiöser Knochen besteht aus einem dreidimensionalen Trabekelsystem feiner Knochenbälkchen und befindet sich im Knocheninneren. Zwischen den Trabekeln, die entsprechend der funktionellen Belastung ausgerichtet sind, befindet sich das Knochenmark. Diese Bauweise ermöglicht eine hohe Festigkeit bei vergleichsweise geringem Gewicht (WELSCH 2006). Die Kompakta bildet die homogene, äußere Schicht des Knochens. Nach Devlin et al. (1998) ist die Dichte der Maxilla aufgrund des hohen Spongiosaanteils nicht nur geringer als die Dichte der Mandibula, sondern zudem auch innerhalb der Maxilla nicht konstant. Der posteriore Anteil der Maxilla hat die geringste knöcherne Dichte, da der Anteil der Spongiosa von anterior nach posterior zunimmt (DEVLIN et al. 1998).

Zwei verschiedene Formen von Knochen lassen sich unterscheiden: Geflechtknochen und Lamellenknochen. Geflechtknochen entsteht in der Entwicklung zuerst und entspricht unreifem Knochen aus verwobenen Kollagenfibrillen. Durch weitere Ausreifung entsteht daraus biomechanisch hochwertigerer Lamellenknochen. Die Kompakta des Lamellenknochens ist aus Osteonen und die Spongiosa aus geschichteten Knochenlamellen aufgebaut. Diese Knochenlamellen sind etwa 3-7 $\mu \mathrm{m}$ dick und bestehen aus etwa gleich ausgerichteten, mineralisierten Kollagenfibrillen (WELSCH 2006). Osteone bestehen aus konzentrischen Knochenschichten um einen zentralen, gefäßführenden Kanal, genannt Havers-Kanal, mit Ernährungsfunktion. Der Durchmesser der Osteone beträgt zwischen 100 und $400 \mu \mathrm{m}$ (WELSCH 2006). Querverbindungen zwischen den Havers-Kanälen heißen Volkmann-Kanäle.

Zwischen den Osteonen liegen die Schaltlamellen, wobei es sich um Überreste älterer Osteone handelt. Diese sind Ausdruck der lebenslangen Dynamik des Knochenumbaus, genannt Remodelling. Dabei passt sich der Knochen Belastungen an und wird regelmäßig erneuert. Als Speicherort von Kalzium und Phosphat dienen Umbaumaßnahmen des Knochens auch der Homöostase des Kalzium- und Phosphathaushaltes. Hormone wie Parathormon, Kalzitriol und Kalzitonin sowie die Plasmakonzentrationen der genannten Ionen steuern somit auch den Knochenmetabolismus. 
Mikroskopisch besteht Knochengewebe aus verschiedenen Zellen und einer extrazellulären Matrix, welche sich vorwiegend aus Kollagenfibrillen (Typ 1) und daran angelagerten Hydroxylapatitkristallen zusammensetzt. Daneben finden sich in geringerem Ausmaße noch andere Proteine wie Osteokalzin, Osteopontin und Osteonektin (WELSCH 2006).

Knochenzellen sind Knochen bildende Osteoblasten, Knochen abbauende Osteoklasten und Osteozyten. Osteozyten sind eingebaute, ehemalige Osteoblasten, die in Lakunen zwischen den Knochenlamellen liegen (FRANZ-ODENDAAL et al. 2006). In Knochenkanälchen stehen die Ausläufer dieser Osteozyten miteinander und mit den Zellen des Endosts über Gap-Junctions in Verbindung (FRANZ-ODENDAAL et al. 2006).

Werden die Osteozyten avital, so beginnen Osteoklasten damit, den Knochen abzubauen (TATSUMI et al. 2007).

Die äußere Oberfläche des Knochens ist von Periost bedeckt. Alle inneren Oberflächen sind mit dessen Äquivalent, dem Endost, überzogen. Das Endost besteht aus Kollagenfibrillen, inaktiven Osteoblasten-, klasten sowie den Osteoprogenitorzellen mesenchymalen Ursprungs. Bei Bedarf können die Zellen in den aktiven Zustand übergehen (LÜLLMANN-RAUCH 2006).

Das Periost ist aus dem äußeren Stratum fibrosum, bestehend aus straffem Bindegewebe, und dem inneren Stratum osteogenicum aufgebaut, das in seinen Bestandteilen dem zellreichen Endost entspricht und somit auch osteogene Potenz besitzt. (LÜLLMANNRAUCH 2006). Es konnte nachgewiesen werden, dass dieses osteogene Potential des Periosts im Alter geringer wird (REID et al. 1981, WENG et al. 2000). Die äußeren Schichten des Knochens werden vom Periost aus per Diffusion versorgt. Folglich werden nach einer chirurgischen Periostablösung diese äußersten Anteile minderversorgt.

Die Osteoblasten liegen inneren und äußeren Oberflächen des Knochens einschichtig auf und haben je nach Funktionszustand unterschiedliche Formen. Im aktiven Zustand sind sie annähernd kubisch, während sie im inaktiven Zustand flacher sind. Dabei sitzen sie direkt dem von ihnen produzierten Osteoid auf, einer noch nicht mineralisierten Knochenschicht, organisieren die Mineralisation und steuern zudem die Aktivität der Osteoklasten (LIAN und STEIN 1993, STEIN und LIAN 1993). So exprimieren Osteoklasten-Vorläuferzellen den receptor activator of nuclear factor kappa B-Rezeptor (RANK-Rezeptor) und Osteoblasten sind in der Lage, über ihren RANK-Liganden Fusionen dieser Zellen sowie deren Differenzierung und Aktivierung zu fördern (BOYLE et al. 2003). Andererseits 
können die Osteoblasten durch ihr Protein Osteoprotegerin diese Effekte hemmen (BAUD'HUIN et al. 2007).

Bei den Osteoklasten handelt es sich um durch Fusionen entstandene mehrkernige Riesenzellen, die im aktiven Zustand der zu resorbierenden Oberfläche direkt mit ihrer sogenannten ruffled border, einer vorgrößertem Oberfläche, anliegen. Über eine $\mathrm{H}^{+}$ATPase werden hier Protonen von den Osteoklasten nach außen gepumpt (ROUSSELLE und HEYMANN 2002). Außerdem seziernieren die Osteoklasten lysosomale Enzyme. Der Osteoklast nimmt die entstandenen Fragmente durch Endozytose auf und gibt sie rückseitig nach Transzytose wieder ab. Bei dieser Tätigkeit entstehen die charakteristischen Resorptionslakunen, in welchen die Osteoklasten liegen.

Da es sich beim Knochen um ein gut vaskularisiertes, dynamisches Gewebe handelt, bietet es gute Voraussetzungen für Heilung und Regeneration bis hin zur möglichen Restitutio ad integrum.

Bei der Knochenheilung werden die primäre und die sekundäre Knochenheilung unterschieden. Die primäre Knochenheilung ist nur möglich, wenn Frakturenden sehr eng und stabil aneinander gelagert sind, wie es bei einer operativen Reposition mit Osteosyntheseplatten gegeben ist. Dabei wird der Bruchspalt direkt überbrückt und die Heilung geht ohne Kallusbildung einher (SCHELL et al. 2005).

Bei der sekundären Knochenheilung blutet es zunächst aus den versorgenden Gefäßen der Wunde in den Defekt ein. Durch die Gerinnung bildet sich ein Koagulum, das zur Stabilisierung der Wunde dient (AMLER 1969, CARDAROPOLI et al. 2003). Die darin enthaltenen Thrombozyten setzen entsprechende Wachstumsfaktoren und Zytokine frei, wie z.B. transforming growth factor beta (TGF- $\beta$ ), insulin like growth factor (IGF), platelet derived growth factor (PDGF) und induzieren damit die Chemotaxis von Entzündungszellen (BOLANDER 1992), aber auch von Osteoprogenitorzellen (PFEILSCHIFTER et al. 1990). Granulozyten und Makrophagen werden in dieser Entzündungsphase angelockt, dienen der Abwehr und dem Abbau avitaler Zellen und extrazellulärer Matrix und sezernieren wiederum selber proinflammatorische Zytokine und Wachstumsfaktoren (BOLANDER 1992). Diese führen zu der Proliferationsphase, in der es zu Granulationsgewebe mit reichlich Fibroblasten und Makrophagen kommt. Die Angiogenese und das Einwandern von mesenchymalen Vorläuferzellen folgt, welche über Osteoprogenitorzellen zu Osteoblasten heranreifen (AUBIN et al. 1995, BOLANDER 1992). An dieser Reifung sind verschiedene osteoinduktive Signalmoleküle, genannt bone morphogenetic proteine (BMP) beteiligt, die die Osteogenese steuern (LÜLLMANN-RAUCH 2006, URIST et al. 
1983). BMP's sind Mitglieder der TBF- $\beta$-Superfamilie (WOZNEY 1998) und in der Lage, die Differenzierung von Mesenchymzellen $\mathrm{zu}$ Osteoprogenitorzellen auszulösen (RENGACHARY 2002).

Die Osteoblasten beginnen mit der Osteoidproduktion bevorzugt an osteoinduktiven Oberflächen wie dem Defektrand. Schließlich wird dieses organische Grundgerüst mineralisiert und es entsteht vorläufig Geflechtknochen. Der Geflechtknochen wird anschließend zu Lamellenknochen weiter umgebaut (CARDAROPOLI et al. 2003, DAVIES 2003).

Um die Regenerationsfähigkeit des Knochens zu untersuchen, wurden bereits in vielen Studien operativ geschaffene Knochendefekte angewandt (DAHLIN et al. 1990, LUNDGREN et al. 1995, SCHENK et al. 1994), da davon auszugehen ist, dass die Heilung in weiten Teilen der sekundären Knochenheilung bei Brüchen und der Heilung von Extraktionsalveolen ähnelt (CARDAROPOLI et al. 2005, HOLLINGER und WONG 1996).

\subsection{Knochenersatzmaterialien}

Überschreiten Knochendefekte eine gewisse Größe, so werden sie als critical size defect bezeichnet. Der Körper ist nicht mehr in der Lage, diese Defekte selbstständig zu heilen (HOLLINGER und KLEINSCHMIDT 1990). Die Größe dieser Defekte ist von der Lokalisation und der Spezies abhängig (BOSCH et al. 1998).

Die vollständige knöcherne Ausheilung eines Defektes wird jedoch vor allem von der Form des Defektes und weniger von der absoluten Größe bestimmt (TERHEYDEN 2010). Vertikale Kieferkammdefekte heilen wesentlich schlechter als beispielsweise Extraktionsalveolen. Außerdem sind nutritive Faktoren wie die Qualität des umgebenden Weichgewebes oder eine intakte Periostbedeckung entscheidend (HUH et al. 2005).

Entstehen können Knochendefizite aufgrund von Tumorleiden, Trauma, kongenitalen Anomalien, Entzündungen oder mangelnder mechanischer Beanspruchung nach Zahnverlust. Nach Zahnverlust reduziert sich physiologischerweise die Höhe und Breite des Alveolarkammer (HANSSON und HALLDIN 2012). Neben Funktionsverlusten führen diese Defekte auch zu ästhetischen Einschränkungen.

Während für die Rekonstruktion von sehr großen knöchernen Defekten vor allem bei zusätzlichem Weichteildefizit die Thearpie mittels vaskularisierten Transplantaten 
anerkannt ist, besteht bei eher „kleineren“ Defekten des Alveolarfortsatzes wissenschaftliche Uneinigkeit bezüglich einer idealen Therapie. Neben der Transplantation von Eigenknochen als Block oder in partikulärer Form gibt es Alternativ die Möglichkeit des Einsatzes von Knochenersatzmaterialien, die von kleinen parodontalen Defekten, Augmentationen des Kieferhöhlenbodens, bis zu größeren Augmentationen ganzer Kieferabschnitte mit dem Ziel der beschleunigten bzw. verbesserten Knochenheilung eingesetzt werden. Speziell auf dem Gebiet der Knochenersatzmaterialien wird seit Jahrzehnten nach einem Material gesucht, das alle gewünschten Eigenschaften vereint und das Eigenknochentransplantat überflüssig macht. Die Vielzahl an kommerziell verfügbaren Materialien mit unterschiedlichsten Eigenschaften macht dabei deutlich, dass besonders durch die zunehmende dentale Implantologie und den Wunsch der Patienten nach möglichst schonenden Therapieverfahren ein großer Bedarf an guten Augmentationsmaterialien besteht.

Dabei sind wichtige allgemeine Anforderungen an ein Knochenersatzmaterial gute Verfügbarkeit, Lagerbarkeit, Stabilität, Biokompatibilität, (temporäre) Platzhalterfunktion, Stabilisierung des Blutkoagulums, angenehme Verarbeitungseigenschaften und eine definierte Biodegradibilität (AL-NAWAS et al. 2012).

Wichtige gewünschte Charakteristica sind außerdem Osteoinduktivität, Osteokonduktivität und osteogenetische Eigenschaften. Osteoinduktion bedeutet, dass die Differenzierung mesenchymaler Stammzellen des umgebenden Gewebes zu knochenbildenden Zellen angeregt wird. Definitionsgemäß muss eine osteoinduktive Substanz eine Knochenneubildung an einem extraskelettalen Ort bewirken können (BECKER und TERHEYDEN 2006). Ein osteokonduktives Knochenersatzmaterial dient als Leitstruktur für das Einsprossen von Gefäßen und neue Knochenneubildung und unterstützt somit das spontane Knochenwachstum (CORNELL und LANE 1998). Osteogenetisch potent sind Transplantate, die knochenbildende Zellen enthalten. Diese Zellen können neuen Knochen im Transplantat bilden. 


\subsubsection{Autologer Knochenersatz}

Die Verpflanzung körpereigenen Knochens innerhalb eines Menschen ist in diesem Zusammenhang der Goldstandard (BAUER und MUSCHLER 2000, GOSAIN und PERSING 1999, LAURENCIN et al. 2006).

Grundsätzlich ist zwischen Spongiosatransplantaten und Kompaktatransplantaten zu unterscheiden. In einem Spongiosatransplantat finden sich viele osteogene und vitale Zellen, während Kompakta der initialen Resorption besser standhält. Autologer Knochen besitzt osteoinduktive, osteogenetische, osteointegrative und osteokonduktive Eigenschaften (MOORE et al. 2001). Im Transplantat sind Differenzierungs- und Wachstumsfaktoren enthalten.

Für Alveolarfortsatzdefekte sind mögliche intraorale Entnahmestellen der retromolare Bereich des Oberkiefers sowie im Unterkiefer der Kieferwinkel, die Linea obliqua oder die interforaminale Symphyse (SCHWARTZ-ARAD und LEVIN 2005). Bei ausgedehnteren Defekten mit größerem Transplantatbedarf wird Beckenkammtransplantat eingesetzt.

Bei autologem Knochen besteht für den Patienten nicht die Gefahr der Infektionsübertragung und es entfällt die Gefahr einer immunologischen Transplantatabstoßung (DAMIEN und PARSONS 1991). Dem gegenüber stehen Nachteile des autologen Knochens wie Hebedefektmorbidität und eine begrenzte Knochenmenge, insbesondere im enoralem Gebiet. Durch die nötige Entnahme verlängert sich die Operationszeit und es kann zu Nervschädigungen oder Verletzungen anderer wichtiger Strukturen kommen (CLAVERO und LUNDGREN 2003, NKENKE et al. 2001, SHINDO et al. 2000). Außerdem sind Wundinfektionen der Entnahmestelle oder chronische Schmerzen möglich und Narbenbildungen nicht zu vermeiden (ARRINGTON et al. 1996, HEARY et al. 2002, NIEDHART et al. 2003).

Im Anschluss an die Transplantation autologen Knochens wird das Transplantat nach kapillärer Einsprossung aus dem ortsständigen Knochengewebe sukzessive resorbiert und neu formiert. Wichtig ist stets ein suffizienter weichgewebiger Wundverschluss, da das Transplantat ansonsten bakteriell besiedelt werden könnte. Problematisch ist die initiale Resorption bei autologen Knochentransplantaten, weshalb tendenziell überkonturiert wird. Das Hinzugeben von KEM kann zum Teil diese Resorption bremsen bzw. vermindert die Menge an nötigem autologem Knochen (MAIORANA et al. 2005). Nach der Einheilphase muss ein Transplantat zum Beispiel durch ein Implantat funktionell belastet werden, um die weitere Resorption zu unterbinden. 
Es bleiben kritische Situationen durch ungenügende Empfängerlager oder schwierige Defektmorphologien, die bislang nur mit autologem Knochentransplantat beherrschbar sind. Einzig im Bereich der Sinusliftoperationen sind Knochenersatzmaterialien dem autologen Knochen gegenüber als gleichwertig anzusehen (NKENKE und STELZLE 2009).

Da es sich zumindest im Bereich der dentalen Implantologie um elektive Chirurgie handelt und die Patientenbelastung so gering wie möglich gehalten werden soll, entwickelt sich ein klarer Trend weg von den autologen Knochenentnahmen hin zu belastungsarmen, körperfremden Augmentationsmaterialien, bei denen die Entnahme des Knochens entfällt.

\subsubsection{Allogener Knochenersatz}

Allogener Knochen stammt von einem Individuum der gleichen Spezies, d.h. menschlichen Knochenspendern. Um die Übertragung von Infektionskrankheiten wie Hepatitis oder HIV zu verhindern, wird der Spenderknochen mittels verschiedener Verfahren vorbehandelt. Dazu gehört Lyophilisation und Demineralisierung (BODNER 1996). Bei so aufbereitetem Knochen ist das Risiko der Übertragung von Krankheitserregern zwar sehr klein, jedoch nicht auszuschließen. Die Präparate aus Knochenbanken stammen von HIV-seronegativen menschlichen Spendern. Dennoch existieren dokumentierte Berichte über HIV-Übertragungen (SCHRATT et al. 1996) und bakterielle Infektionen (KAINER et al. 2004) aus der Orthopädie, jedoch nicht aus dem Bereich der Zahn-, Mund-, Kieferheilkunde. Stets müssen die Patienten über dieses potentielle Risiko aufgeklärt werden. Aufgrund der Latenzzeit zwischen der Infektion mit HIV und dem Auftreten von Antikörpern, welche mittels Test nachgewiesen werden können, existiert immer ein Restrisiko.

Da der Knochen genetisch nicht mit dem des Empfängers übereinstimmt, besteht außerdem auch das Risiko einer immunologischen Reaktion. Verschiedene zusätzliche Bearbeitungsverfahren durch Enzyme, Oxidantien oder osmotisch wirksame Stoffe sollen die Antigenität und damit eine immunologische Reaktion verhindern. Aufgrund der Prozessierung geht dem Knochen jedoch biologische Aktivität verloren. Je nach Bearbeitung und Ursprung kann der Knochen noch osteoinduktive Eigenschaften aufweisen (SCHWARTZ et al. 1998). Vor allem ist das allogene Transplantat jedoch osteokonduktiv (ENDRES et al. 2005). 
Allogene Knochentransplantate zeigten in einigen Studien signifikante Erfolge in der Behandlung von parodontal bedingten Knochendefiziten als Alternative zum autologen Transplantat (REYNOLDS et al. 2003). Andere Vergleichsstudien konnten jedoch keine Überlegenheit gegenüber xenogenen oder alloplastischen Knochenersatzmaterialien in der Implantologie oder Parodontologie nachweisen (VALENTINI und ABENSUR 2003), (BOWEN et al. 1989, FROUM et al. 2002). Insgesamt ist aufgrund fehlender wissenschaftlicher Evidenz zur Langzeitstabilität und der insgesamt dürftigen Datenlage jedoch keine abschließende Bewertung möglich (WAASDORP und REYNOLDS 2010).

\subsubsection{Xenogener Knochenersatz}

Xenogene Knochenersatzmaterialien stammen aus Tierknochen. Das wissenschaftlich am Besten untersuchte sowie bekannteste xenogene Knochenersatzmaterial ist BioOss (Geistlich, Wolhusen, Schweiz) mit bovinem Ursprung aus Hydroxylapatit. Dieses Produkt wird aus dem mineralischen Anteil von australischem Rinderknochen gewonnen (GEISTLICH BIOMATERIALS 2013). Die Tiere werden Gesundheitstests unterzogen und der Knochen sterilisiert sowie deproteinisiert. Um potentielle Krankheitserreger zu inaktivieren und immunologische Reaktiones des Empfängers zu verhindern, wird der Knochen mittels hohen Temperaturen und stark alkalischen Lösungen bearbeitet. Diese Transplantate dienen als poröse Leitstruktur mit osteokonduktiver Funktion und werden vom Knochengewebe eingebaut (SCHWARTZ et al. 2000). Häufig werden xenogene Knochenersatzmaterialien auch in Kombination mit autologem Knochen eingesetzt.

Aufgrund der Bearbeitung des Knochens ist das Material im Bezug auf die Übertragung einer spongiformen Enzephalopathie als unbedenklich einzuschätzen (BECKER 2006) Eine Infektion ist bisher nicht nachgewiesen worden (SOGAL und TOFE 1999, WENZ et al. 2001).

Eine weitere wichtige Quelle für xenogene Transplantate sind Korallen.

\subsubsection{Phykogener Knochenersatz}

Das in dieser Arbeit verwendete Knochenersatzmaterial wird aus marinen Rotalgen der Sorten Corallina officinalis und Amophiroa ephedra hergestellt und ist somit pflanzlichen Ursprungs (SPASSOVA et al. 2007). Dieses biphasische Material besteht aus einer Mischung aus $60 \% \quad \beta$-Trikalziumphosphat ( $\beta$-TCP) und $40 \%$ Hydroxylapatit (HA). Aufgrund dieser Zusammensetzung werden die Stabilität und Osteokonduktivität des HA mit der Resorbierbarkeit des $\beta$-TCP verknüpft (HASHIMOTO-UOSHIMA et al. 1995, 
KOERTEN und VAN DER MEULEN 1999, YAMADA et al. 1997). Idealerweise sollte die Abbaugeschwindigkeit eines KEM mit der Geschwindigkeit der Knochenneubildung übereinstimmen, um somit eine kontrollierte Umbaureaktion $\mathrm{zu}$ ermöglichen (MANJUBALA et al. 2005).

HA wird im Körper aufgrund seiner niedrigen Biodegradationsrate kaum abgebaut. Wenn es osseointegriert wird, verbleibt es im Knochen. $\beta$-TCP löst sich im Körper auf und ermöglicht somit den Ersatz durch Knochen (DACULSI et al. 1989, HASHIMOTOUOSHIMA et al. 1995, LU et al. 2002).

SCHOPPER et al. zeigten 2005, dass die Kombination dieser beiden Variationen des Kalziumphosphates im Gegensatz zur alleinigen Anwendung eines phykogenen HA eine signifikant höhere Knochenregeneration zur Folge hat (SCHOPPER et al. 2005). In dieser Studie wurden sowohl gleichmäßige 50/50-Mischungen des TCP/HA angewendet als auch eine 70/30-Mischung. Statistisch zeigte sich zwischen beiden kein signifikanter Unterschied in der Menge des gebildeten Knochens, nur war die 70/30-Mischung besser in das physiologische Remodelling eingebaut. Eine Arbeit von NERY et al. zur Anwendung einer keramischen Mischung von TCP und HA an parodontalen Defekten von Hunden beschreibt hingegen, dass diese besonders gut bei einem Mischungsverhältnis von 15TCP/85HA heilten und diese Mischung mehr Attachmentgewinn und Knochenregeneration zeigte (NERY et al. 1992). Durch den Abbau der Kalziumphosphate werden Kalzium- und Phosphationen frei, die als Knochenbestandteile förderlich auf die Knochenneubildung wirken können (PIATTELLI et al. 1996).

Neben der chemischen Zusammensetzung eines Knochenersatzmaterials sind die strukturellen Eigenschaften entscheidend. Dazu gehören die Porenstrukturen eines Materials, genauer gesagt die dreidimensionale Makro- und Mikroporosität genauso wie die Größe und Form der Partikel und die Oberflächenbeschaffenheit (MONCHAU et al. 2002). Idealerweise sind diese Poren so konfiguriert, dass die Integration des Materials sowie der Transfer von Nährstoffen und Zytokinen möglich sind. Sie vergrößern die funktionelle Oberfläche und ermöglichen die nutritive Versorgung.

Makroporenstrukturen dienen als Leitschienen für das Einsprossen der Gefäße und des Gewebes. Sie sollten größer als $100 \mu \mathrm{m}$ sein. Ein Porenvolumen von 200 bis $400 \mu \mathrm{m}$ ist noch günstiger, da das Einsprossen von Kapillaren schneller vonstatten gehen kann. 
Ebenso ist dieses Porenvolumen vorteilhaft für die Osteokonduktion (KARAGEORGIOU und KAPLAN 2005, TSURUGA et al. 1997).

Mikroporen mit Größen von weniger als $10 \mu \mathrm{m}$ sind für die osteoblastäre Adhäsion sowie die Proliferation und Differenzierung der Osteoblasten relevant und vergrößern die Gesamtoberfläche (HABIBOVIC et al. 2005). Die Poren sollten außerdem interkonnektierend sein, um die Neovaskularisierung und somit die Ernährung des neu gebildeten Knochens zu gewährleisten (LU et al. 1999). Bei dem in dieser Studie eingesetzten HA/TCP werden hydrothermale Prozesse zur Umwandlung des Carbonatskeletts der Rotalgen angewandt, welche die dreidimensionale Geometrie der Poren erhalten (EWERS 2007, SPASSOVA et al. 2007). Materialien, die aus Meeresalgen oder Korallen und tierischen Knochen gewonnen werden, bieten ausgeprägte interkonnektierende Poren, wie sie technisch schwer herstellbar sind und haben daher eine gute Osteokonduktivität (EWERS 2005).

Das in dieser Arbeit eingesetzte Knochenersatzmaterial besteht aus interkonnektierendem, mikroporös biphasischem TCP-HA-Komposite. Sein sehr gleichmäßiges Porensystem enthält hauptsächlich Poren von 5 bis $10 \mu \mathrm{m}$ Durchmesser, die untereinander über laterale Perforationen (1-3 $\mu \mathrm{m})$ verbunden sind (SPASSOVA et al. 2007).

Kalziumphosphat Derivate sind sehr biokompatibel und osteokonduktiv (JARCHO 1986) und zeigten als Gerüst für die Knochenregeneration gute Ergebnisse (SCHOPPER et al. 2005). Aus Algen hergestelltes Hydroxylapatit fördert die Proliferation und Differenzierung von osteoblastären Vorläuferzellen (osteoblast like cells) auf seiner Oberfläche in vitro (TURHANI et al. 2005). Besonders erprobt und erfolgreich sind phykogene Materialien in klinischen Studien zur Sinusbodenaugmentation (IEZZI et al. 2012, SCARANO et al. 2012). Der Hersteller empfielt die Anwendung von Membranen über dem augmentierten Bereich. Diese dienen bei der Augmentation vertikaler Defekte wie in diesem Versuchsaufbau nicht nur als Barriere gegenüber dem Weichgewebe, sondern auch als dreidimensionale Stabilisierungshilfe.

\subsubsection{Alloplastischer Knochenersatz}

Die alloplastischen Knochenersatzmaterialien sind synthetisch hergestellte anorganische, osteokonduktive Materialien (HASHIMOTO-UOSHIMA et al. 1995, NERY et al. 1992). Dazu gehören keramische Werkstoffe wie Kalziumphosphate (Hydroxylapatit, Trikalziumphosphat) oder Biogläser (Kalziumhaltige Silikate). Sie haben den Vorteil der einfachen Verfügbarkeit. Außerdem besteht keine Infektionsgefahr und keine 
immunologische Reaktion. Dafür haben diese Substanzen keine osteoinduktiven oder osteogenen Eigenschaften (JENSEN et al. 2007).

Je nach Hersteller weisen diese Materialien unterschiedliche Porengrößen, Kristallgrößen, und unterschiedliche Konfigurationen der Makro- und Mikroporosität auf (JENSEN et al. 2007, KLEIN et al. 2009). Daher zeigen die Materialien trotz gleicher chemischer Zusammensetzung unterschiedliche in vitro- und in vivo-Ergebnisse (JENSEN et al. 2007).

Bioaktive Gläser besitzen die Eigenschaft, eine direkte chemische Bindung mit Knochen einzugehen, da sich ihre Oberfläche nach dem Kontakt mit Flüssigkeit im Gewebe verändert. Eine Siliziumgelschicht bildet sich auf der Glasoberfläche aus, und Kristalle aus Hydroxylapatit ermöglichen die starke Bindung (HENCH und WILSON 1984).

\subsection{Guided Bone Regeneration (GBR)}

Der relativ langsame Vorgang der Knochenbildung steht in direkter Konkurrenz zur bindegewebigen Narbenheilung durch Fibroblasten. Somit ist neben einer ausreichenden Blutversorgung und einem stabilisierten Hämatom das Abhalten des schnell proliferierenden Bindegewebes Voraussetzung für die intraorale Defektheilung (MELCHER und DREYER 1962).

Dies führte zur Entwicklung der Guided Bone Regeneration (GBR), bei der Membranen als Barriere gegenüber einwachsenden Fibroblasten angewandt werden (HÄMMERLE und JUNG 2003). Durch den Einsatz der Membranen entsteht ein abgegrenzter Raum für die ungestörte Osteogenese (LINDE A. et al. 1993). Außerdem stabilisieren sie das Augmentat dreidimensional.

Es gibt resorbierbare und nicht-resorbierbare Membranen.

Nicht resorbierbare Membranen sind beispielsweise aus Polytetrafluorethylen oder Titan. Da diese Membranen den Patienten und das Gewebe durch den zusätzlichen Entnahmeeingriff stärker belasten, werden sie weniger eingesetzt. Dafür bieten sie eine höhere mechanische Stabiliät (HÄMMERLE und JUNG 2003).

Moderne Membranen sind häufig resorbierbar und erübrigen daher einen zweiten Eingriff zur Membranentfernung. In den letzten Jahren wurden hauptsächlich Kollagenmembranen eingesetzt, welche durch Kollagenasen abgebaut werden können (JUNG et al. 2012, ROTHAMEL et al. 2005).

Sie sind weich und lassen sich gut dem Knochen anlegen, ohne zusätzlich fixiert werden zu müssen, weshalb sie unproblematisch anzuwenden sind. Dafür haben sie aber nur eine 
geringe mechanische Stabilität. Daher hält die Membranforschung weiterhin an, da bislang alle Membranen Vor- aber auch Nachteile aufweisen. Eine ideale Membran für den klinischen Einsatz konnte noch nicht gefunden werden (RAKHMATIA et al. 2013).

In dieser Studie wurde eine Kollagenmembran mit Bilayer-Struktur aus porcinem Kollagen Typ I und III eingesetzt (ROTHAMEL et al. 2005). Diese diente als Vergleich zum Poloxamer, da sie in zahlreichen Studien ihre gute Weichgewebsintegration, Vaskularisation, Biokompatibilität und angemessen schnelle Degradation ohne inflammatorische Reaktion bereits bewiesen hat (JUNG et al. 2012, ROTHAMEL et al. 2005, ZITZMANN et al. 1997).

\subsection{Degradierbare Polymere}

Neben der dreidimensionalen Stabilisierung von partikulärem KEM durch konventionelle Membranen, besteht auch die Möglichkeit das Augmentat mit Hilfe von Polymeren zu stabilisieren. Unter Polymeren versteht man makromolekulare Verbindungen, die aus mehreren gleichen oder unterschiedlichen Monomeren aufgebaut sind (AMECKE et al. 1992). Diese können natürlichen oder synthetischen Ursprungs sein.

$\mathrm{Zu}$ den wichtigsten synthetischen und degradierbaren Polymeren gehören Polyester wie die Polylaktide (Polymilchsäure) und Polyglykolsäure (Polyhydroxyessigsäure), sowie deren Derivate (SCHLIEPHAKE 2010). Diese Polymere werden im Körper durch Hydrolyse gespalten und metabolisiert. Ihre Abbaugeschwindigkeit ist abhängig von ihrer Zusammensetzung, dem Molekulargewicht und ihrer Kristallinität (SCHLIEPHAKE 2010).

Eingesetzt werden diese Verbindungen aufgrund Ihrer guten Bioresorbierbarkeit vielfach als medizinisches Nahtmaterial, in der Ostesynthese oder als Membran zur GBR (AMECKE et al. 1992, IGLHAUT et al. 2014, VIINIKAINEN et al. 2009).

Problematisch ist, dass ihre kristallinen Anteile schwieriger degradierbar sind, weshalb Überreste des Materials zu Fremdkörperreaktionen führen können (MEIKLE et al. 1994, PISTNER et al. 1993). Ein weiterer Nachteil ist, dass die Abbauprodukte dieser Polymere zu einer lokalen Übersäuerung führen. Dieser pH-Wert Abfall kann schließlich auch zu Gewebsirritationen führen (SCHLIEPHAKE 2010).

Ein anderer Polyester, Polyhydroxybutyrat, hat sich in einer Tierstudie nicht als resorbierbare Membran zur GBR parodontaler Defekte bewährt (REIS et al. 2013). 
Polyethylenglycol (PEG) ist ein weiteres synthetisches und degradierbares Polymer, bietet aber den Vorteil erst in situ zu erhärten. Diese Moleküle formen ein dreidimensionales Hydrogel, so dass auch Wirkstoffe in die Matrix eingebaut und später kontrolliert freigesetzt werden können (SCHLIEPHAKE 2010). PEG wird als sehr biokompatibel beschrieben (PANG 1993). Membranen aus in situ erhärtendem Polyethylenglykol zeigten im Tierversuch eine gute Biokompatibilität ohne Fremdkörperreaktionen und entsprechend gute Ergebnisse wie Kollagenmembranen (HERTEN et al. 2009, JUNG et al. 2009).

Auch in einer prospektiven, randomisierten klinischen Studie zeigte sich PEG als in situ erhärtende Membran zur Behandlung von Knochendehiszenzen an Implantaten im Vergleich mit einer Kollagenmembran gleichwertig (RAMEL et al. 2012).

Bei dem in dieser Studie untersuchten Trägermaterial handelt es sich um das Poloxamer 407. Es wurde mit dem Ziel eingesetzt, als intraoral aushärtendes Polymer das Augmentat $\mathrm{zu}$ stabilisieren, das intraoperative Handling $\mathrm{zu}$ verbessern und vor allem die dreidimensionale Form des eingebrachten Materials zu erhalten.

Poloxamere sind amphiphile Blockcopolymere aus Ethylenoxid und Prophylenoxid (SCHMOLKA 1972).

Der Name Blockcopolymer erklärt sich daher, dass sich in der Molekülmitte ein Prophylenoxidblock (X) befindet, der beidseitig von Ethylenoxidblöcken (Y) flankiert wird. Somit ergibt sich die Struktur $\mathrm{Y}_{\mathrm{a}}-\mathrm{X}_{\mathrm{b}}-\mathrm{Y}_{\mathrm{a}}$ wie in Abbildung 1 dargestellt (BASFLABORATORIES 2004, SCHMOLKA 1972).

\section{$\mathrm{H}\left(\mathrm{O}-\mathrm{CH}_{2}-\mathrm{CH}_{2}\right)_{a}\left(\mathrm{O}-\mathrm{CH}-\mathrm{CH}_{2}\right)_{b}\left(\mathrm{O}-\mathrm{CH}-\mathrm{CH}_{2}\right)_{\mathrm{a}} \mathrm{OH}$ \\ $\mathrm{CH}_{3}$}

Abbildung 1 Summenformel des Poloxamers. Für Poloxamer 407 gilt $a=101$ und $b=56$ (BASF-LABORATORIES 2004)

Die Synthese wurde von Schmolka (1972) beschrieben als eine fortlaufende Polymerisationsreaktion zunächst von Prophylenoxid und anschließend von Ethylenoxid.

Unter Anwesenheit von Kaliumhydroxid oder Natrium als basischem Katalysator kann zunächst Prophylenoxid wiederholt an den Initiator Prophylenglycol addiert werden, wobei Polyoxypropylenglycol entsteht. Dieses hydrophobe Molekül wird anschließend beidseitig mit hydrophilem Ethylenoxid versehen. Somit entsteht ein amphiphiles Blockcopolymer, 
da der Polyethylenoxidanteil hydrophil ist, während der Polyprophylenoxidanteil hydrophobe Eigenschaften aufweist (PRICE et al. 2010).

Der Katalysator kann mit Phosphorsäure neutralisiert werden, wobei das neutrale Salz in einer Konzentration von weniger als $0,05 \%$ in dem Endprodukt verbleibt (SCHMOLKA 1972). Abhängig von dem Verhältnis Prophylenoxid zu Ethylenoxid ändert sich die Hydrophilie bzw. Hydrophobie des Polymers.

Hauptsächlich werden die Poloxamere 407 und 188 genutzt, die sich in ihrer Molekülmasse unterscheiden (FOWLER et al. 2002, HOKETT et al. 2000, KABANOV et al. 2002).

Auch Poloxamere formen ein dreidimensionales Hydrogel, in das Wirkstoffe eingebaut und später kontrolliert freigesetzt werden können.

Bisher untersuchte Anwendungsarten dieser Poloxamer-Arzneistoff-Kombinationen sind topisch (JANSEN et al. 2013, LESZCZYNSKA et al. 2011, MORIKAWA et al. 1987, PADILLA et al. 2000), vaginal (IBRAHIM et al. 2012), rektal (BARICHELLO et al. 1999, MIYAZAKI et al. 1986), okular (DESAI und BLANCHARD 1998, EDSMAN et al. 1998) und subkutan (BARICHELLO et al. 1999 b). Außerdem wurden Wirkstoffe gebunden in ein Poloxamer direkt an ihren Zielort injiziert (PLUTA und KAROLEWICZ 2006). Auch als Träger für den Einsatz von Antibiotika und anti-inflammatorischen Wirkstoffen in parodontalen Taschen wurde das Poloxamer 407 von Kumari und Pathak 2012 untersucht.

Ein weiterer aktueller Forschungsbereich ist die Kombination vom Poloxameren mit Wachstumsfaktoren bzw. Stammzellen (CAMPION et al. 2011, IM und LEE 2010, LIPPENS et al. 2010). LIPPENS et al. setzten eine Modifikation des Poloxamer 407 in Kombination mit mesenchymalen Stammzellen erfolgreich im Tierversuch ein (2010). Hierfür wurde das Poloxamer nach Swennen et al. (2006) modifiziert, um die Stabilität zu erhöhen und ein Photoinitiator eingebaut. Es zeigte sich, dass das Polymer aufgrund seiner Durchlässigkeit für Sauerstoff und Nährstoffe gute Überlebensmöglichkeiten für Stammzellen bietet.

Auch als strukturelles Gerüst für das tissue engineering können Poloxamere aufgrund ihrer Fähigkeit zur Interaktion mit Zelloberflächen eingesetzt werden (CUNHA et al. 2011, VASHI et al. 2008). Ein positiver Effekt des Poloxamer 407 auf die Stammzellen konnte von DOGAN et al. jedoch nicht nachgewiesen werden (2012). Einen positiven Effekt konnte hingegen Poloxamer 188 erzeugen. 
Chen et al. kombinierten den Einsatz von Stammzellen, Poloxamer und einem Hydroxylapatit aus Korallen und setzten dies an der Wirbelsäule von Kaninchen ein (CHEN et al. 2009). Dabei zeigte sich im Vergleich zum autologen Knochenersatz kein signifikanter Unterschied in der quantitativen Histomorphometrie.

Huang kombinierte phykogenes HA mit Stammzellen und Poloxamer in einer in vitroStudie. Es zeigte sich, dass die Stammzellen überlebten und sich in dieser Umgebung zu Osteoblasten differenzieren konnten (HUANG et al. 2006).

\subsection{Fragestellung}

Augmentationen des Alveolarfortsatzes mit partikulärem KEM sollen möglichst formbeständig sein, um eine knöchernen Regeneration in der angestrebten Form zu ermöglichen. Insbesondere bei vertikalem Knochendefizit ist es aber äußerst schwierig das KEM längerfristig mechanisch zu stabilisieren.

Trotz der zuvor erläuterten, weitreichenden Forschung bezüglich neuer Materialien und Membranen, konnte bisher kein ideales Material zur effektiven Stabilisierung eines partikulären Knochenersatzmaterials ohne unerwünschte Nebenwirkungen gefunden werden. Neben der ausreichenden Stabilität sollte ein ideales Material problemlos resorbierbar sein, um dem Patienten einen erneuten operativen Eingriff zu ersparen und die knöcherne Regeneration nicht zu behindern.

Wie bereits aufgezeigt, wurden Poloxamere bereits in verschiedensten Teilbereichen der Medizin untersucht. Die bisherigen Forschungsergebnisse machen Poloxamere auch zu einem interessanten Material für die intraorale Knochenaugmentation.

Daraus ergibt sich die Fragestellung der vorliegenden Studie, ob ein in situ erhärtendes Poloxamer vergleichbare oder gar bessere Ergebnisse liefert als eine konventionelle Kollagenmembran. 


\section{Material und Methoden}

\subsection{Versuchsübersicht}

Ziel dieser Untersuchung war es, die Regeneration von Alveolarfortsatzdefekten unter Anwendung von Knochenersatzmaterialien zur Augmentation histomorphometrisch und histologisch zu untersuchen. Das Knochenersatzmaterial Martrix (KLS Martin, Tuttlingen) aus Trikalziumphosphat (60 \%) und Hydroxylapatit (40\%) in Verbindung mit einer Kollagenmembran sowie seine Modifikation durch das Bindemittel Pluronic (Poloxamer 407 / Pluronic F127, Aldrich, St., Louis, USA) sollten in ihrer Wirkungsweise verglichen werden.

Dafür wurde eine tierexperimentelle Untersuchung an 6 Hunden gewählt.

Im Oberkiefer der Tiere wurden jeweils drei Alveolarfortsatzdefekte geschaffen und unterschiedlich versorgt.

Ein Defekt diente als Kontrolldefekt und wurde ungefüllt verschlossen.

Ein Defekt wurde mit dem Material Martrix gefüllt und mit einer Membran abgedeckt und ein weiterer Defekt wurde mit der Kombination von Martrix und Pluronic versorgt.

Abbildung 2 visualisiert den Ablauf dieser Studie. 


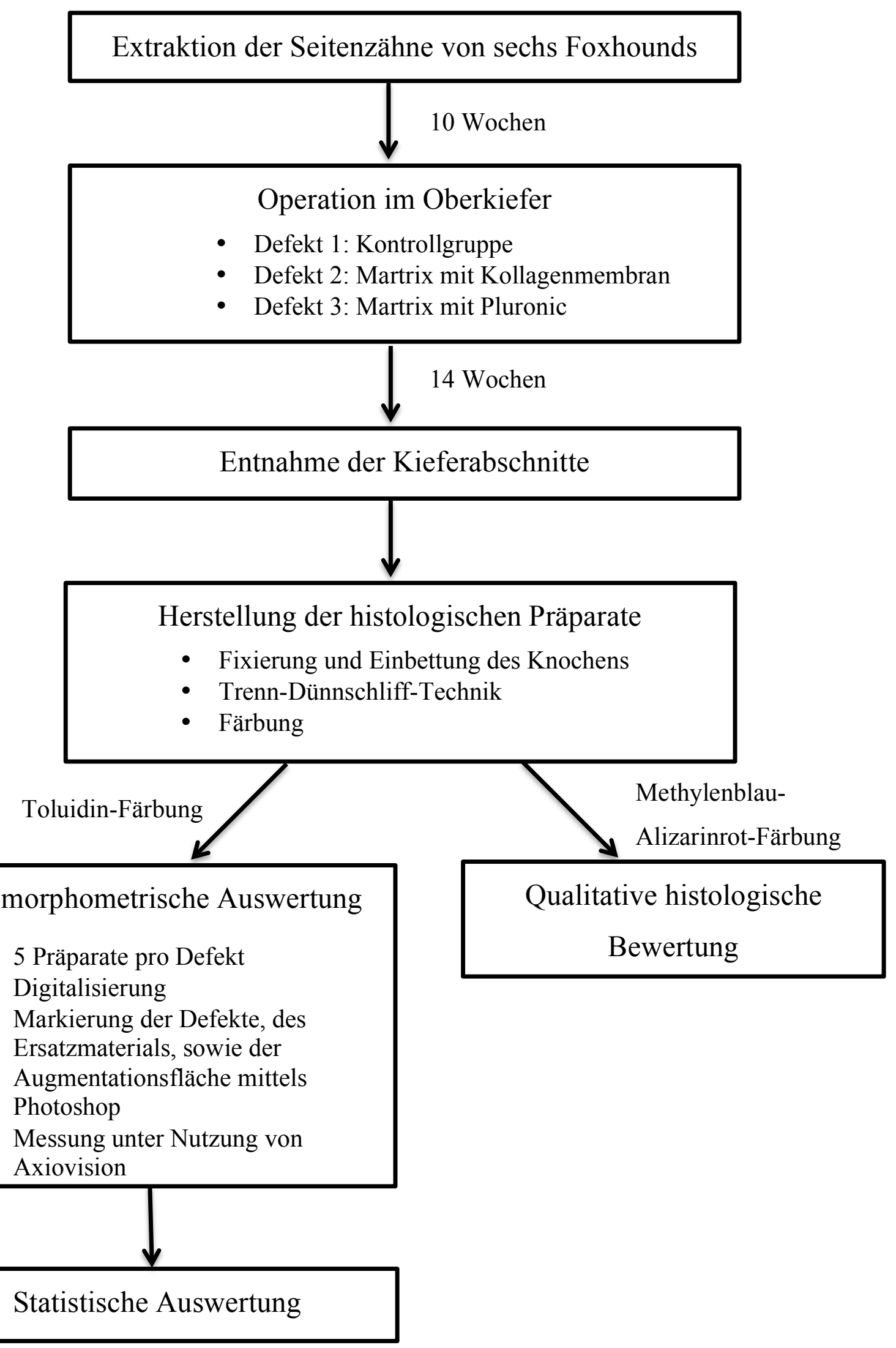

Abbildung 2 Versuchablauf dieser tierexperimentellen Studie 


\subsection{Versuchstiere}

Der Hund dient besonders in der Parodontologie und Implantologie als gängiges Versuchstier (COHEN et al. 2010, DE VICENTE et al. 2006, HOWELL et al. 1993, OH et al. 2003, SIMION et al. 2006, SVANBERG et al. 1982, VON ARX et al. 2001).

Das bleibende Gebiss des Hundes hat 42 Zähne. Es finden sich in jedem Quadranten drei Inzisivi, ein Caninus sowie vier Prämolaren. Zudem existieren im Oberkiefer zwei und im Unterkiefer drei Molaren. Die erste Dentition des Hundes fasst dagegen nur 28 Zähne (BUDRAS und NÖLLER 2010).

Teil dieser Studie waren sechs ausgewachsene Foxhounds aus institutseigener Zucht im Alter von 18 bis 22 Monaten und vollständig ausgebildeter zweiter Dentition.

Das Körpergewicht der Hunde betrug 32-41 kg.

Während der Versuchszeit wurden die Tiere einmal täglich mit weicher Nahrung und Wasser ad libitum gefüttert.

Der chirurgische Teil der Untersuchung wurde in Zusammenarbeit mit dem tierexperimentellen Institut der Heinrich-Heine-Universität unter Aufsicht von Prof. Jürgen Becker in Düsseldorf durchgeführt und von dem dortigen Landesamt für Natur, Umwelt und Verbraucherschutz Nordrein-Westfalen geprüft und genehmigt (Genehmigungsnummer G230/09 AZ 8.87-50.10.37.09.230).

Die Prinzipien des Labortierschutzes wurden beachtet und eingehalten.

\subsection{Poloxamer 407}

Poloxamer 407 wurde in den 1950er Jahren von BASF (Mississauga, Kananda) entwickelt und wird seitdem unter dem Handelsnamen Pluronic F-127 (Pluronic) vertrieben (BASFLABORATORIES 2007). Pluronic F-127 findet ein breites Anwendungsspektrum als Träger für die Applikation von Wirkstoffen und ist weit verbreitet in der Pharma-, Nahrungsmittel- und Kosmetikindustrie (DUMORTIER et al. 2006).

Die Poloxamer-Moleküle sind synthetische Blockcopolymere aus Ethylenoxid und Prophylenoxid mit einer Molekülmasse von annähernd 12600, wovon etwa $70 \%$ auf das Ethylenoxid zurückgehen (BASF-LABORATORIES 2007).

Pluronic F-127 hat einen Schmelzpunkt von 56 Grad Celsius (SCHMOLKA 1972).

Es löst sich aufgrund seiner hohen Molekülmasse langsam in Wasser, wobei es durch die Ausbildung von Wasserstoffbrückenbindungen besser in kaltem als in warmem Wasser 
löslich ist (SCHMOLKA 1972). Beschrieben wird es als nichtionisches Tensid (FOWLER et al. 2002), das die Oberflächenspannung des Wassers herabsetzen kann.

Außerdem dient es laut Hersteller auch zur Dispergierung und Emulgierung von Substanzen (BASF-LABORATORIES 2004).

Besonders interessant ist das temperaturabhängige rheologische Verhalten von Poloxamer 407 mit einem Sol-Gel-Übergang. Diese Veränderung geschieht durch Interaktion der verschiedenen Copolymermolekülbereiche (DUMORTIER et al. 1991).

20 bis 30-prozentige Lösungen der Substanz zeigen eine starke Viskositätszunahme beim Erwärmen von Raumtemperatur auf Körpertemperatur, wobei sich die Flüssigkeit in ein Gel umwandelt (WARREN et al. 2011).

Dieses Verhalten erklärt sich auf molekularer Ebene. Bei sehr geringen Konzentrationen $\left(10^{-4}\right.$ bis $\left.10^{-5}\right)$ liegen die Moleküle einzeln in Wasser gelöst vor, doch bei höheren Konzentrationen oder Temperaturen findet eine Dehydratation der hydrophoben Prophylenoxidanteile statt, woraufhin sie sich zusammenlagern, um Mizellen zu bilden. Als Mizellen treten nur die hydrophilen, hydratisierten Polyoxyethylenketten in Kontakt mit dem Wasser, während die hydrophoben Anteile sich im Inneren der Mizellen zusammenlagern (LENAERTS et al. 1987).

Steigt dann die Temperatur, wird der Gel-Zustand erreicht, die Mizellen lagern sich in einem geordneten Gitter zusammen (GUZMAN et al. 1994) und die Hydroxygruppen bilden Wasserstoffbrücken aus. Diese kubischen Strukturen mit ihren Mizellengewirr führen zu der hohen Viskosität und hohen Stabilität der Gele (CHEN-CHOW und FRANK 1981). Bei $37{ }^{\circ} \mathrm{C}$ zeigt das Gel eine Viskosität von $205.1-267.7 \cdot 10^{3} \mathrm{cP}$, was in etwa der Viskosität fester putty Silikone entspricht (IBRAHIM EL et al. 2012).

Diese Vorgänge ermöglichen auch die Beimischung hydrophiler und hydrophober Substanzen.

Bei höheren Konzentrationen des Poloxamers wird der Abstand zwischen den Mizellen geringer und damit das nötige Anschwellen der Mizellen zum Interagieren mit anderen Polymeren. Daher sinkt bei höheren Konzentrationen die Temperatur, bei der die Gelierung einsetzt (GUZMAN et al. 1994).

Die Gelbildung ist thermoreversibel (siehe Abbildung 3). Die Brücken, die das Netztwerk zusammenhalten, können aufbrechen oder sich wieder ausbilden (GILBERT et al. 1986, SCHMOLKA 1972). 


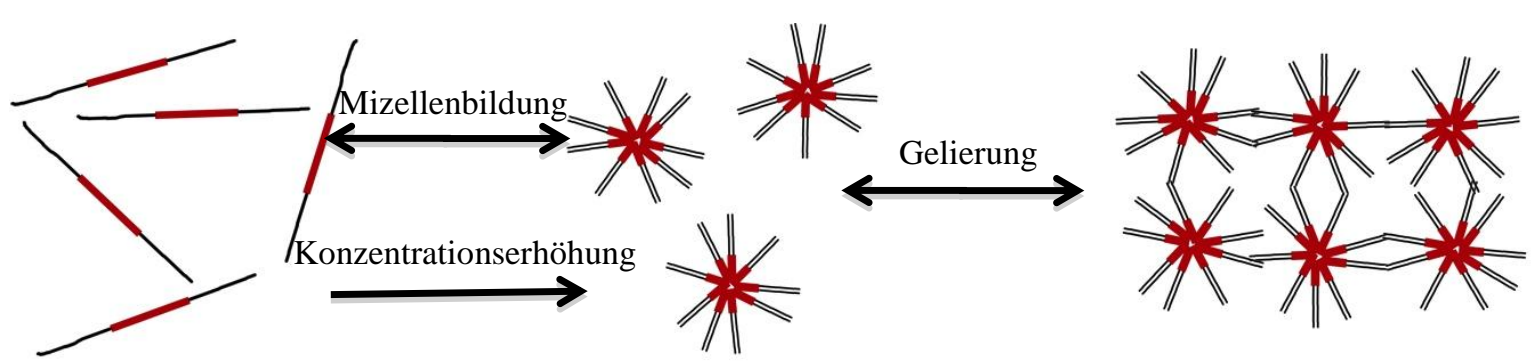

Temperaturerhöhung

Temperatursenkung

Abbildung 3 Verhalten der Poloxamer 407-Moleküle bei Temperaturänderung

Eine der ersten Anwendungsbeschreibungen von Pluronic F-127 war die Versorgung von Brandwunden der Haut (SCHMOLKA 1972).

Seither wurde das Material in diversen medizinischen und pharmazeutischen Bereichen getestet. Insbesondere als Träger für die gezielte Medikamentenverabreichung, um längerfristig stabile Plasmakonzentrationen eines Wirkstoffes $\mathrm{zu}$ erreichen und die Resorption zu verbessern.

Pluronic ist relativ leicht herstellbar und kompatibel mit vielen Substanzen. Es wurde beschrieben als das Blockcopolymer mit der geringsten, unbedenklichsten Toxizität und guter Biokompatibilität (GILBERT et al. 1986, PARK und PARK 1996, SCHMOLKA 1972). In verschiedenen Zellkulturtests konnte keine Mutagenität der Substanz nachgewiesen werden (BASF-LABORATORIES 2007).

\subsection{Operatives Vorgehen}

Während der operativen Eingriffe wurde eine Intubationsnarkose durchgeführt. Zur Vermeidung intraoperativer Komplikationen wurden die Versuchstiere vor den operativen Eingriffen nüchtern gehalten. Präoperativ wurden die Hunde mit Acepromazin (Vetranquil $1 \%$, Ceva Tiergesundheit, Düsseldorf) in einer Dosierung von $0,17 \mathrm{mg} / \mathrm{kg}$ intramuskulär sediert.

Die Intubationsnarkose wurde mittels $21,5 \mathrm{mg} / \mathrm{kg}$ Thiopental (Trapanal 2,5\%, Altana $\mathrm{GmbH}$, Konstanz) intravenös durchgeführt. Zur Aufrechterhaltung der Narkose wurde Isofluran in Verbindung mit einem Sauerstoff-Lachgas-Luftgemisch verabreicht. 
Außerdem erfolgte kontinuierlich eine intravenöse Infusion mit Ringer-Lactat-Lösung und eine maschinelle Beatmung.

Piritramid (Dipidolor, Janssen-Cilag GmbH, Neuss) in einer Dosierung von 0,4 mg/kg und Carprofen (Rimadyl, Pfitzer Pharma GmbH, Karlsruhe) in einer Dosierung von 4,5 mg/kg KG wurden zur intraoperativen Analgesie verwendet.

Gleichzeitig mit dieser Untersuchung fand eine zweite Studie am Unterkiefer der Versuchstiere statt.

Zunächst wurden die Zähne der Hunde im Oberkieferseitenzahnbereich (P1-M1) extrahiert. Um die Zähne vorsichtig entfernen zu können, wurden Mukoperiostlappen präpariert, die Zähne geteilt und die Wunde mit Matratzennähten verschlossen. Nun wurde 10 Wochen abgewartet, um eine knöcherne Ausheilung der Extraktionsalveolen zu erreichen. Drei Tage postoperativ wurde die Analgesie der Hunde mittels Piritramid (0,4 $\mathrm{mg} / \mathrm{kg})$ und Carprofen $(4,5 \mathrm{mg} / \mathrm{kg})$ subkutan verabreicht sichergestellt.

Zusätzlich erfolgte eine prophylaktische Antibiose durch den Einsatz von Clindamycin (Clerobe, Pharmacia Tiergesundheit, Erlangen) in einer Dosierung von $11 \mathrm{mg} / \mathrm{kg} \mathrm{KG}$ intravenös während der Operation und postoperativ für drei Tage per os.

Während der zweiten Operationen wurde auf dem Alveolarkamm krestal eine Inzision durchgeführt und anschließend je ein Mukoperiostlappen nach palatinal und vestibulär abpräpariert. Vertikale Entlastungen wurden etwa $5 \mathrm{~mm}$ vom Untersuchungsbereich entfernt geschaffen.

Nun wurden jeweils drei sattelförmige Defekte im Bereich der Oberkieferprämolaren mit Verlust der vestibulären und palatinalen Knochenwand geschaffen.

Das Ausmaß dieser „critical size“ Defekte betrug in mesio-distaler Richtung $10 \mathrm{~mm}$ und vom krestalen Knochen aus gemessen apikal-koronal $8 \mathrm{~mm}$.

Im Split-Mouth-Design wurden willkürlich jeweils in einer Kieferhälfte zwei Defekte und in der anderen Kieferhälfte ein Defekt gesetzt. Zwischen den zwei Defekten wurde ein Mindestabstand von $5 \mathrm{~mm}$ beachtet. Eine Parodontalsone (PCP12, Hu-Friedy Co., Chicago, USA) diente zur Kontrolle der Osteotomien, welche stets unter ausreichender Spülung mit steriler Kochsalzlösung stattfanden.

Randomisiert (RandList, DatInf GmbH, Tübingen) wurde einer der Defekte ungefüllt als Kontrollgruppe nur mit einem Nahtverschluss der Weichgewebe versorgt. Ein zweiter Defekt wurde nur mit dem partikulären Knochenersatzmaterial Martrix gefüllt, wie in 
Abbildung 4 dargestellt mit einer kollagenen Membran (Bio-Gide, Geistlich, Wolhusen, Schweiz) abgedeckt und durch eine Dehnungslappenplastik spannungsfrei verschlossen.

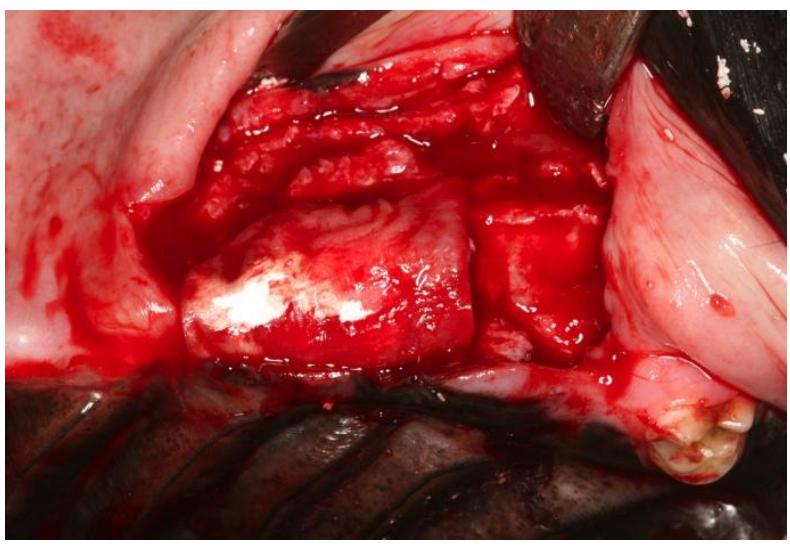

Abbildung 4 Intraoperative Aufnahme mit aufgelegter Kollagenmembran

Ein dritter Defekt im Oberkiefer der Versuchstiere wurde mit dem Knochenersatzmaterial Martrix, eingebettet in ein Trägermaterial auf der Basis von Pluronic F-127, versorgt. Dabei galt das Verhältnis $0,74 \mathrm{~g}$ TCP/HA in jedem Milliliter Poloxamerlösung. Das Poloxamerhydrogel erhärtete bei Körpertemperatur. Auch diesen Defekt wurde durch eine Dehnungslappenplastik verschlossen. Als Nahtmaterial wurden Vicrylfäden der Stärke 5-0 (Resorba, Nürnberg) für vertikale und horizontale Matratzennähte verwendet. Wieder erfolgte die postoperative Analgesie und Antibiose der Hunde analog der ersten Operation. Nachdem die Versuchstiere durch eine Überdosis Pentobarbital $3 \%$ euthanasiert wurden, fand schließlich die Entnahme der Kieferanteile nach 14 Wochen statt.

Eine Perfusion mit 10\%ig gepuffertem Formalin wurde zur Fixation in die Arteriae carotides injiziert. 


\subsection{Aufbereitung des Knochenmaterials}

\subsubsection{Geräte und Materialien}

- Ethanol (Chemikalien Vertrieb Hannover, Hannover)

- Exsikkator (Duran Group GmbH, Mainz)

- Xylol (Avantor Performance Materials, Deventer, Niederlande)

- Polymerisationssystem Technovit 9100 NEU (Heraeus Kulzer GmbH, Wehrheim)

- Kühlschank (Bauknecht, Stuttgart)

- Tiefkühlschrank (Elektronik-Bau K. Schneider, Groß-Lüdershagen)

\subsubsection{Vorgehensweise}

Die fixierten Kieferknochen wurden in 70\%iger Alkohollösung in das Universitätsklinikum Göttingen überführt.

Daraufhin erfolgte die Dehydratation in einer aufsteigenden Alkoholreihe mit den Konzentrationen $70 \%, 90 \%, 96 \%$ und $100 \%$ bei Raumtemperatur jeweils zwei Tage lang. Nur im absoluten Ethanol verblieben die Knochen 72 Stunden. Die Flüssigkeit wurde täglich gewechselt. Um die Entwässerung zu optimieren, wurde nach jedem Arbeitsschritt eine Vakuumbehandlung im Exsikkator durchgeführt. Xylol diente daraufhin als Intermedium, um anschließend die Präinfiltration und Infiltration mit Technovit 9100 NEU, entsprechend der Gebrauchsanweisung des Herstellers, durchzuführen.

Die Gewebeproben wurden bei jedem Schritt der Präinfiltration und Infiltration für mindestens 48 Stunden im Kühlschrank bei $+5^{\circ} \mathrm{C}$ belassen .

Zur abschließenden Polymerisation wurden die Einbettformen zunächst auf 200mbar evakuiert, anschließend luftdicht verschlossen und mindestens 3 Tage im Tiefkühlschrank bei $-8^{\circ} \mathrm{C}$ gelagert. Zuletzt wurden die ausgehärteten Blöcke aus den Formen genommen und weiterhin einige Stunden bei $+5^{\circ} \mathrm{C}$ im Kühlschrank aufbewahrt. 


\subsection{Trenn-Dünnschliff-Technik}

\subsubsection{Geräte und Materialien}

- Tellerschleifgerät Struers RotoPol-35 (STRUERS GmbH, Willich)

- Haarlineal

- Sofortklebstoff Loctite 420 (Henkel AG \& Co. KGaA, Düsseldorf)

- Objektträger Plexiglas planparallel Nummer 40415025 x 75 x 2 mm (PathoService GmbH, Oststeinbek)

- Objektträgerpresse (Eigenbau)

- Bandsägen EXAKT 300 CP und 310 CP (EXAKT Advanced Technologies GmbH, Norderstedt)

- Schleifbänder EXAKT Bandsystem 306/310 Nummer 30/841 (EXAKT Advanced Technologies GmbH, Norderstedt)

- Schleifgerät EXAKT Typ AW-10 (EXAKT Advanced Technologies GmbH, Norderstedt)

- Schleifscheiben P800 und P1200 (Hermes Schleifmittel GmbH, Hamburg)

- Schleifscheiben Körnung 4000 (dia-plus, Oststeinbek)

\subsubsection{Herstellung der Präparate}

Die Knochenbiopsien wurden nach Fixierung und Einbettung unter Anwendung der TrennDünnschliff-Technik nach DONATH und BREUNER (1982) aufbereitet. Dabei handelt es sich um eine Methode, welche die Herstellung dünner Präparatschliffe von nicht schneidbaren Geweben, wie zum Beispiel zahn- oder implantattragenden Kieferabschnitten, ermöglicht.

Zu Beginn konnten grobe Überschüsse des Materials mit der Bandsäge entfernt und die einpolymerisierten Knochenblöcke zunächst einmal von Hand am Tellerschleifgerät senkrecht zur Längsachse des Alveolarfortsatzes plangeschliffen und poliert werden. Dies wurde mit Hilfe eines Haarlineals kontrolliert. Daraufhin konnte diese Seite des zu untersuchenden Knochens mittels Sofortklebstoff auf einem Plexiglasobjektträger befestigt werden. Nachdem der Kleber eine Stunde unter Druck der Objektträgerpresse zu einer gleichmäßig dünnen Schicht ausgehärtet war, konnte der Objektträger mitsamt angeklebtem Knochenblock in die Bandsäge eingespannt werden (Abbildung 5). Die Säge trennte den Knochenblock so ab, dass am Objektträger $300 \mu \mathrm{m}$ fest verbundener Knochen 
verblieb. Diese Dicke wurde dann sukzessive durch Anwendung des Schleifgerätes verringert (Abbildung 6).

Zunächst wurde die Dicke der Präparate bis auf etwa $170 \mu \mathrm{m}$ mit Schleifscheiben der Körnung P800 heruntergeschliffen. Anschließend wurde das Präparat mit Schleifscheiben der Körnung P1200 unter regelmäßiger mikroskopischer Kontrolle weiter bis auf etwa 30 $\mu \mathrm{m}$ reduziert. Daraufhin folgte eine fünfminütige Politur mit der Schleifscheibenkörnung 4000, worauf sich dann die Färbung der Präparate anschloss.

Das Verfahren wurde, beginnend beim Planschleifen, in gleicher Weise wiederholt, bis der zu untersuchende Knochenabschnitt abgearbeitet war.

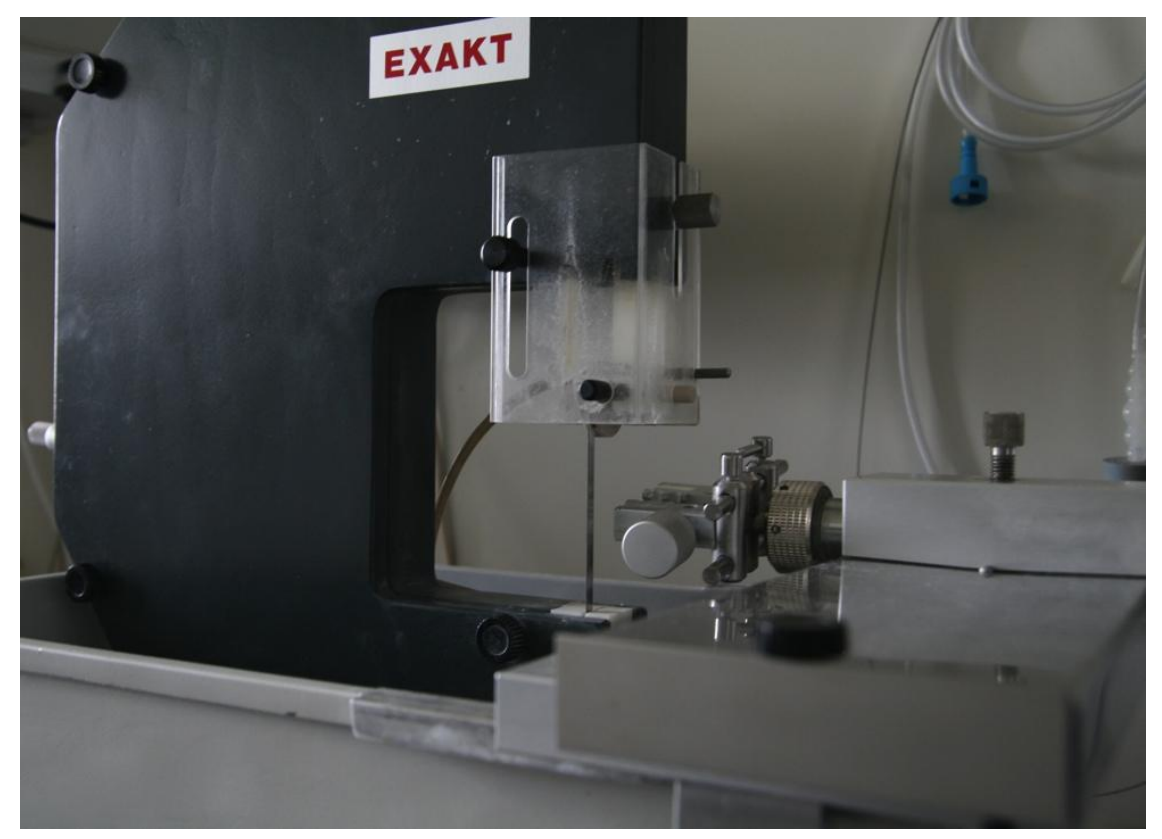

Abbildung 5 Bandsäge EXAKT 


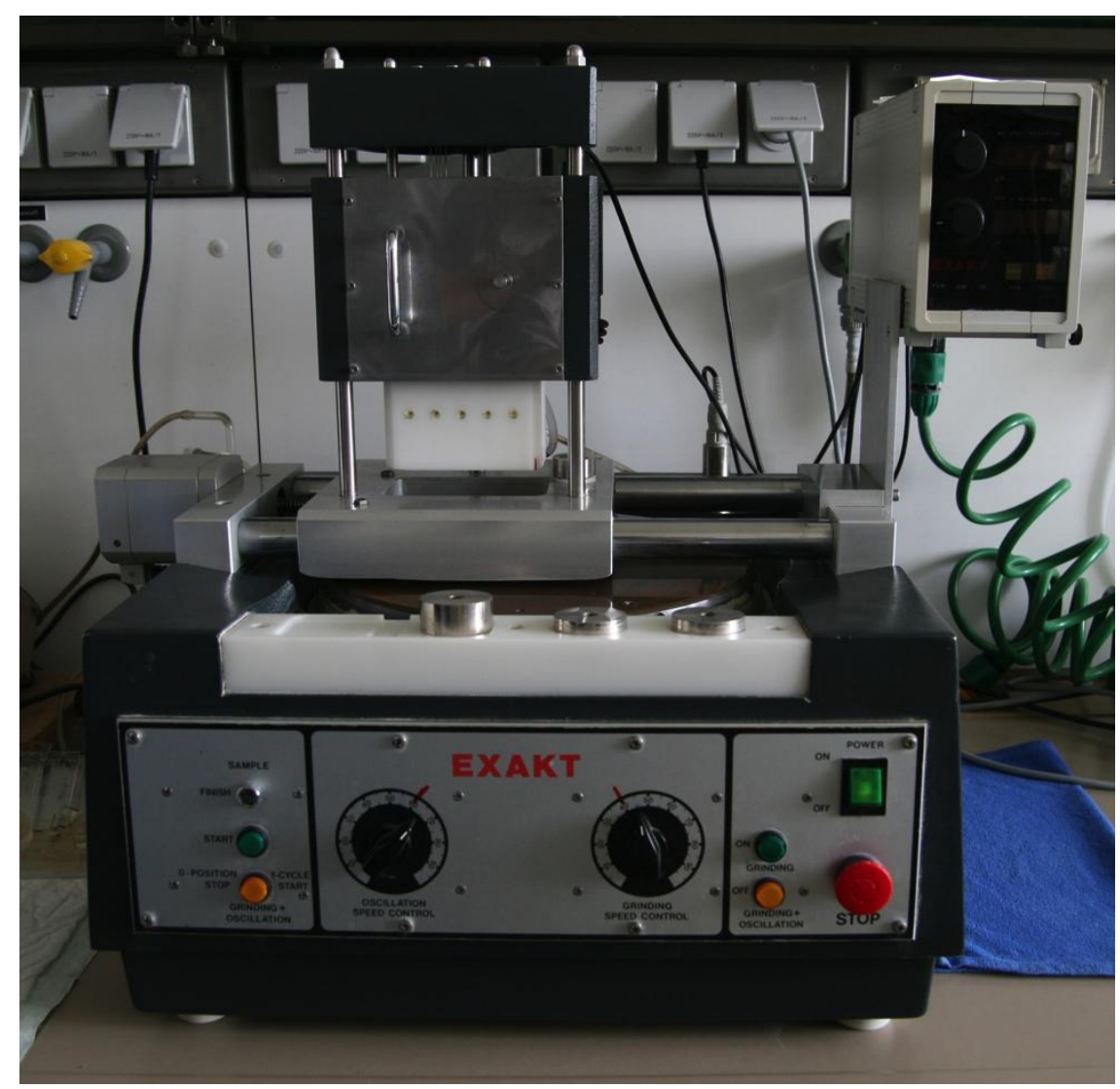

Abbildung 6 Schleifgerät EXAKT

\subsection{Färbung}

\subsubsection{Reagenzien und Chemikalien für die Färbung der histologischen Präparate}

- 3\%ige Essigsäure (Merck KGaA, Darmstadt)

- Aceton (Merck KGaA, Darmstadt)

- Ethanol (Merck KGaA, Darmstadt)

- demineralisiertes Wasser (Centramed GmbH \& Co. KG, Koblenz)

- Wasserstoffperoxid $\left(\mathrm{H}_{2} \mathrm{O}_{2}\right) 15 \%$ ig (Merck, KGaA, Darmstadt)

- Di-Natriumtetraborat-10-hydrat (Merck KGaA, Darmstadt)

- Alizarinrot S 5229 (Merck KGaA, Darmstadt)

- Löfflers Methylenblau 1287 (Merck KGaA, Darmstadt)

- Salzsäure (Merck KGaA, Darmstadt)

- Pyronin G 7518 (Merck KGaA, Darmstadt)

- Toluidinblau O 1273 (Merck KGaA, Darmstadt)

- Deckgläser MENZEL 24 x 48mm (Gerhard Menzel GmbH, Braunschweig)

- Schnelleindeckelmittel Entellan Neu (Merck KGaA, Darmstadt) 
Ansatz für die Alizarinrotlösung:

0,5 g Alizarinrot in $45 \mathrm{ml}$ demineralisiertem Wasser lösen und bei Bedarf mit Salzsäure auf den pH-Wert 6 bis 6,3 einstellen.

Ansatz für die Toluidinlösung:

Lösung 1: $1 \mathrm{~g}$ Toluidinblau in $100 \mathrm{ml}$ Di-Natriumtetraborat-10-hydrat (1\%ig) lösen.

Lösung 2: $1 \mathrm{~g}$ Pyronin $\mathrm{G}$ in $100 \mathrm{ml}$ destilliertem Wasser lösen.

Für die Gebrauchslösung vier Teile Lösung 1 mit einem Teil Lösung 2 zusammengeben.

Vor jedem Gebrauch erneut filtrieren.

\subsubsection{Färbung der Präparate}

Zur Kolorierung der Präparate wurden im Wechsel die Methylenblau-Alizarinrotfärbung (SMITH und KARAGIANES 1974) und die Tolouidinfärbung verwendet.

Die Tolouidinfärbung ist für die histomorphometrische Auswertung gut geeignet, da sie zum einen gut standardisierbar ist und zum anderen gute Differenzierungsmöglichkeiten zwischen altem und neu regeneriertem Knochen bietet. Diese Unterscheidung ist möglich durch Metachromasie und die unterschiedlich starke Anfärbung des Knochens durch dieses Reagenz.

Junger, neu regenerierter Knochen erscheint stark blau, wohingegen alter Knochen und Bindegewebe nur blass blau angefärbt wird.

Das Färbeprotokoll sah folgendes Vorgehen vor:

- 3 Minuten in 3\%iger Essigsäure

- 2 Minuten Spülen in Leitungswasser

- 10 Minuten in $15 \%$ igem $\mathrm{H}_{2} \mathrm{O}_{2}$

- 2 Minuten Spülen in Leitungswasser

- 5 bis 10 Minuten in frisch filtrierter Toluidinlösung mit Mikroskopkontrolle

- Spülen in demineralisiertem Wasser

- Trocknen

- Differenzieren mit Aceton/Alkohol im Verhältnis 1:1

- Eindeckeln 
Die Färbung nach Smith und Karagianes (1974) diente der qualitativen Untersuchung reaktiver Prozesse, da sie Aussagen über zelluläre Vorgänge durch eine orange-braune Färbung des Knochens und dunkelblau gefärbte Zellen ermöglicht. Auch Kollagen wird blau angefärbt.

Zunächst wurden die Präparate für 30 Sekunden mit auf 80 Grad Celsius im Wärmeschrank erwärmter Methylenblaulösung gefärbt.

Im zweiten Schritt, nach Spülen mit Wasser und Trocknen, wurden sie für eine Minute mit Alizarinrotlösung, entsprechend der Technik von Dahl (1952), bei Zimmertemperatur gefärbt. Nach erneutem Spülen und Trocknen waren die Präparate bereit zum Eindeckeln mit einem Tropfen Schnelleindeckmittel und einem Deckglas.

\subsection{Histomorphometrie}

\subsubsection{Geräte und Software für die Histomorphometrie}

- dotSlide Version 2.1 (Olympus Soft Imaging Solutions GmbH, Münster)

- Kamera Olympus dotSlide SL (Olympus Europa Holding GmbH, Hamburg)

- Mikroskop Olympus BX51 (Olympus Europa Holding GmbH, Hamburg)

- Vorschau Version 5.0.3 (Apple Inc., Cupertino)

- Adobe Photoshop CS5 Extended Version 12.0 (Adobe Systems GmbH, München)

- AxioVision AxioVs40 Version 4.8.2.0 (Carl Zeiss MicroImaging GmbH, Jena)

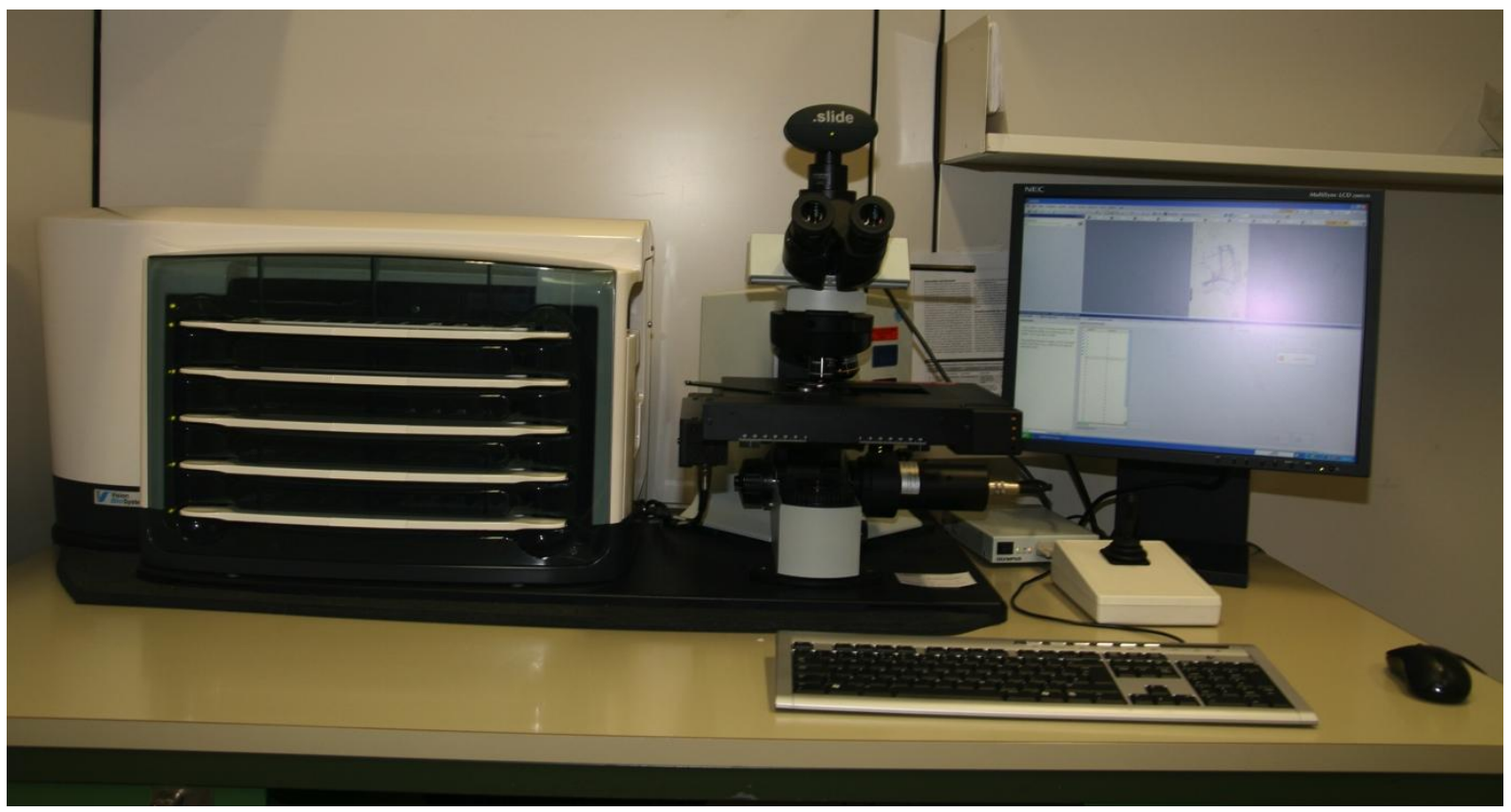

Abbildung 7 Komplettsystem dotSlide SL 


\subsubsection{Digitalisieren der Präparate}

Die Auswertung der Dünnschliffpräparate erfolgte mit Hilfe der Histomorphometrie, einer Methode, welche die Möglichkeit bietet, Flächen in histologischen Präparaten zu quantifizieren. Somit werden durch die Messung des neu formierten Knochens sowie des Knochenersatzmaterials vergleichende Aussagen über die knöcherne Regeneration der drei Defektgruppen möglich.

Die Auswahl der Präparate geschah unter dem Aspekt, möglichst verschiedene Defektabschnitte auszuwerten.

Zunächst wurden fünf Präparate je Defekt mit einem Mikroskop und einer Kamera der Firma Olympus digitalisiert.

Das in Abbildung 7 sichtbare Komplettsystem dotSlide SL von Olympus ermöglicht durch seine vollautomatische Ausführung, bis zu 50 Präparate automatisiert zu scannen. Die Kamera scannte den gesamten Objektträger und erstellte daraus detailgetreue digitale Bilder.

Bei den auswählbaren Parametern wurde für die Fokuseinstellung „pre focus“ und für die Verteilung der Fokuspunkte ,extra fine“ ausgewählt.

Das gesamte Präparat wurde zur Übersicht mit einem zweifach vergrößernden Objektiv aufgenommen. Der im Übersichtsscan markierte Defektbereich wurde mit einem Objektiv zehnfacher Vergrößerung aufgenommen.

Nach dem Scanvorgang lagen die Präparate als VSI-Dateien vor, die sich mit dem Olympusprogramm dotSlide in das Tagged Image File Format (TIFF) konvertieren ließen.

Von nun an konnte dieses gängige Dateiformat exportiert werden, was die weitere Auswertung unabhängig von dem Programm dotSlide machte.

In einer TIFF-Datei können mehrere Bilder abgelegt werden, sie sind dementsprechend mehrseitig. Die hier exportierten TIFF-Dateien enthielten vier Seiten und ließen sich unter Anwendung des Apple-Programms Vorschau splitten.

Somit ergab sich für jedes Präparat ein Übersichtsbild und eine Defektaufnahme in höherer Vergrößerung zur weiteren Bearbeitung (Abbildung 8). 


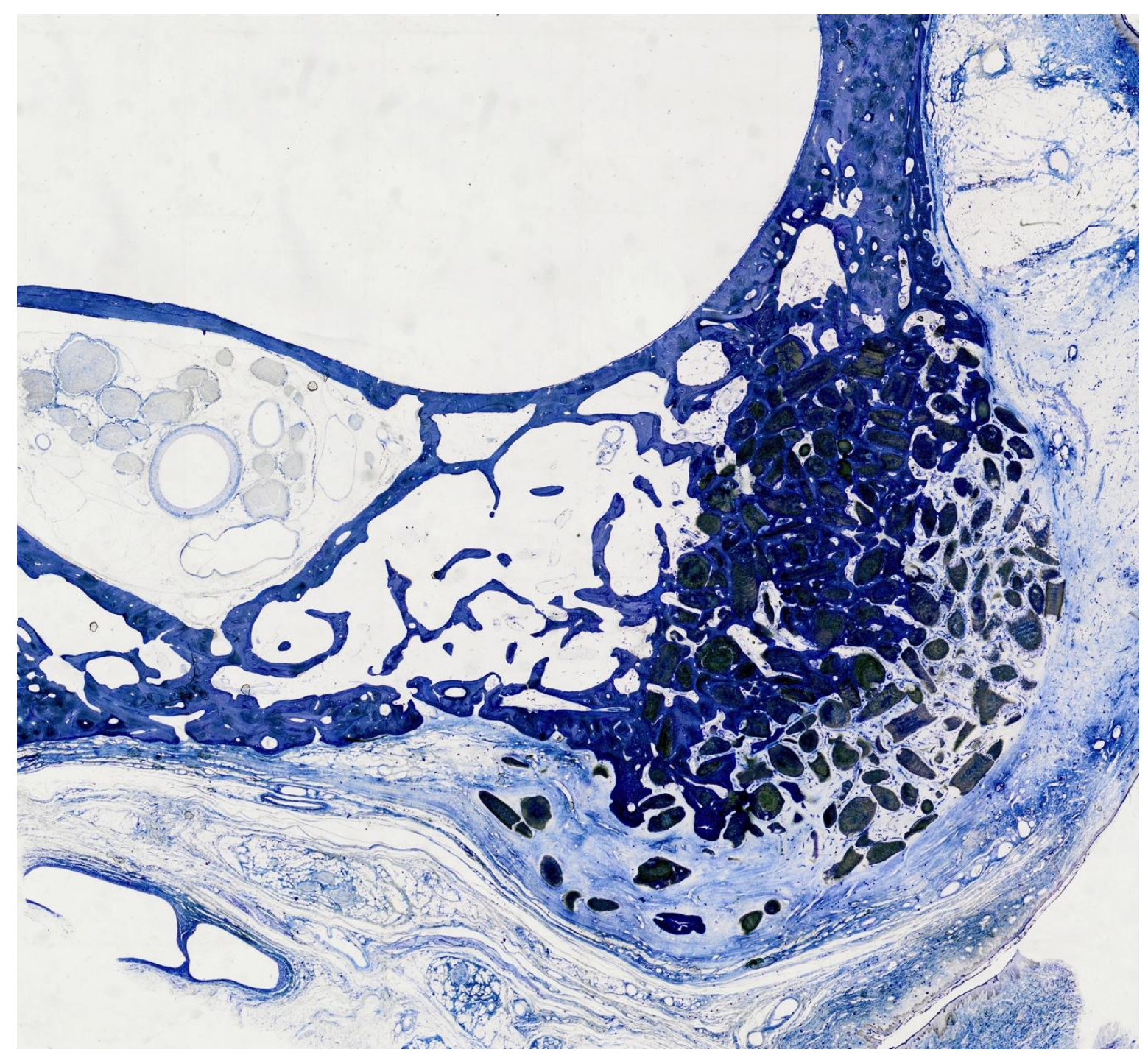

Abbildung 8 Ein digitalisiertes Präparat (Übersichtsaufnahme)

\subsubsection{Markierung der Flächen mit Photoshop}

Der nächste Schritt war die Markierung der Defektgrenzen im Programm Photoshop mit dem Werkzeug „magnetisches Lasso“ (Abbildung 9). Die Einstellungsparameter für dieses Instrument wurden je nach Intensität der Präparatfärbung bei Bedarf angepasst. 


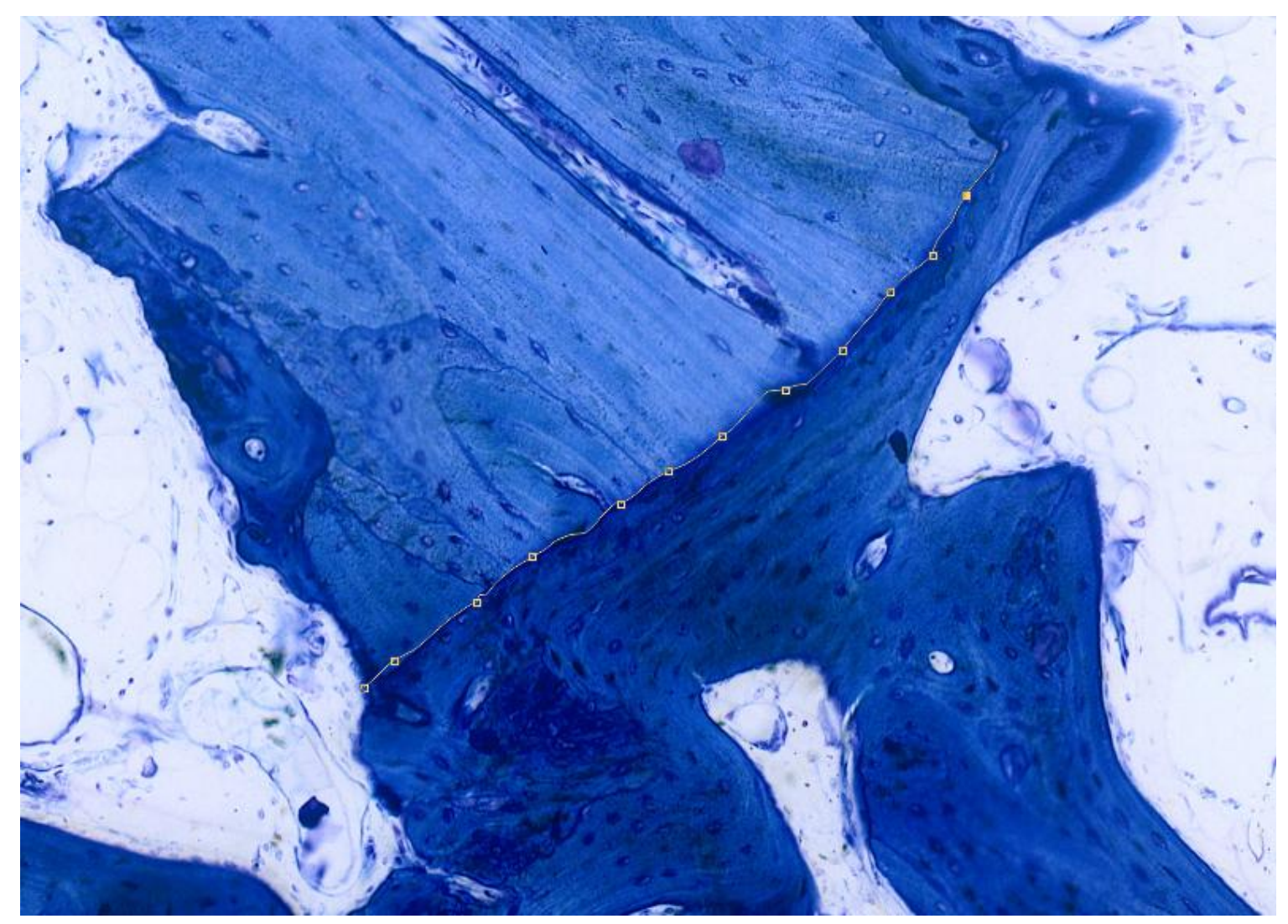

Abbildung 9 Markierung der Defektgrenze mit dem Instrument "magnetisches Lasso"

Die resultierende Regenerationsfläche wurde daraufhin in ein neues Dokument mit weißem Hintergrund kopiert und wieder im TIFF-Format abgespeichert (Abbildung 10). Der weiße Hintergrund garantierte bei der späteren Anwendung des Programms „Axiovision“ eine eindeutig definierte Begrenzung.

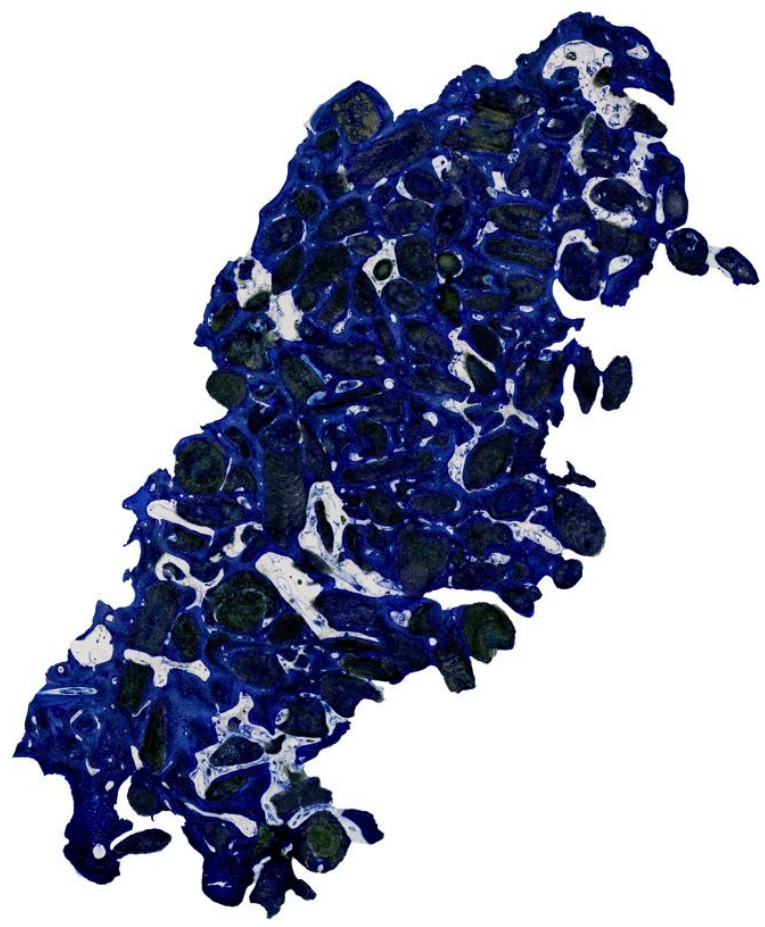

Abbildung 10 Die ausgeschnittene Regenerationsfläche 
Außerdem wurde innerhalb dieser Fläche das Knochenersatzmaterial wieder mit dem „magnetischen Lasso“ markiert, kopiert und in einem weiteren neuen Dokument abgespeichert (Abbildung 11).

Das ursprünglich vorhandene Gesamtbild diente auch zur Markierung des nicht integrierten Knochenersatzmaterials außerhalb des Regenerationsbereiches (Abbildung 12). Hiermit konnte in der weiteren Auswertung der Anteil des osseointegrierten Knochenersatzmaterials bestimmt werden.

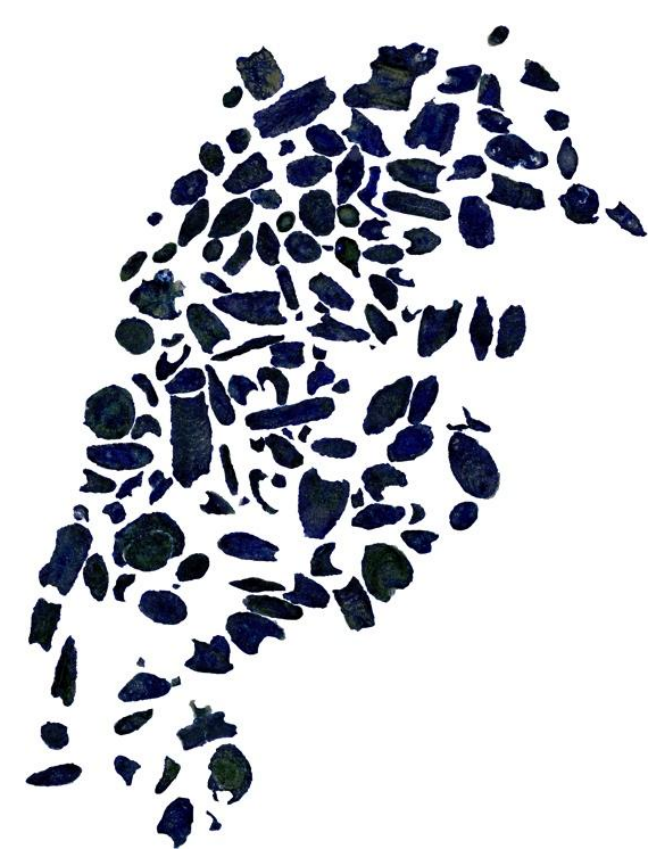

Abbildung 11 Knochenersatzmaterial innerhalb des Regenerationsbereiches

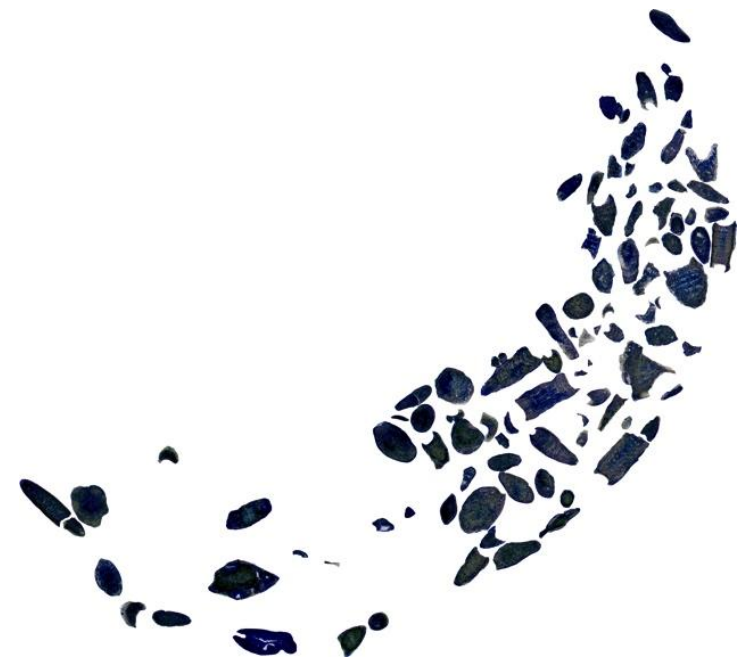

Abbildung 12 Knochenersatzmaterial außerhalb des Regenerationsbereiches

Die Flächen des im Regenerationsbereich markierten Knochenersatzmaterials wurden weiß gefüllt, so dass nur die reine Knochenfläche zurückblieb (Abbildung 13).

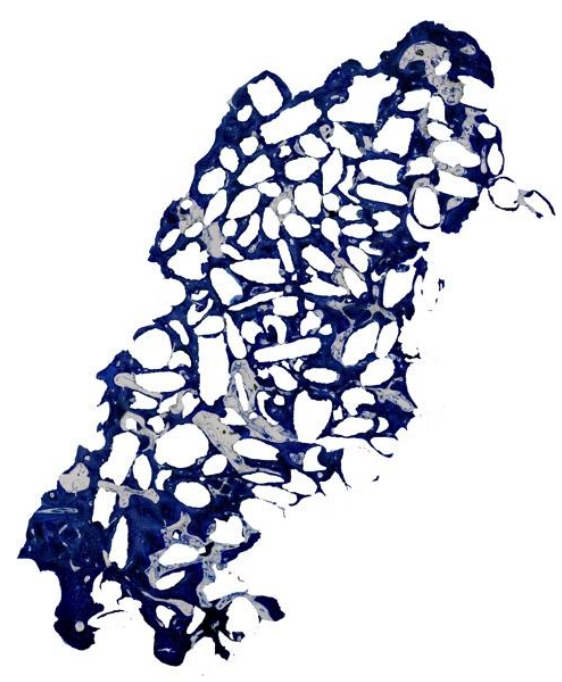

Abbildung 13 Die reine Knochenfläche ohne Knochenersatzmaterial 
Als weiterer Auswertungsparameter wurde die augmentierte Fläche bestimmt, um später den Regenerationsumfang vergleichen zu können. Hierfür wurde die krestale Begrenzung des Augmentationsbereiches mit dem Werkzeug „magnetisches Lasso“ markiert. Das Periost sowie das Knochenersatzmaterial waren für die Begrenzung kennzeichnend.

Die Markierung der basalen Grenze konnte dabei direkt von der Markierung der Regenerationsfläche übernommen werden. Wie in Abbildung 14 sichtbar, beinhaltete die schließlich gekennzeichnete Fläche somit sowohl die regenerierte Fläche als auch die Bereiche mit dem nicht osseointegrierten Knochenersatzmaterial.

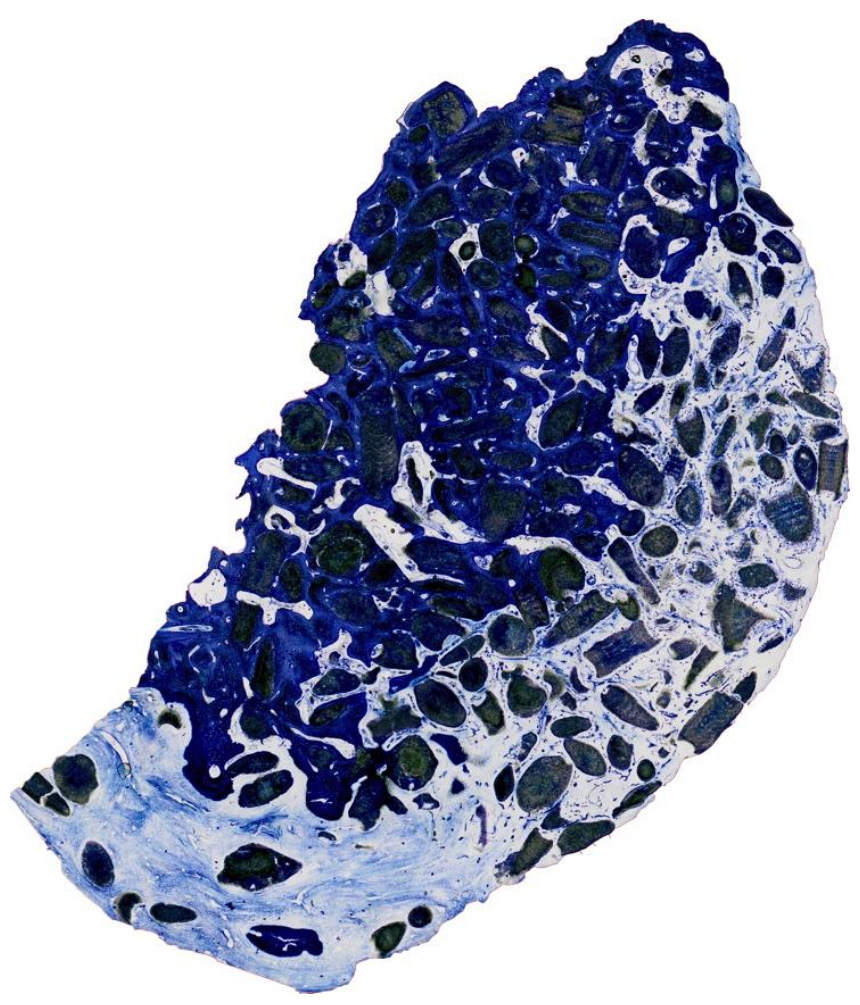

Abbildung 14 Der ausgeschnittene Augmentationsbereich

Alle Markierungen wurden aus Dokumentationsgründen zusätzlich rot hinterlegt abgespeichert.

Zusammenfassend resultierten nun als einzelne TIFF Bilddateien für jedes Präparat:

- die Knochenersatzmaterialfläche im Regenerationsbereich

- die Knochenersatzmaterialfläche außerhalb des Regenerationsbereiches

- die reine Knochenfläche im Defektbereich

- die augmentierte Fläche 


\subsubsection{Flächenmessung mittels Axiovision}

Die Histomorphometrie bietet die Möglichkeit, digitalisierte Präparate zu vermessen und quantitativ zu vergleichen.

Unter Nutzung der Funktion „AutMess“ der Axiovision Bildanalysesoftware wurde die Gesamt-, und Knochenfläche bzw. die Knochenersatzfläche jeder Bilddatei interaktiv definiert und ausgemessen. Mit Hilfe der Funktion „Region Growing“ (Bereichswachstumsverfahren) konnten Knochenbereiche Stück für Stück markiert und somit identifiziert werden. Damit wurden die Schwellenwerte für die Markierung des Knochens dynamisch ermittelt (Abbildung 15).

Aufgrund der niemals völlig identischen Färbung musste die Farbspektrumbestimmung für jedes Präparat neu durchgeführt werden.
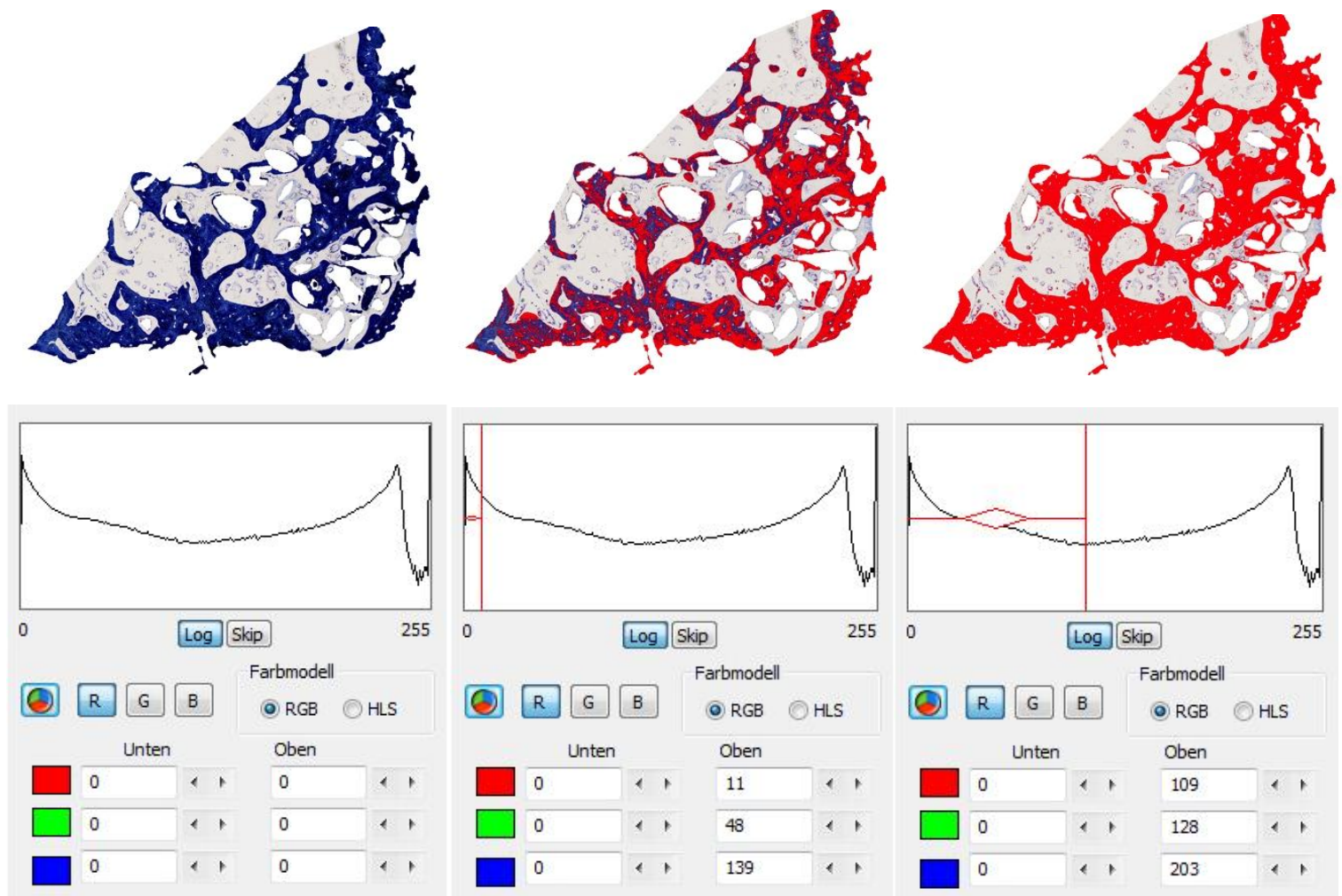

Abbildung 15 Der Beginn, ein beispielhafter Zwischenschritt und das Ende des "Region Growing" mit dem jeweiligen Histogramm

Entsprechend dieser Festlegung ergab sich in der Ansicht die vorläufige Knochenfläche, die anschließend im Binärbild Editor manuell korrigiert werden musste. Hierbei konnten beispielsweise Artefakte aus dem markierten Bereich entfernt oder fehlende Bereiche hinzugefügt werden. 
Die Software segmentierte diese eingegebenen Informationen und erstellte daraus ein Binärbild (Abbildung 16), mit welchem schließlich die Parameter Knochen- und Gesamtfläche berechnet werden konnten.

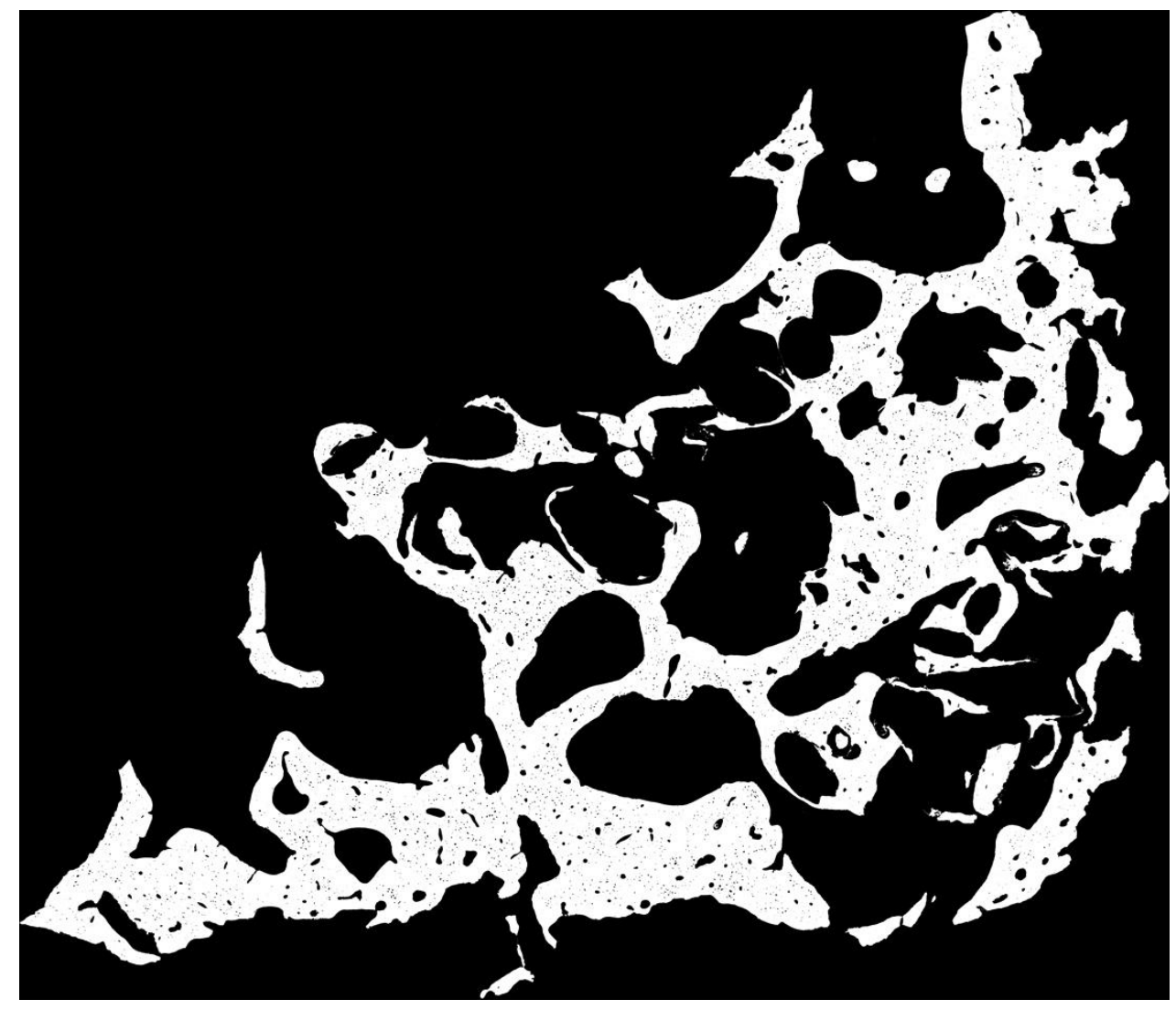

Abbildung 16 Das erstellte Binärbild

Aufgrund des weißen Bildhintergrundes war die Begrenzung der Gesamtfläche eindeutig und musste nicht korrigiert werden.

Eine mit demselben Mikroskop eingescannte Skalierung diente als zugeordnete Referenz. Pro Pixel ergab sich ein Wert von $0,649 \mu \mathrm{m}$ bei Anwendung des zehnfach vergrößernden Objektivs und 3,24 $\mu \mathrm{m}$ bei dem Objektiv zweifacher Vergrößerung.

\subsubsection{Messung der maximalen Defektausdehnung}

Ein weiterer Messparameter bei der Analyse der Schliffpräparate war die maximale Breite und Höhe der Knochenregeneration.

Die Abbildung 17 zeigt, wie hierfür das Längenmesswerkzeug in Axiovision angewendet wurde. Auch die maximale Höhe und Breite der augmentierten Fläche wurde hiermit ausgemessen. 


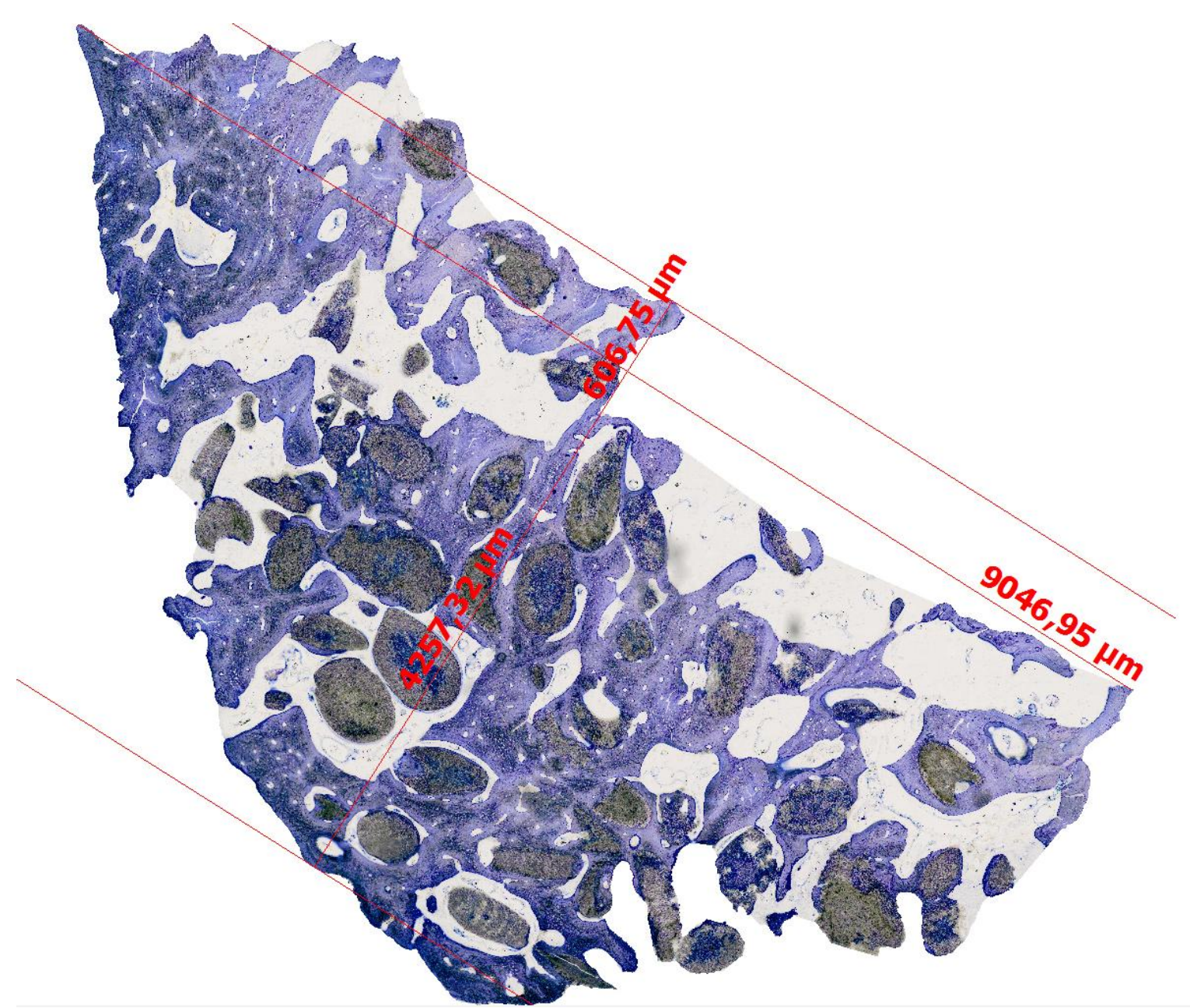

Abbildung 17 Messung der maximalen Defektausdehnung in Axiovision

\subsubsection{Statistische Auswertung}

Die Auswertung der erhobenen Daten erfolgte nach Beratung durch die Abteilung für Medizinische Statistik der Universität Göttingen mit den Statistikprogrammen STATISTICA (Version 10, StatSoft Inc., Tulsa, USA) und SAS (Version 9, SAS Institute Inc., Cary, USA).

Um die histomorphometrisch ausgemessenen Daten zu vergleichen, wurden zunächst die Mittelwerte der einzelnen Defekte bestimmt. Anschließend wurden daraus die Mittelwerte und Standartabweichungen der verschiedenen Augmentationsmaterialien bzw. der Kontrollgruppe mit STATISTICA bestimmt.

Mithilfe von Boxplots wurden die Verteilungen visualisiert.

Es wurde eine Normalverteilung der Messergebnisse angenommen.

Der Vergleich der drei Gruppen erfolgte mit Hilfe von SAS über eine Varianzanalyse für verbundene Stichproben (ANOVA). Als Signifikanzniveau wurde der Wert $\mathrm{p}<0,05$ 
festgelegt. Bei einem signifikanten Einfluss wurde ein paarweiser Vergleich durch den tTest für verbundene Stichproben bei gleichem Signifikanzniveau durchgeführt.

Bei Kriterien, von denen nur Daten zu zwei Gruppen vorlagen, wurde direkt der t-Test für verbundene Stichproben durchgeführt. 


\section{Ergebnisse}

\subsection{Klinische Heilung}

Postoperativ traten keine Infektionen oder Komplikationen bei der Wundheilung auf. Ein Defekt aus der Gruppe des TCP/HA-Gemisches ohne Poloxamer, aber mit Kollagenmembran, war nicht auswertbar, da die augmentierte Fläche deutlich verkleinert und somit von nahezu vollständigem Materialverlust betroffen zu sein schien. Auch zwei mit TCP/HAPartikeln und Poloxamergel gefüllte Defekte schienen einen größeren Materialverlust erlitten zu haben, zeigten aber dennoch recht gute Regeneration. Außerdem war ein Defekt der Kontrollgruppe nicht auswertbar.

\subsection{Qualitative histologische Untersuchung}

Auch histologisch waren in der angrenzenden Mukosa der Defektbereiche keine Entzündungsreaktionen sichtbar. In allen Versuchsgruppen wurde Knochenneubildung beobachtet, in den gefüllten Defekten verband eingebautes TCP/HA in einem Trabekelnetzwerk den neuen Knochen.

Die ungefüllten Kontrolldefekte zeigten häufig flache Knochenregeneration, die hauptsächlich direkt von der Osteotomiefläche ausging (Abbildung 18). Teilweise regenerierte der Knochen auch in Form eines verkleinerten Alveolarkammes (Abbildung 19). In einigen Kontrolldefekten konnten vereinzelte TCP/HA-Partikel beobachtet werden, die aufgrund der relativen Nähe sowohl von den angrenzenden Defekten mit Kollagenmembran als auch von Defekten mit Poloxamermatrix in die Kontrolldefekte gelangen konnten (in Abbildung 18 mit einem Pfeil gekennzeichnet).

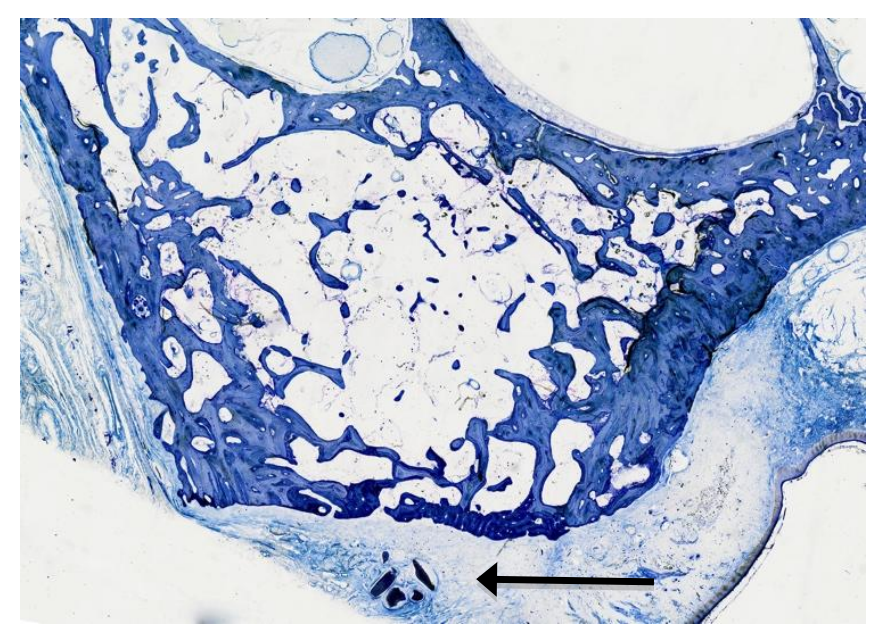

Abbildung 18 Regeneration in der Kontrollgruppe 


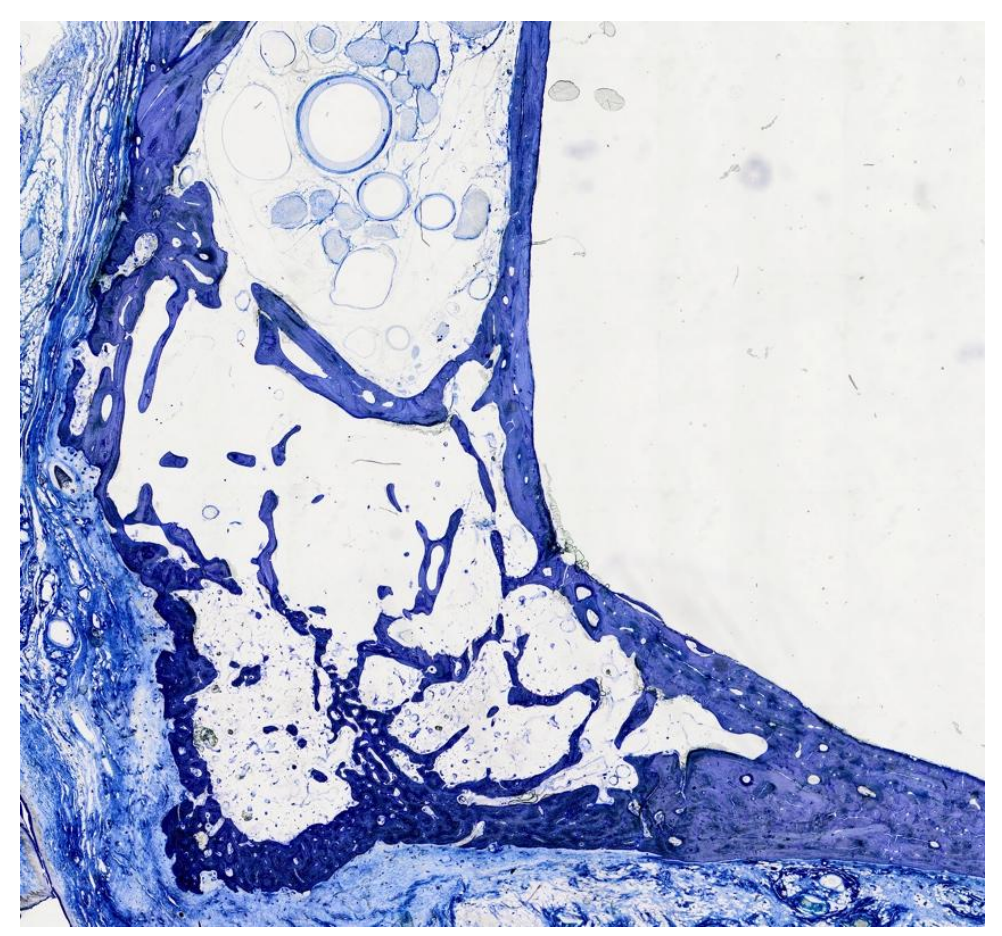

Abbildung 19 Regeneration in der Kontrollgruppe

Mit dem porösen TCP/HA-Material gefüllte Defekte zeigten mehr knöcherne Regeneration. In keinem der Defekte waren jedoch die gesamten Knochenersatzmaterialpartikel knöchern gefasst. Ein großer Teil der TCP/HA-Partikel stellte sich, wie in Abbildung 20 und 21 sichtbar, bindegewebig organisiert dar.

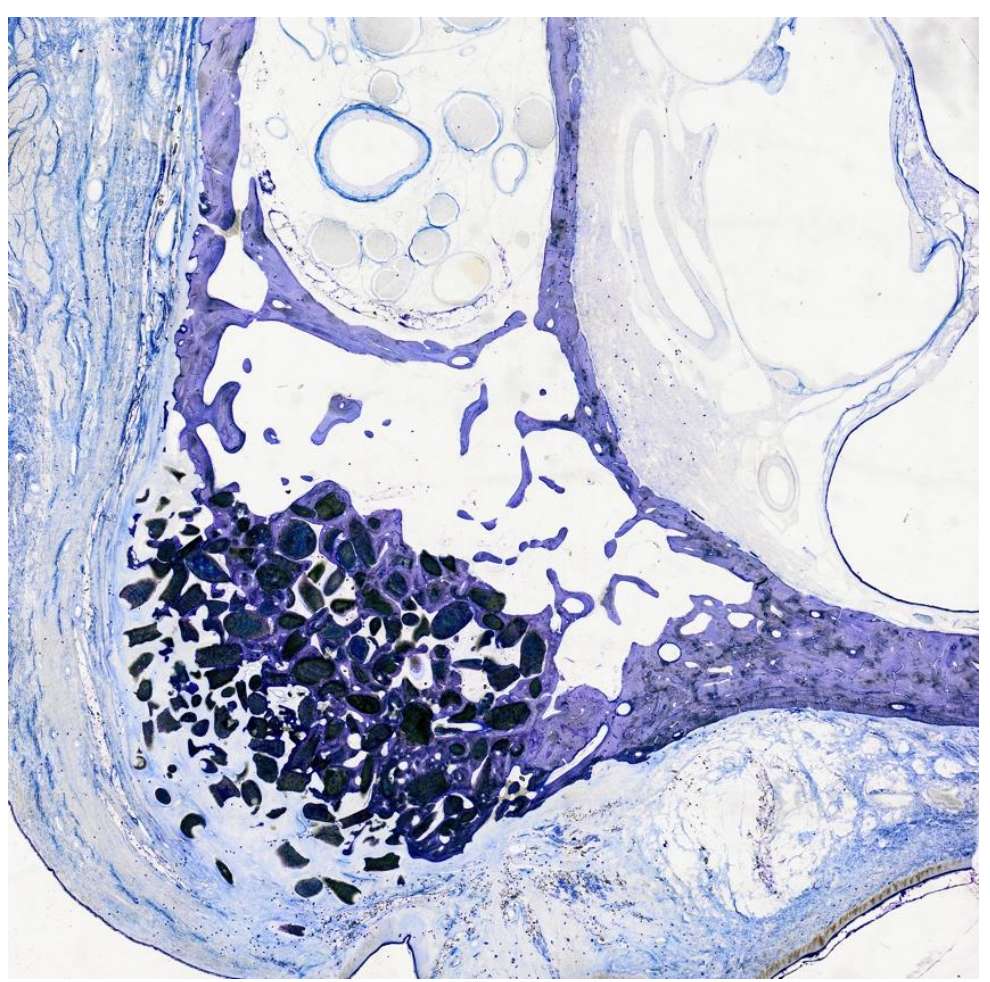

Abbildung 20 Regeneration nach Anwendung von TCP/HA und Kollagenmembran 


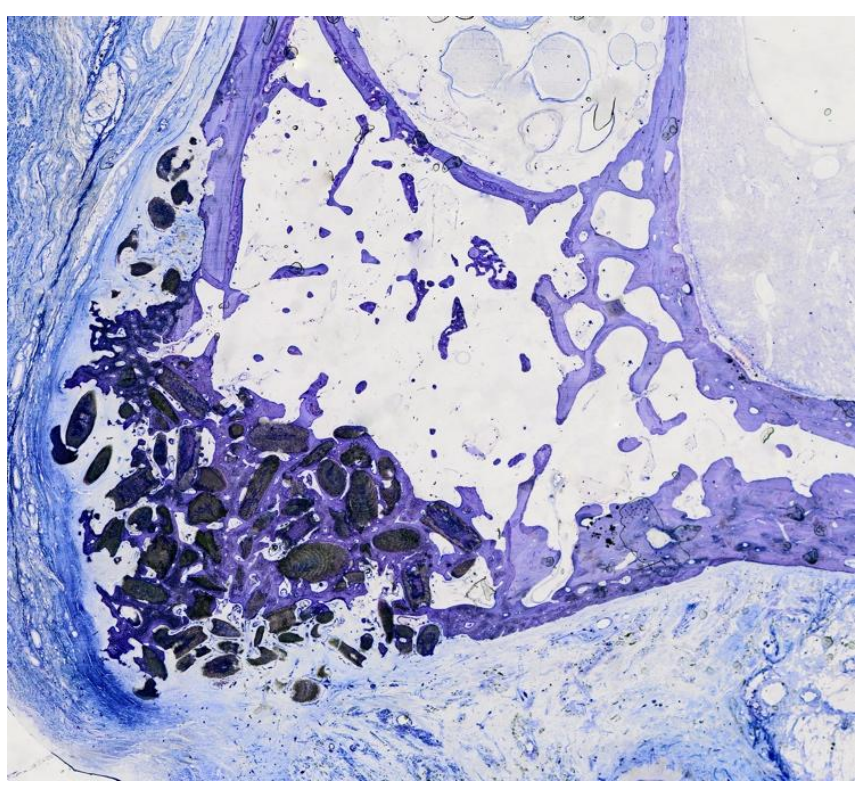

Abbildung 21 Regeneration nach Anwendung von TCP/HA und Kollagenmembran

Die histologischen Präparate aus der Gruppe der durch das Poloxamer stabilisierten TCP/HA-Partikel zeigten größere Unterschiede in der Form der knöchernen Regeneration (Abbildung 22 bis 25). Auch hier war nur ein Teil des Knochenersatzmaterials osseointegriert und der übrige Anteil bindegewebig umschlossen. Außerdem zeigten sich bei einigen Defekten dieser Gruppe größere laterale Verschiebungen des eingebrachten Ersatzmaterials.

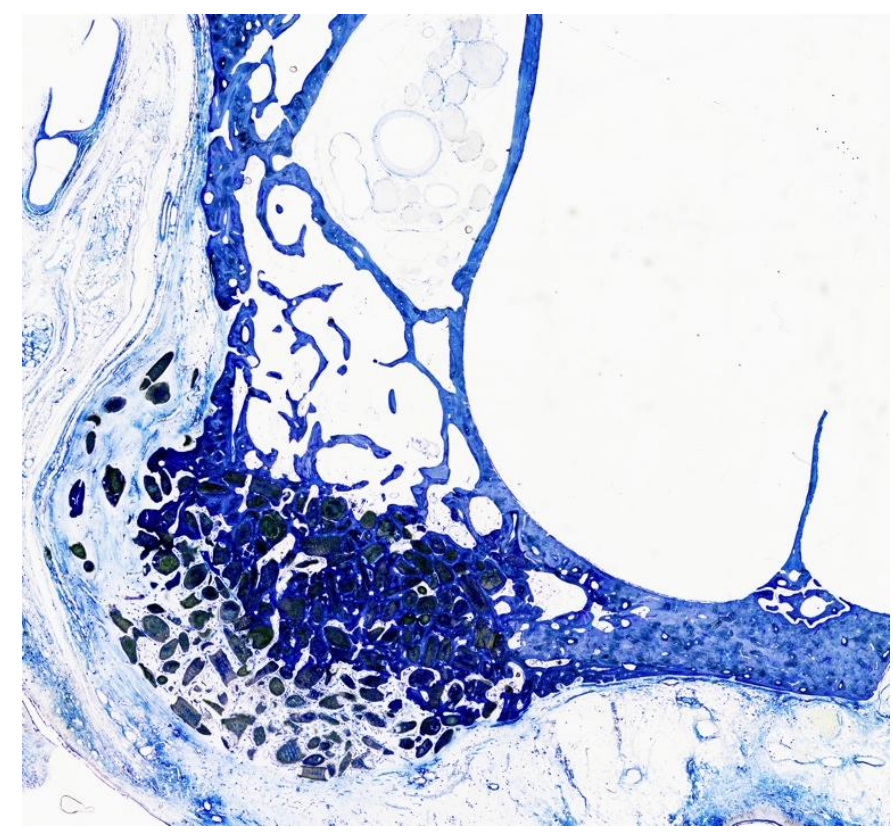

Abbildung 22 Regeneration bei Anwendung von TCP/HA eingebettet in eine Poloxamermatrix

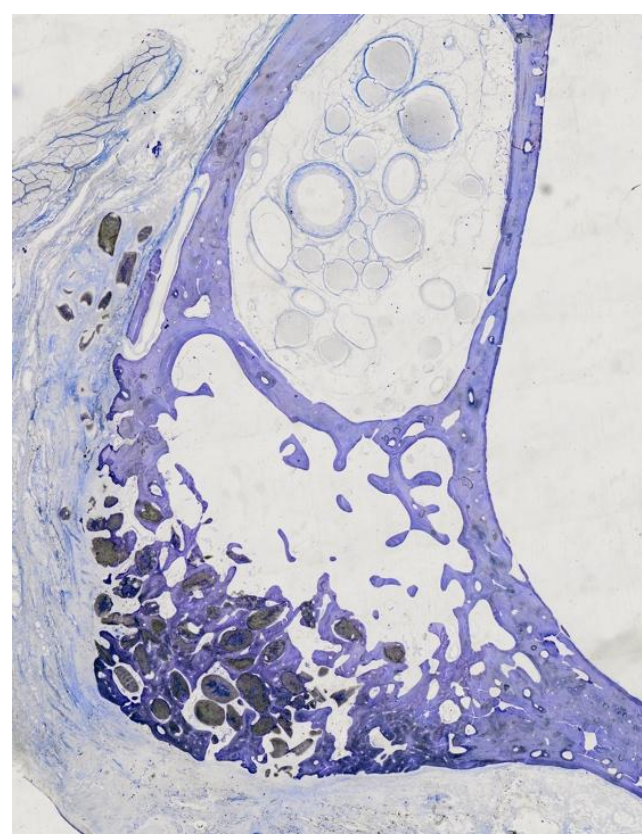

23 Regeneration bei TCP/HA und Poloxamer 


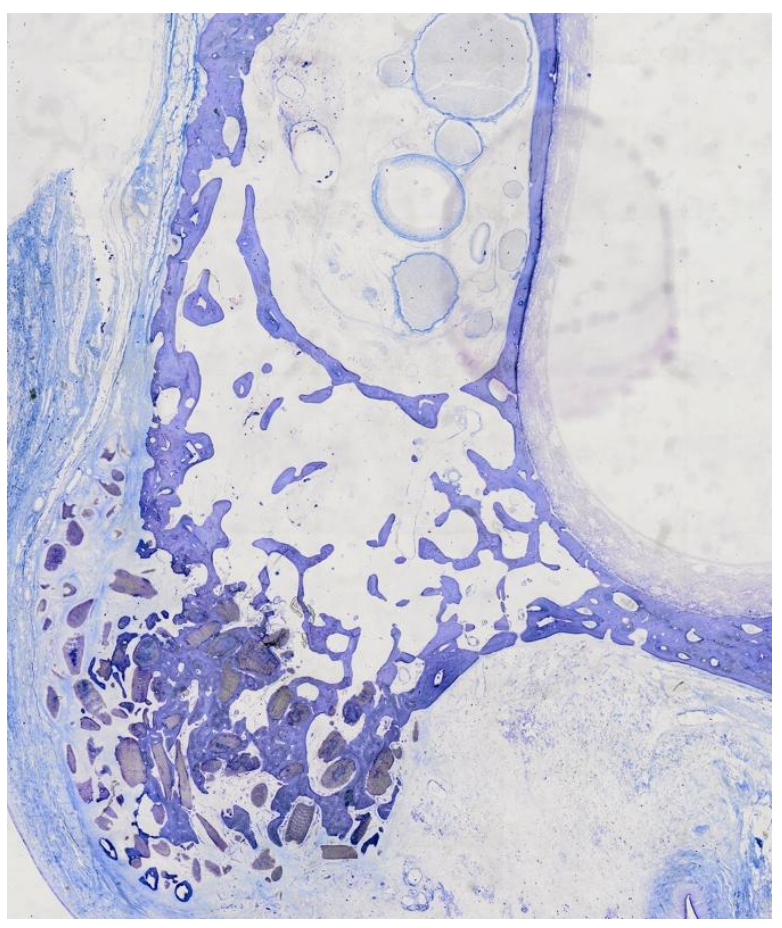

Abbildung 24 TCP/HA und Poloxamer

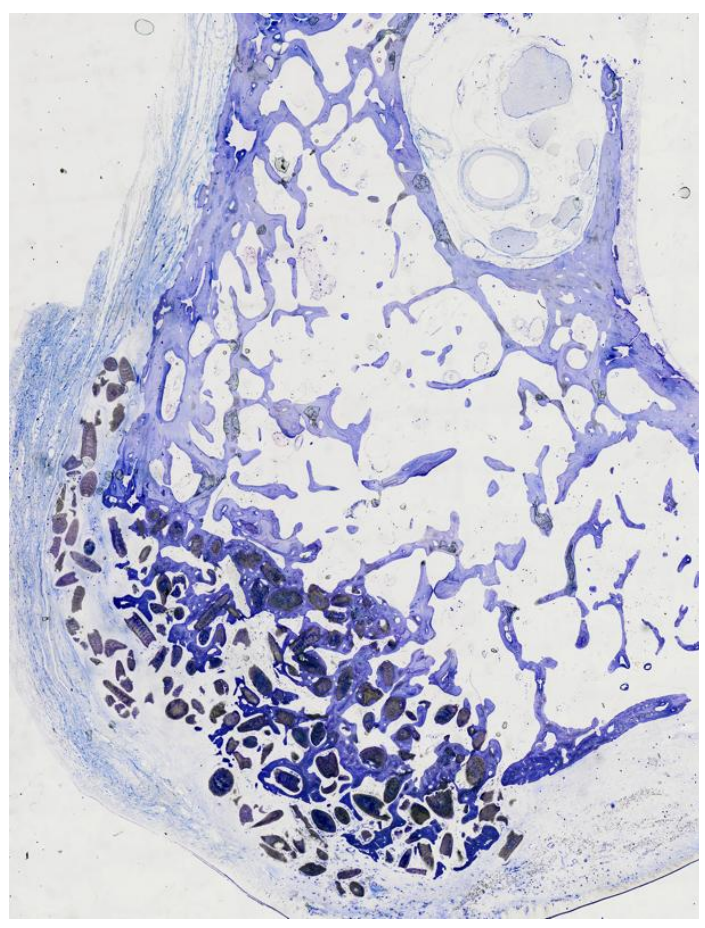

Abbildung 25 TCP/HA und Poloxamer

Weiterhin konnten in dieser Gruppe unfangreiche, weitverzweigte Vaskularisierungen beobachtet werden. Auch unterschiedlich große Mengen basophiler Überreste des Poloxamers waren im gesamten Augmentationsbereich sichtbar. Auffällig war dabei eine nahe Beziehung zwischen Poloxamerüberresten und Blutgefäßen, die auf eine verstärkte Angiogenese in Zusammenhang mit dem Poloxamer hindeuten könnte.

In den folgenden Abbildungen 26 und 27 wird diese verstärkte Vaskularisierung mit dem umliegenden Poloxamer deutlich. 


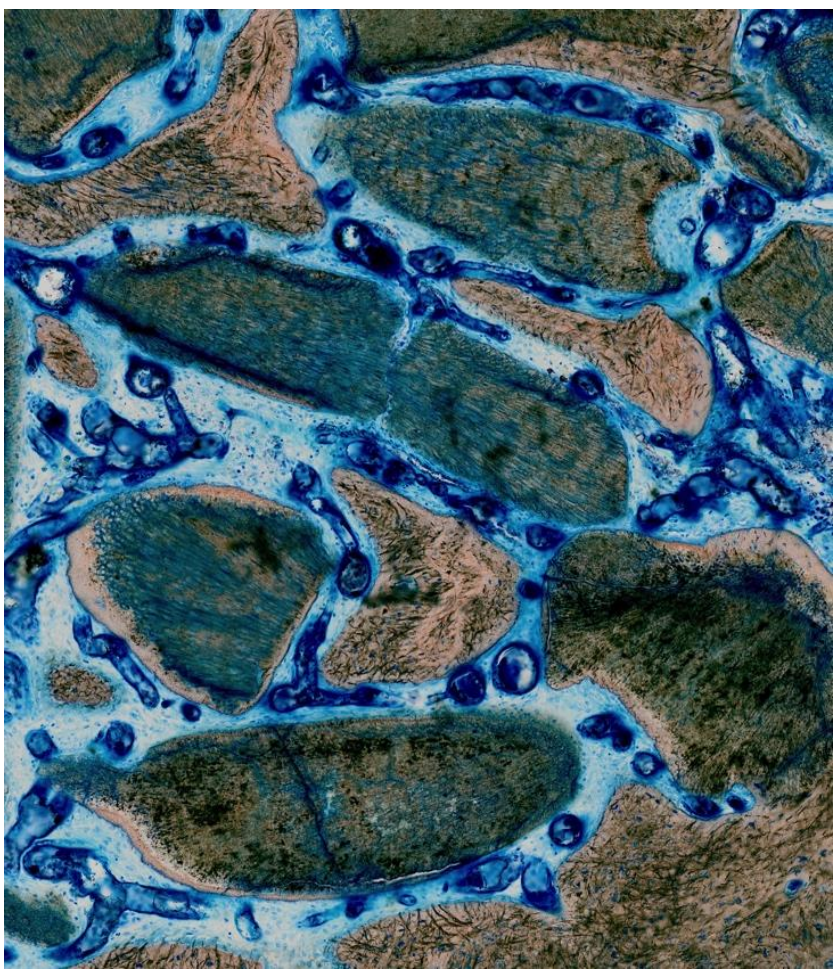

Abbildung 26 Gefäße sowie Poloxamer zwischen den TCP/HA-Partikeln in der 26

Übersicht

Defekte beider augmentierten Gruppen zeigten neben osseointegriertem TCP/HA und bindegewebiger Organisation auch regelrecht abgekapseltes Material ohne Knochenkontakt (Abbildung 28).

Die osseointegrierten Materialanteile hingegen waren von neu formierem Knochen umgeben und zeigten Anzeichen von Osteoid bzw. noch unreifem Knochen in ihren Poren (Abbildungen 29 und 30).

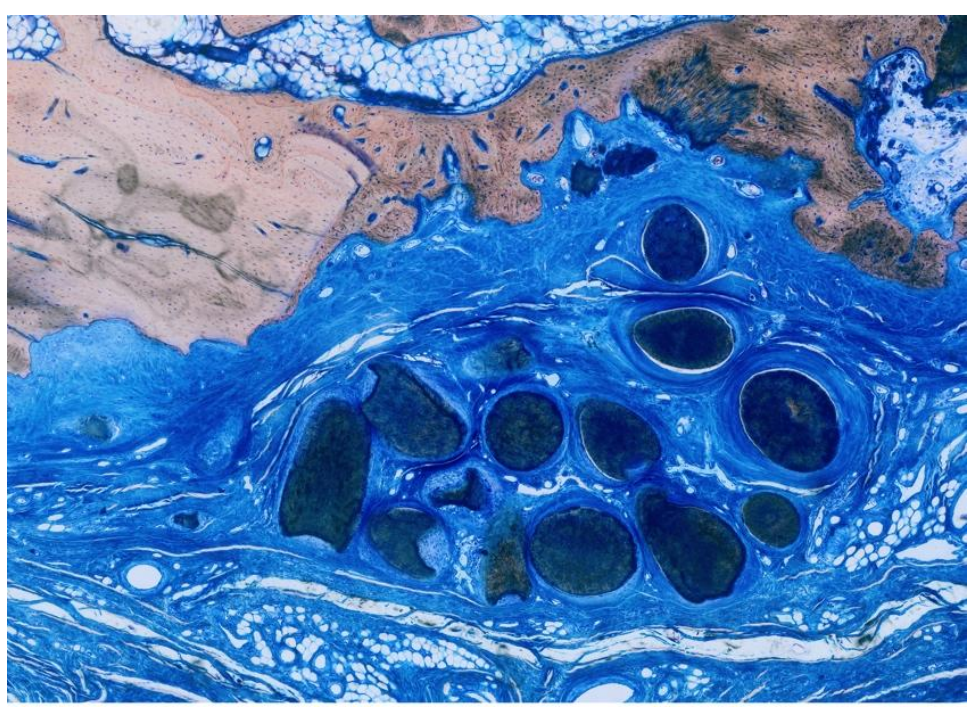

Abbildung 28 Abgekapselte TCP/HA-Partikel 


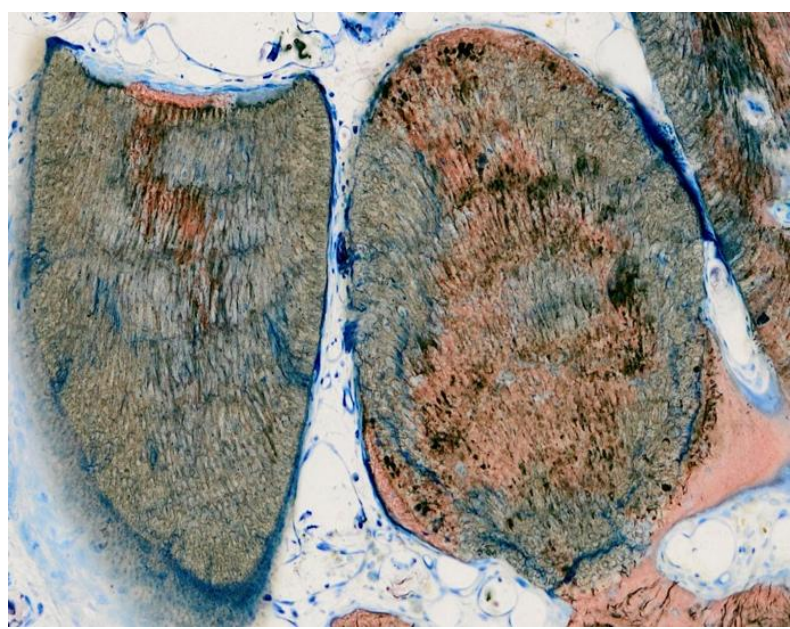

Abbildung 29 Osseointegrierte Partikel

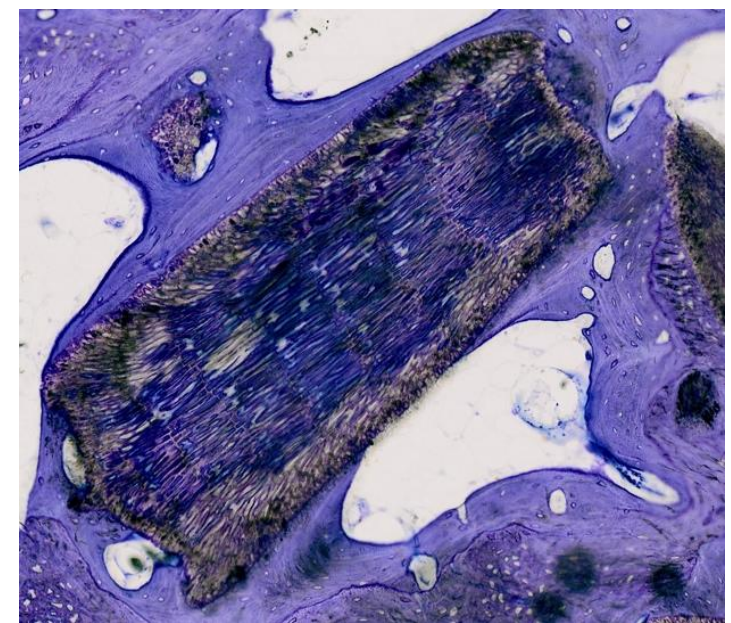

Abbildung 30 Osseointegrierte TCP/HAPartikel

Die voranschreitende Regeneration wurde auch auf zellulärer Ebene sichtbar, da im Bereich der TCP/HA-Partikel beider augmentierter Gruppen neben Osteoblastensäumen (Abbildungen 31 und 32) auch Resorptionvorgänge durch vielkernige Riesenzellen zu beobachten waren (Abbildungen 33 und 34).

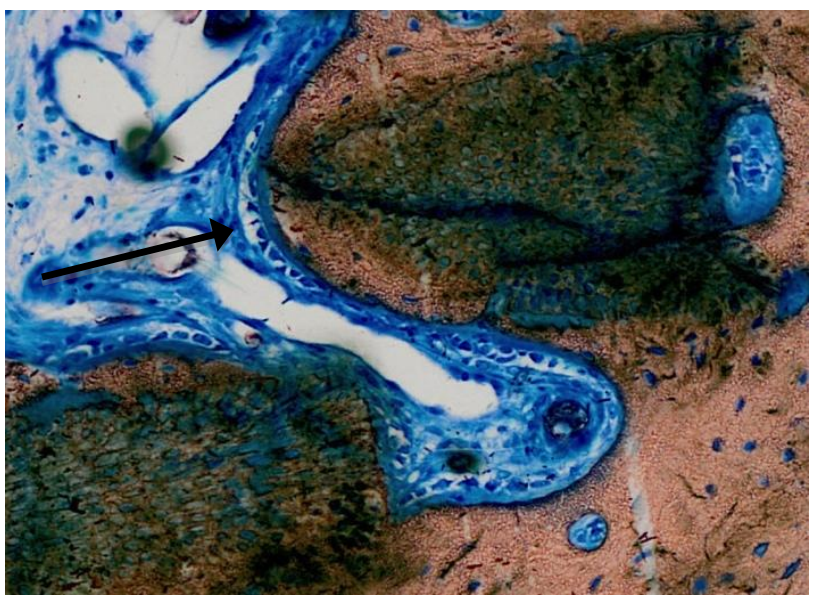

Abbildung 31 Osteoblastensäume um neu gebildeten Knochen (mit Pfeil markiert)

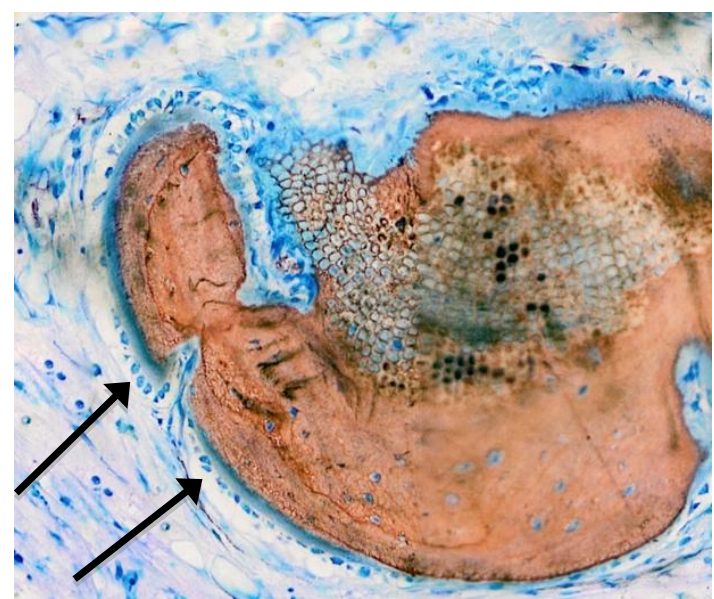

Abbildung 2 Osteoblastensaum (Pfeile) 


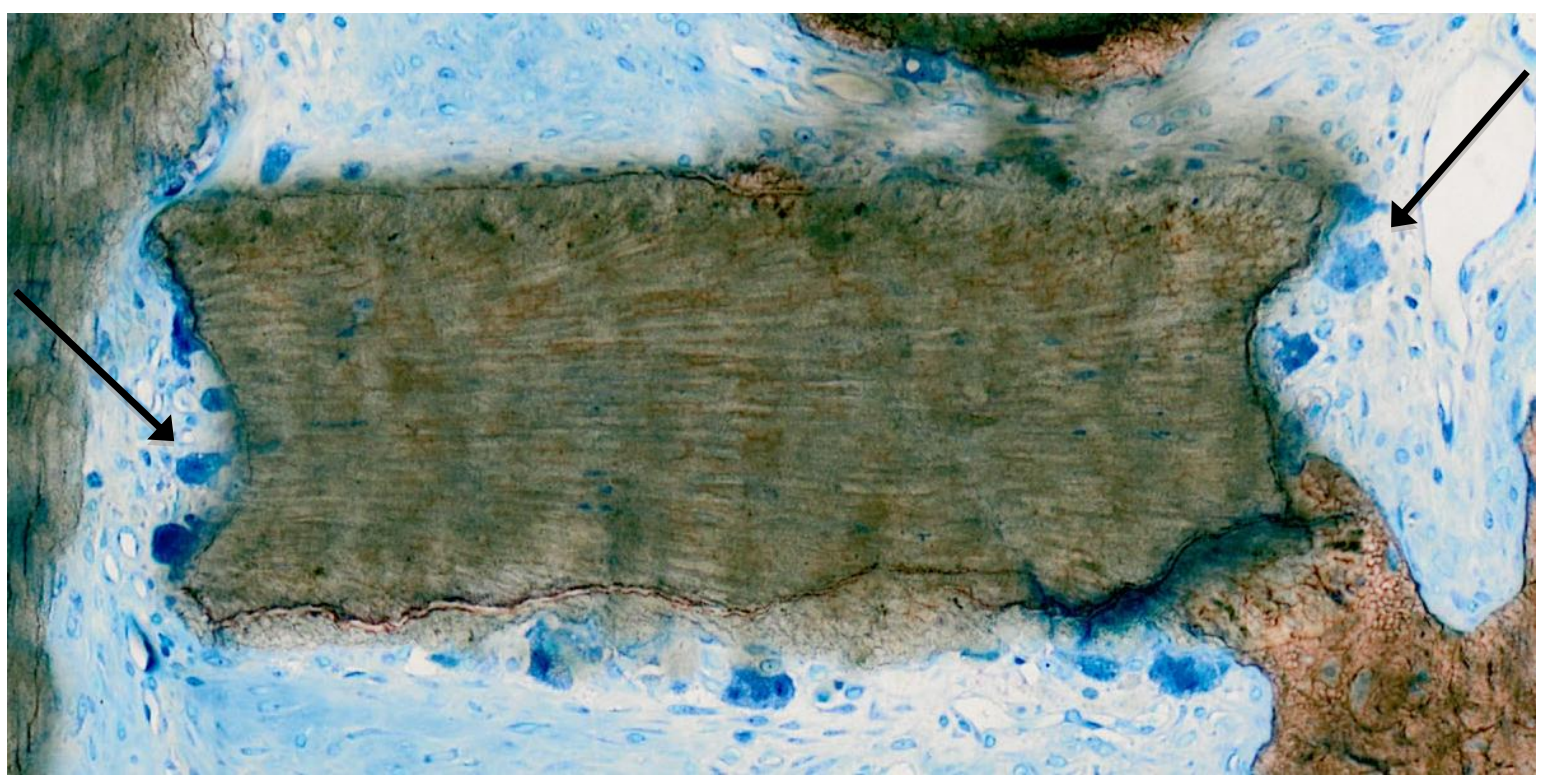

Abbildung 33 Mehrkernige Riesenzellen (Pfeile) an einem TCP/HA-Partikel

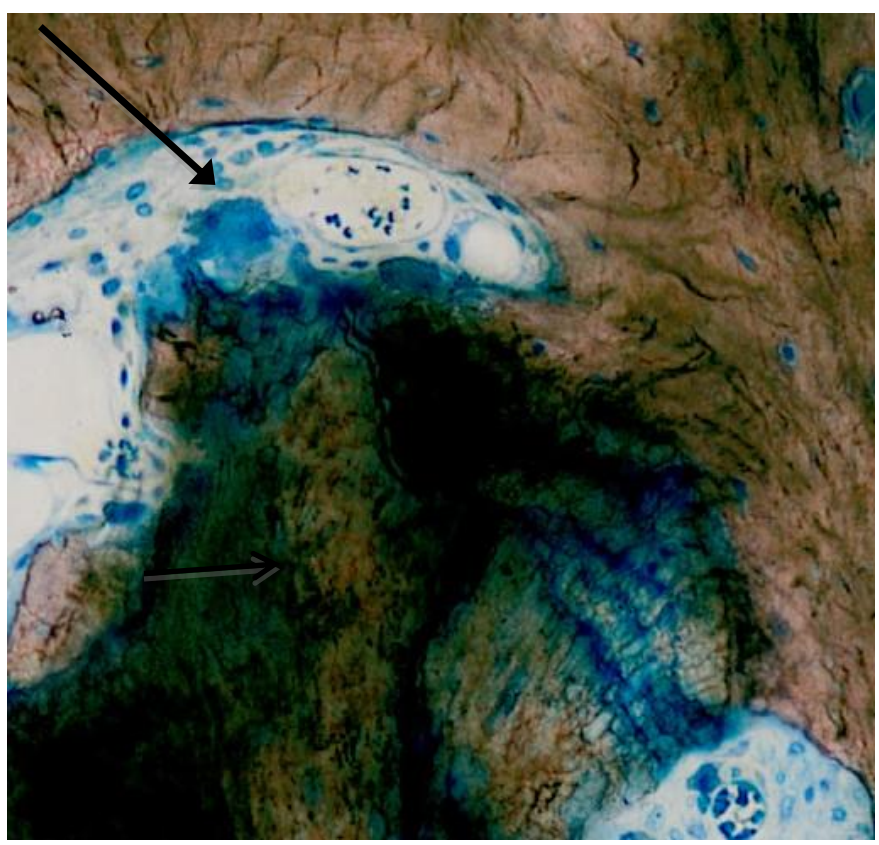

Abbildung 34 Ansicht einer mehrkernigen Riesenzelle am KEM (mit Pfeil markiert) 


\subsection{Histomorphometrische Untersuchung}

\subsubsection{Regenerierte Knochenfläche}

Die ausgemessene neu gebildete Knochenfläche ohne das Knochenersatzmaterial maß im Mittel 7,31 $\mathrm{mm}^{2}$ (SD: 1,53) in der Kontrollgruppe (Abbildung 35). In den mit TCP/HAPartikeln gefüllten und einer Kollagenmembran abgedeckten Defekten betrug dieser Mittelwert 9,71 mm ${ }^{2}$ (SD: 0,84). Bei den mit TCP/HA in einer Poloxamermatrix gefüllten Defekten fiel die Regeneration mit $10,42 \mathrm{~mm}^{2}$ (SD: 2,53) nur geringfügig größer aus. Die Varianzanalyse ergab für alle drei Gruppen keinen signifikanten Unterschied $(p=0,3027)$, so dass ein nachfolgender Vergleich zwischen den Gruppen durch den t-Test unnötig war.

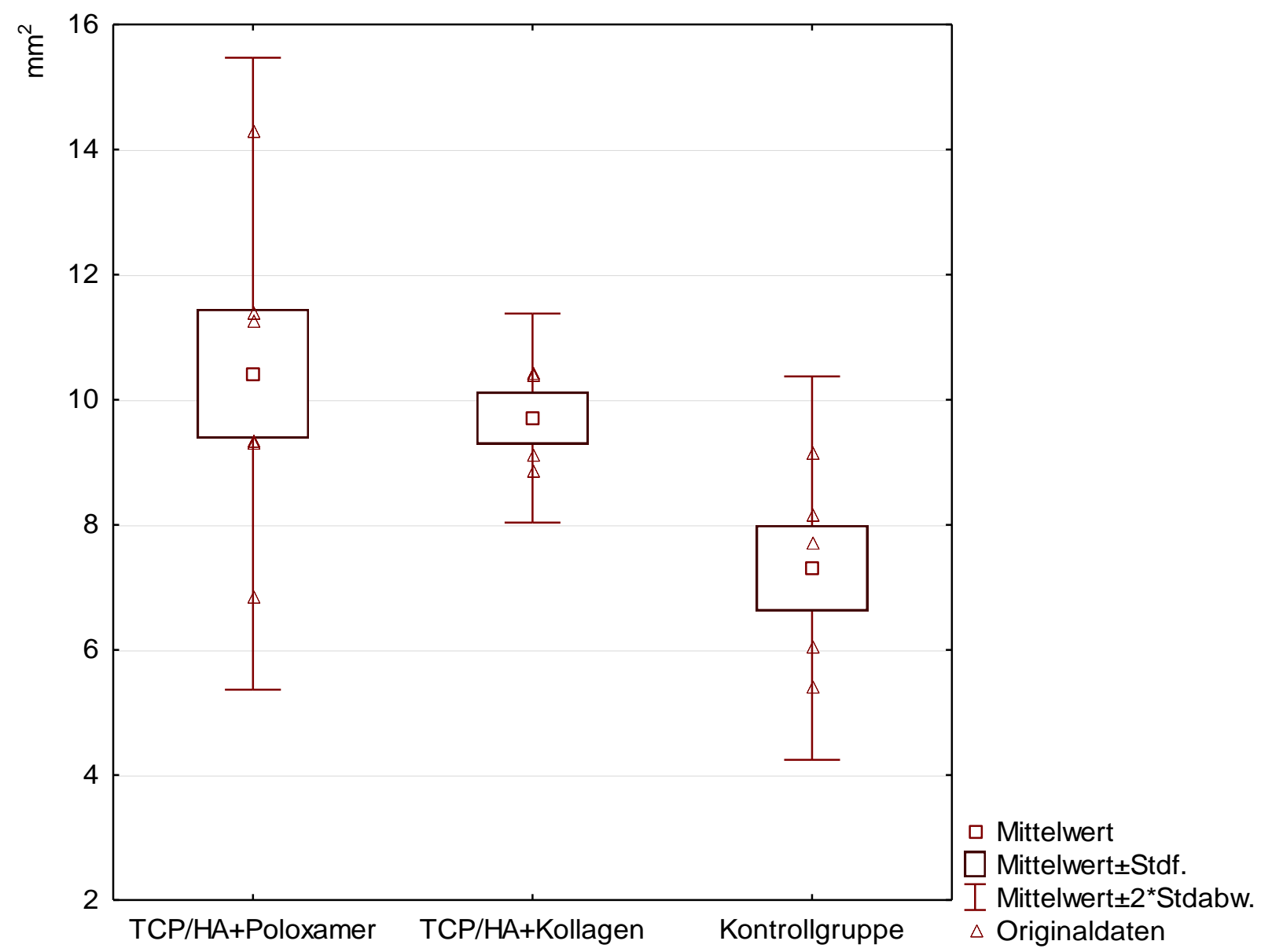

Abbildung 35 Boxplot der neu gebildeten Knochenfläche 


\subsubsection{Knochenersatzmaterial im Regenerationsbereich}

Innerhalb der Regenerationsbereiche befand sich im Mittel in den mit Poloxamermatrix gefüllten Defekten 6,15 mm² TCP/HA-Partikel (SD: 4,1) (Abbildung 36). In den mit einer Kollagenmembran bedeckten Defekten fanden sich 8,36 $\mathrm{mm}^{2}$ TCP/HA-Partikel (SD: 4,15). Aufgrund von dislozierten Partikeln fand sich auch in der Kontrollgruppe geringfügig Material (0.02 mm ${ }^{2}$ TCP/HA (SD: 0,03), weshalb die Variananalyse zunächst einen signifikanten Unterschied zwischen den drei Gruppen ergab $(\mathrm{p}=0,024)$. Im Vergleich der zwei augmentierten Gruppen zeigte sich dann aber im t-Test kein signifikanter Unterschied $(\mathrm{p}=0,6291)$.

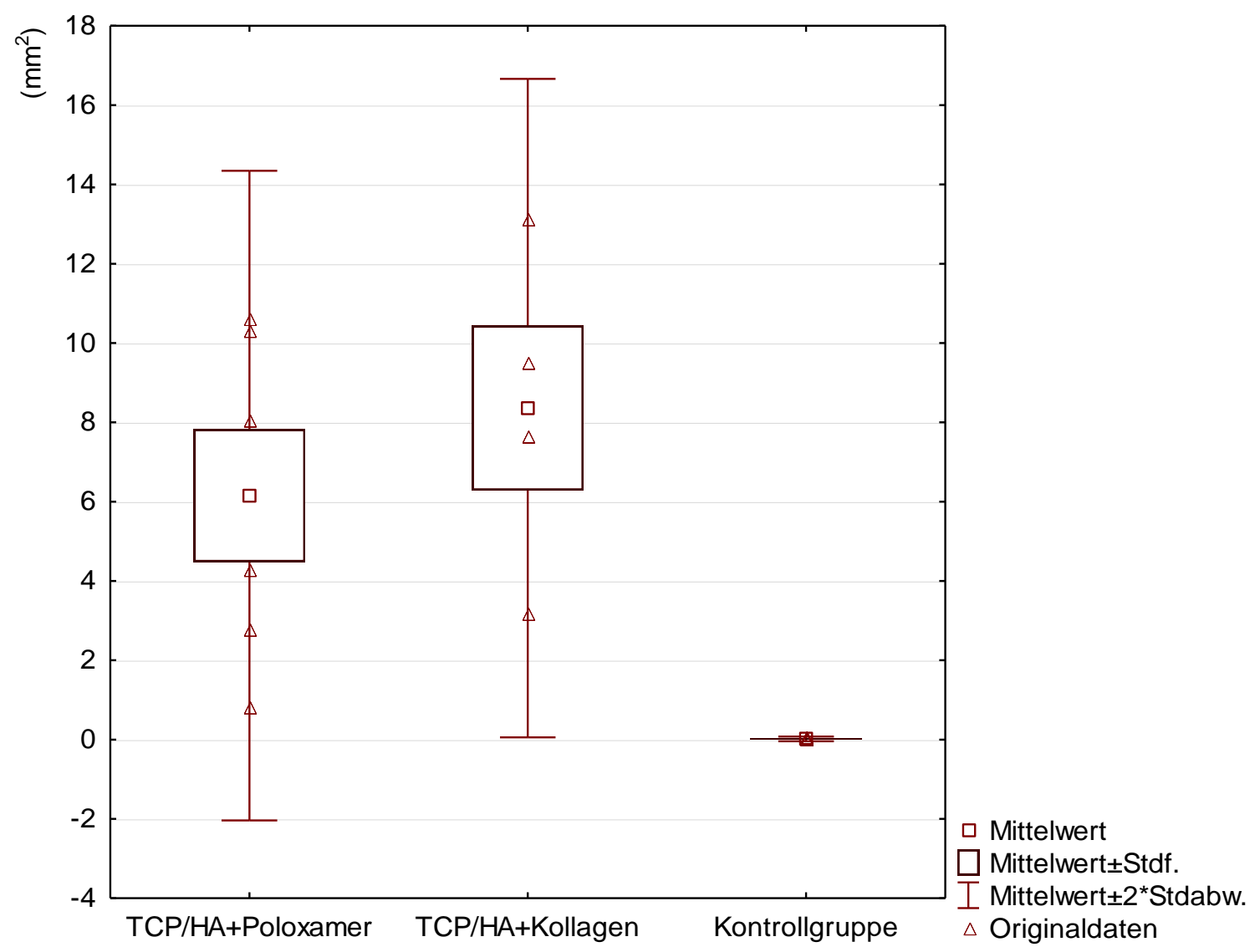

Abbildung 36 Knochenersatzmaterial im Regenerationsbereich 


\subsubsection{Flächenanteil der knöchernen Regeneration}

Als weiterer Parameter wurde die knöcherne Regeneration (Knochenfläche) im Vergleich zur vorliegenden, augmentierten Fläche herangezogen (Abbildung 37). Dies ist also der Anteil des augmentierten Bereiches, der bereits mit neu gebildetem Knochen gefüllt war. Da eine augmentierte Fläche bei der Kontrollgruppe nicht vorhanden war, ließen sich hier nur die beiden anderen Gruppen vergleichen. In der Gruppe der Augmentation mit TCP/HA in einer Poloxamermatrix ergab sich ein Mittelwert von 32,79 \% (SD: 8,34). In der anderen Gruppe, der Augmentation mittels partikulärem TCP/HA, abgedeckt durch eine Kollagenmembran, fiel dieser Wert mit 28,29 \% (SD: 4,93) etwas geringer aus. Dieser Unterschied war jedoch nicht signifikant $(\mathrm{p}=0,61)$.

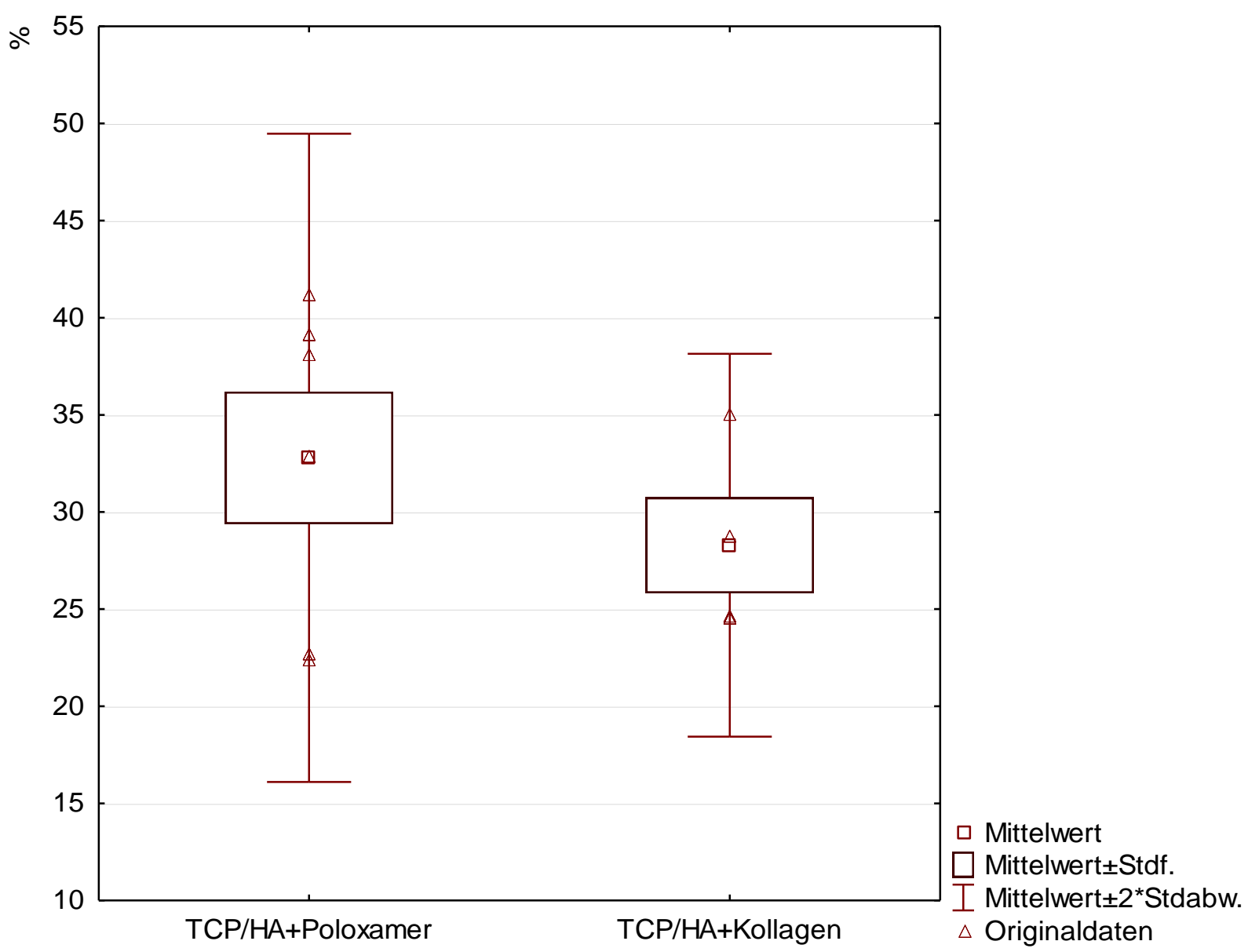

Abbildung 37 Flächenanteil der knöchernen Regeneration 


\subsubsection{Knochenhöhe im Vergleich zur Originalhöhe}

Auch die anteilige Regeneration der ursprünglichen Knochenhöhe wurde verglichen (Abbildung 38).

Hierfür wurde die maximale, ausgemessene Regenerationshöhe herangezogen und mit der ursprünglich operativ geschaffenen, apikal-koronalen Defekthöhe von $8 \mathrm{~mm}$ verglichen. Es zeigte sich, dass bei den TCP/HA-Poloxamer gefüllten Defekten der Knochen im Mittel bis auf $60 \%(\mathrm{SD}:$ 9,91) der ursprünglich vorhandenen Höhe des Alveolarkammes regeneriert war. Bei den partikulär gefüllten Defekten lag dieser Wert mit 62,75 \% (SD: 10,73) ein klein wenig höher. Die Höhe der Kontrolldefekte regenerierte hingegen nur zu 40,32 \% (SD: 11,36). Aus der Varianzanalyse ergab sich ein signifikanter Unterschied ( $\mathrm{p}=0,0245)$, welcher beim nachfolgenden T-Test im Vergleich zur Kontrollgruppe bestätigt wurde (TCP/HA+Poloxamer - Kontroll: $\mathrm{p}=0,0407$; TCP/HA+Kollagenmembran Kontroll: $\mathrm{p}=0$,0364). Ein signifikanter Unterschied zwischen den augmentierten Defekten bestand jedoch nicht (TCP/HA+Kollagenmembran - TCP/HA+Poloxamer: $\mathrm{p}=0,914)$.

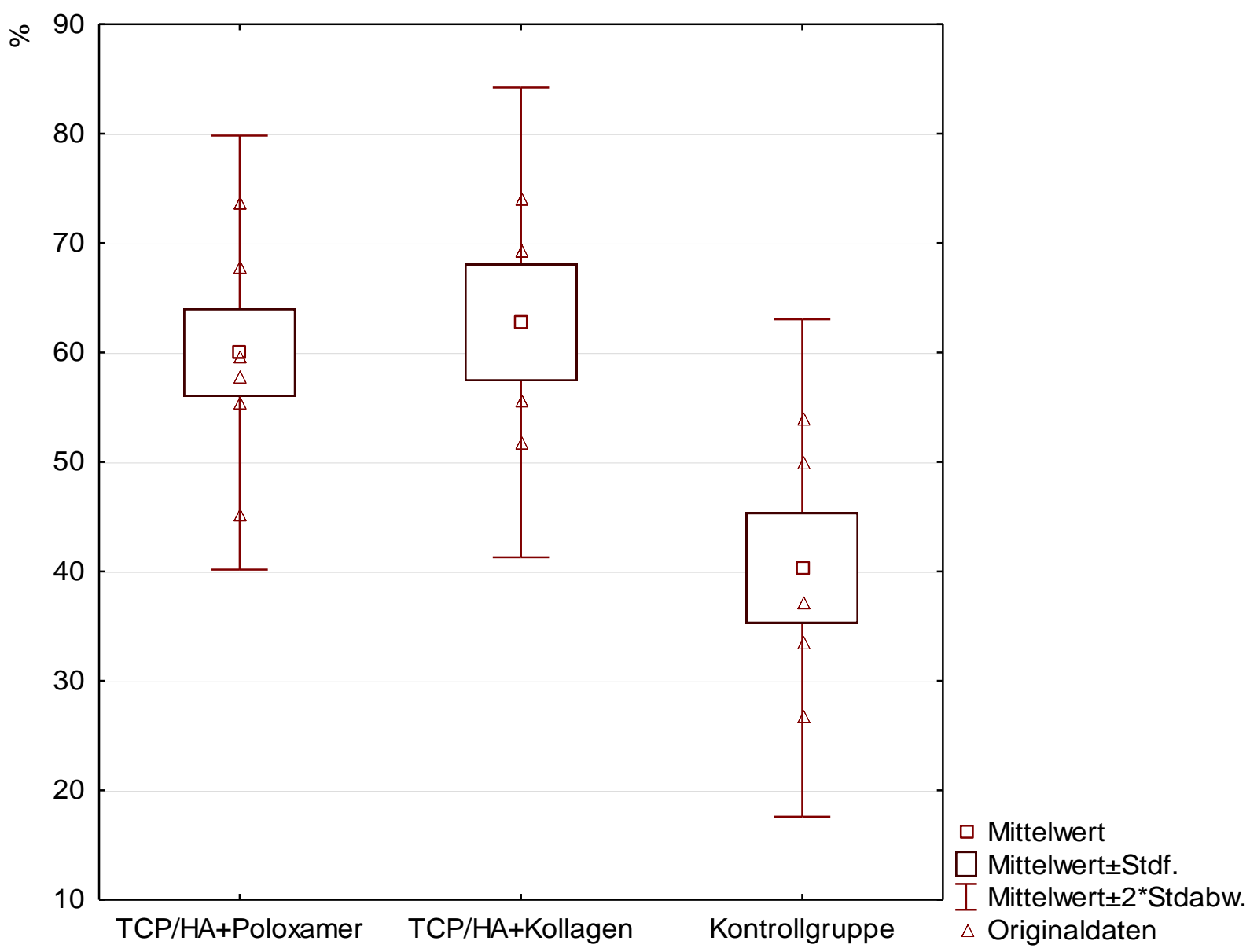

Abbildung 38 Knochenhöhe im Vergleich zur Originalhöhe 


\subsubsection{Erhalt der augmentierten Höhe und Breite}

Außerdem wurden die Dimensionen der Augmentationsfläche untersucht. Interessant war zu erfahren, inwieweit die vorgefundene augmentierte Fläche nach 14 Wochen mit der Originalkontur des Alveolarkammes übereinstimmte (Abbildungen 39 und 40). Bestenfalls sollte die augmentierte Fläche in ihrer Höhe und Breite dem ursprünglichen Alveolarkamm entsprechen, da dessen Form intraoperativ als Anpassungskriterium des Augmentats diente. Eine große Annäherung an die angestrebten $100 \%$ deutete somit auf eine gute Formstabilität des Augmentats hin. Als Originalhöhe wurde wieder die operativ hergestellte Defekthöhe von $8 \mathrm{~mm}$ herangezogen. Die Originalbreite wurde aus einem Referenzpräparat direkt vor oder hinter dem jeweiligem Defekt bestimmt, welches auch als Vergleichspräparat für die Knochendichte diente. Das Referenzpräparat wurde so gewählt, dass es möglichst nah am Defekt lag, aber vor allem eine physiologische, unbeschädigte Kortikalis des Alveolarfortsatzes aufwies.

Bei den mit TCP/HA und Poloxamer augmentierten Defekten ergab sich eine mittlere Höhe von 65,22 \% der Originalhöhe (SD: 13,2) und auffällige 142,64 \% der Originalbreite (SD: 43,71).

Die mittlere Höhe der mit TCP/HA-Partikeln gefüllten und einer Kollagenmembran bedeckten Augmentationsflächen betrug im Vergleich zur Originalhöhe 72,7 \% (SD: 11,7). Die Breite wurde zu 108,57 \% (SD: 8,47) erhalten.

Aufgrund der großen Standardabweichungen bei den Breiten der TCP/HA-Poloxamergefüllten Defekte waren die Unterschiede nicht signifikant (t-Test der Höhe: $p=0,4391$; $t$ Test der Breite: $\mathrm{p}=0,1805)$. 


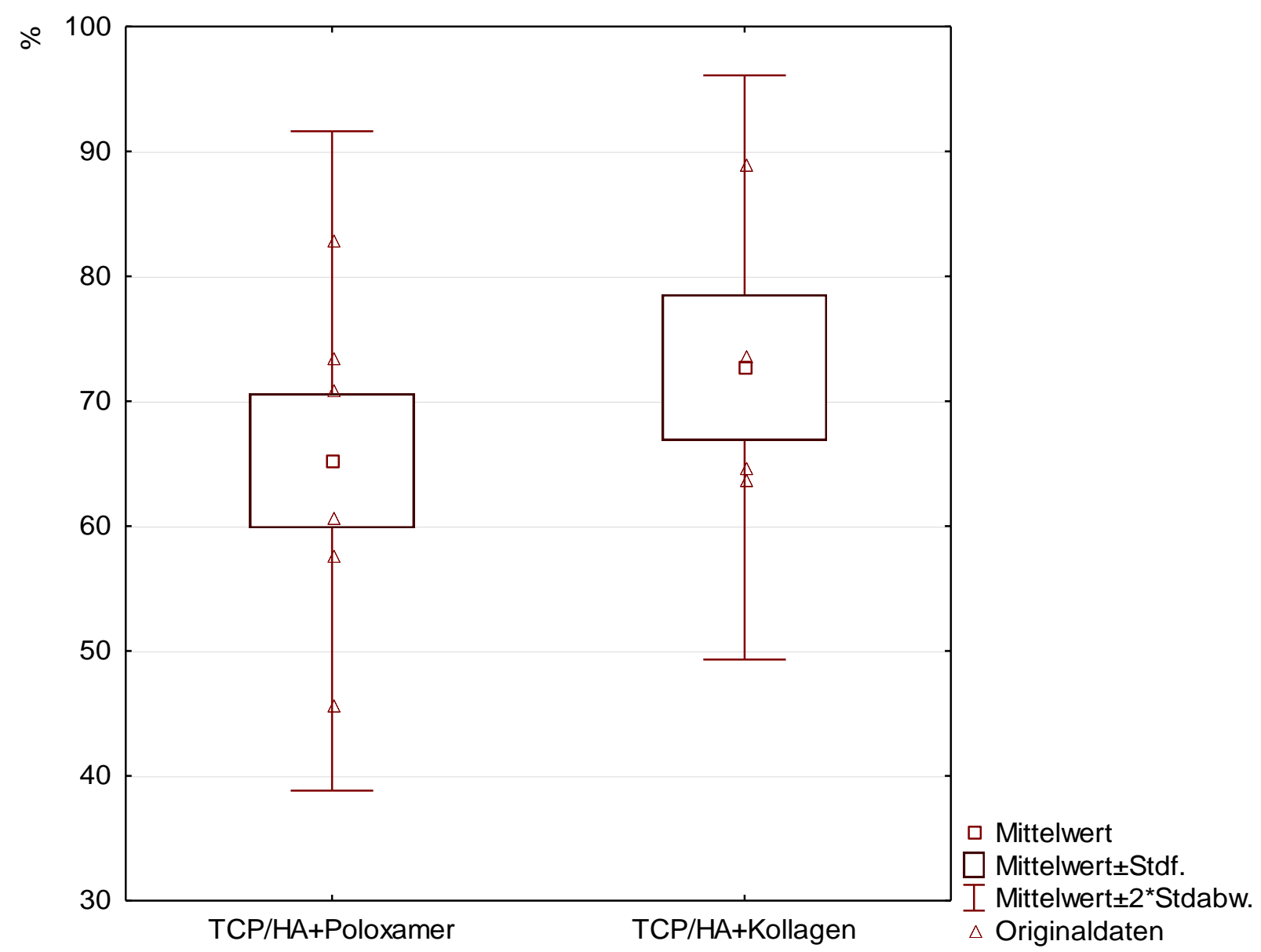

Abbildung 39 Erhalt der augmentierten Höhe 


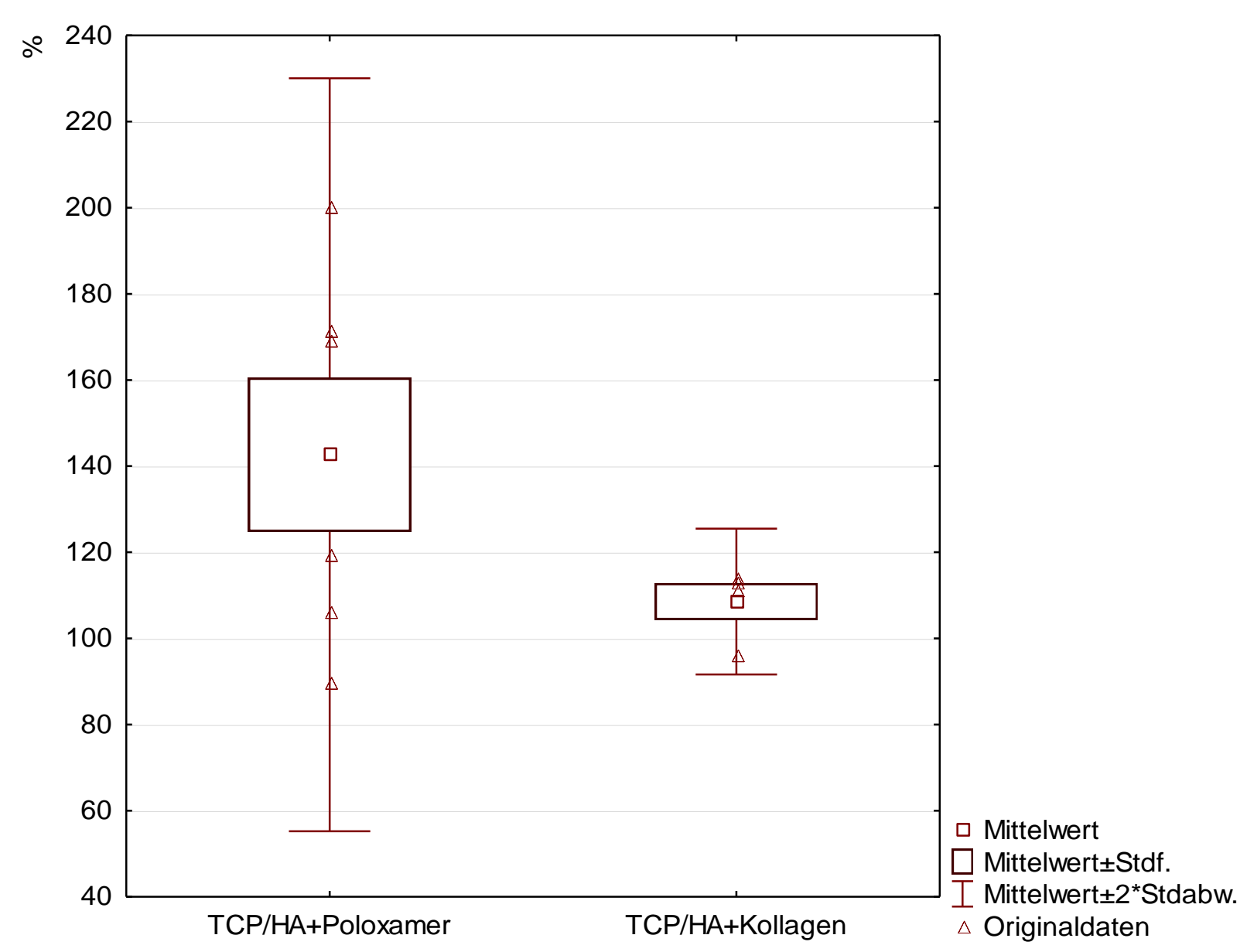

Abbildung 40 Erhalt der augmentierten Breite

\subsubsection{Knochendichte}

Bei der Betrachtung der Knochendichte im Regenerationsbereich wurden die Werte der drei Gruppen nicht nur untereinander, sondern auch mit dem bereits genannten Referenzpräparat verglichen.

Der Mittelwert der Knochendichte in den Kontrolldefekten betrug 53,52 \% (SD: 10,3). In den zugehörigen Referenzpräparaten betrug die Dichte durchschnittlich 44,55 \% (SD: 0,87), was im Vergleich somit eine Erhöhung der Knochendichte in der Kontrollgruppe bedeutet (Abbildung 41).

Bei den mit partikulärem TCP/HA und einer Kollagenmembran versorgten Defekten fand sich eine verringerte mittlere Knochendichte von 41,22 \% (SD: 6,48) im Vergleich mit den zugehörigen Referenzpräparaten mit einer Dichte von 47,46 \% (SD: 11,83). Die kombinierte Dichte von neu gebildetem Knochen und eingebettetem Knochenersatzmaterial betrug 73,06 \% (SD: 4,45) (Abbildung 42).

Die Defekte, gefüllt mit TCP/HA und Poloxamer, zeigten mit 46,25 \% (SD: 5,82) eine etwas höhere Knochendichte als die andere augmentierte Gruppe, jedoch einen größeren 
Unterschied zur Dichte der zugehörigen Referenzpräparate mit 58,32 \% (SD: 15,48). Hier maß die kombinierte Dichte von neu gebildetem Knochen und integriertem Ersatzmaterial mit 69,53\% (SD: 9,14) auch etwas weniger.

Die Unterschiede aller Parameter waren nicht signifikant (Varianzanalyse der Defektdichte: $\mathrm{p}=0,1387$; Varianzanalyse der Dichte der Referenzpräparate: $\mathrm{p}=0,2573$; $\mathrm{t}$ Test der kombinierten Dichte aus Knochen und Ersatzmaterial: p=0,8049).

Der Unterschied in der Dichte zwischen der Kontrollgruppe und den kombinierten Dichten aus neuem Knochen und Knochenersatzmaterial stellte sich als signifikant heraus (TCP/HA+Poloxamer - Kontroll: $\mathrm{p}=0,0424$ : TCP/HA+Kollagenmembran - Kontroll: $\mathrm{p}=0,028)$.

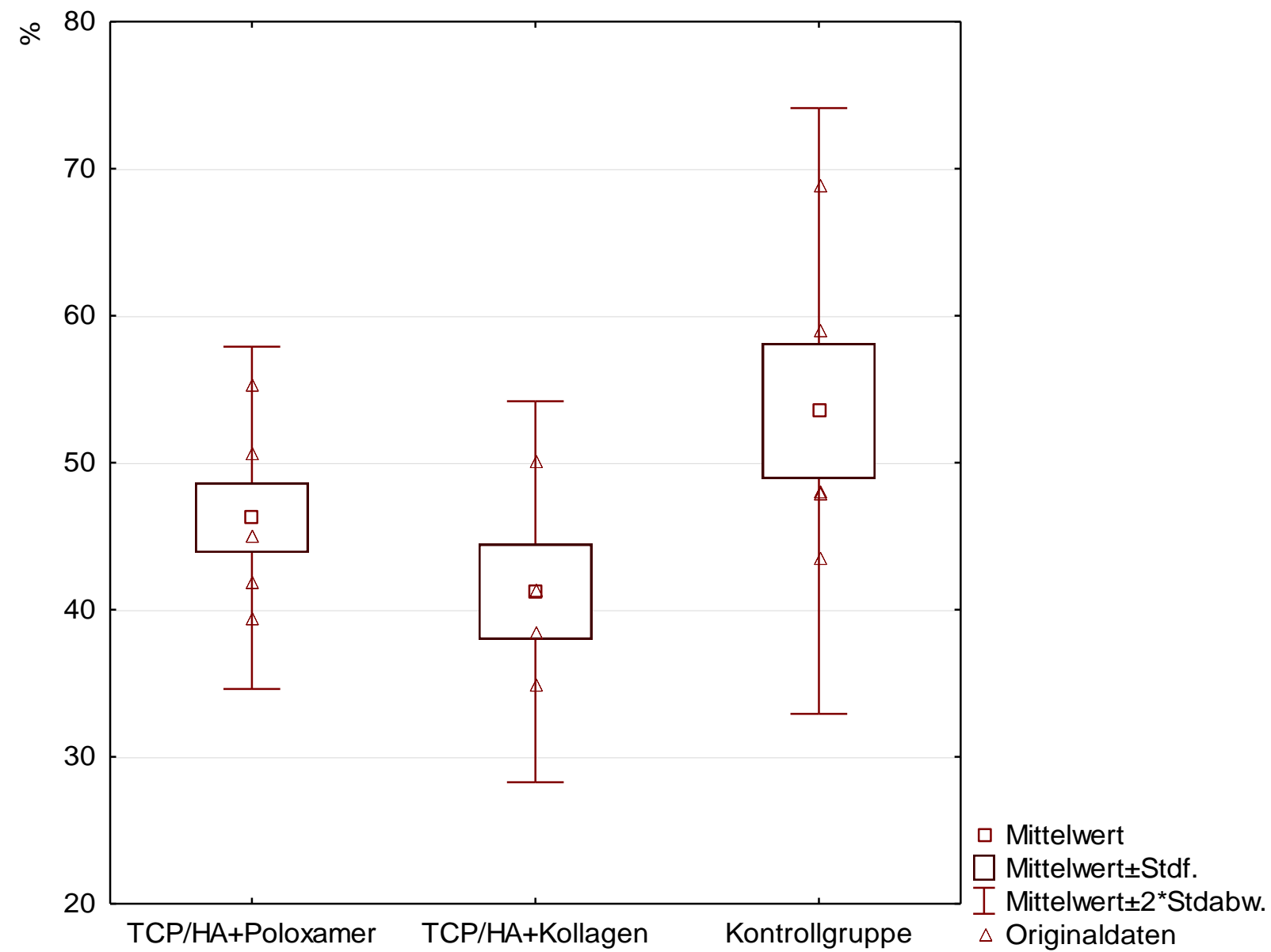

Abbildung 41 Knochendichte 


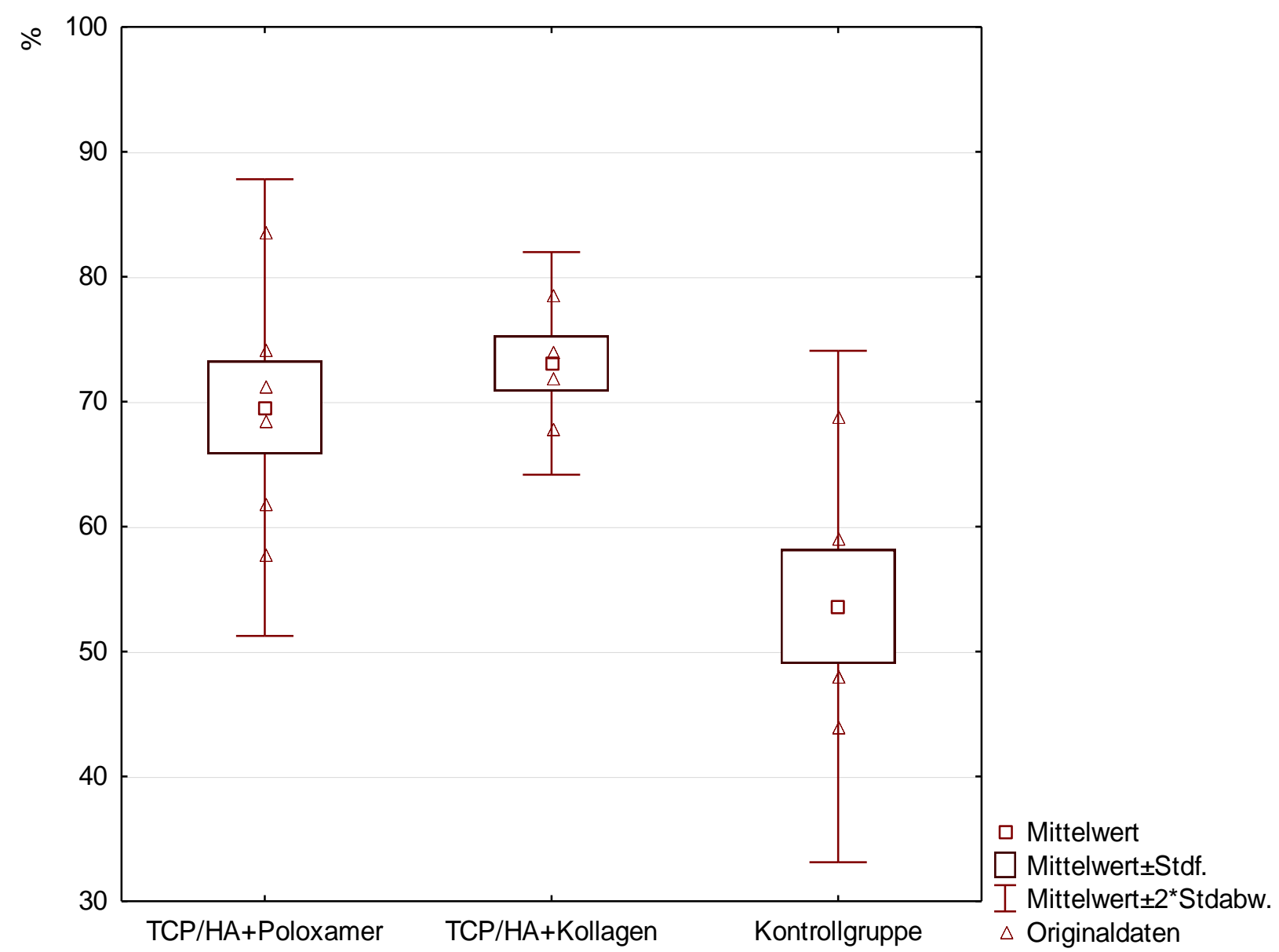

Abbildung 42 Kombinierte Dichte aus neuem Knochen und KEM 


\section{Diskussion}

\subsection{Diskussion der Methode}

Die vorliegende Studie wurde als Tierversuch am Foxhound durchgeführt.

Der Tierversuch ist eine bewährte Methode zur Beantwortung von Fragestellungen, die aus diversen Gründen nicht durch Beobachtungen am Modell oder am Menschen ersetzt werden können. Bei klinischen Studien am Menschen finden sich immer individuelle Defektmorphologien. Da folglich keine standardisierbaren Defekte vorliegen, können diese Defekte nicht uneingeschränkt miteinander verglichen werden. Außerdem wäre eine so umfangreiche histologische Auswertung wie im Tierversuch auch in diesem Fall nicht möglich gewesen. Andererseits ist bei aus Tierversuchen stammenden Ergebnissen keine uneingeschränkte Übertragung der Ergebnisse auf den Menschen, sondern grundsätzlich nur eine Annäherung möglich. Wichtig ist deshalb eine größtmögliche Übereinstimmung der anatomisch-physiologischen Verhältnisse zwischen dem Tiermodell und dem menschlichen Original in dem zu untersuchenden Bereich.

Hunde sind das am häufigsten gewählte Modell bei experimentellen Studien in der Implantologie (VIGNOLETTI und ABRAHAMSSON 2012). Die Anatomie des Hundes mit seiner ausreichenden Fangöffnung ermöglicht ein gut zugängliches Operationsgebiet und folglich die Durchführbarkeit von Operationen am Kiefer analog zum Menschen.

Außerdem ist der Hund aufgrund seiner dem Menschen ähnlichen Knochenheilung ein geeignetes Modell (EITEL et al. 1981). Aus diesen Gründen sind für die vorliegende Untersuchung sechs skelettal ausgewachsene Foxhounds zwischen 18 und 22 Monaten ausgewählt worden, bei denen die zweite Dentition bereits komplett durchgebrochen war. Bei diesen recht jungen Tieren ist von einer guten Regenerationsfähigkeit des Knochens auszugehen. Je älter das Tier, desto geringer fällt die eigene Reparaturleistung des Knochens aus (FISHER et al. 2010, KANEKAWA und SHIMIZU 1998). Das osteogene Potenzial des Periosts wird mit steigendem Lebensalter geringer (REID et al. 1981, WENG et al. 2000). Dies könnte auch erklären, warum die Regeneration in den Kontrolldefekten bezüglich der Knochenfläche den augmentierten Defekten nahezu ebenbürtig war. Es ist bemerkenswert, dass der Einsatz des KEM die Menge an tatsächlich neu gebildeter Knochenfläche nicht signifikant erhöht hat. Meist werden augmentative Verfahren bei älteren Patienten, z.B. nach bereits länger bestehendem Zahnverlust, nötig. Daher wäre es 
interessant herauszufinden, wie sich diese Defekte bei älteren Tieren und somit unter schwierigeren Umständen verhalten hätten.

Es ist bekannt, dass eine notwendige intraoperative Periostablösung in den angrenzenden Bereichen zu einer Minderperfusion mit folgender Knochenresorption führt. Daher ist nicht davon auszugehen, dass der an den Defekt angrenzende Knochen in seiner Form konstant geblieben ist. Nun musste aber der direkt angrenzende Bereich zur Herstellung eines Referenzpräparates genutzt werden. Somit ist auch das Referenzpräparat als Bezugspunkt vermutlich nicht $100 \%$ dem Originalausmaß des Knochens entsprechend. Das Referenzpräparat bot während der Auswertung die größten Schwierigkeiten. Es sollte möglichst nah am Defekt liegen, andererseits aber auch schon im unbeeinträchtigten Bereich. Es zeigte sich während der Herstellung der Präparate, dass sich besonders die Anatomie der Maxilla innerhalb weniger histologischer Schliffe stärker verändert. Bei den für die Mandibula hergestellten Präparaten war dieses Phänomen nicht so stark ausgeprägt. Daher ließen sich die Referenzpräparate der Mandibula deutlich besser vermessen. Folglich sind die durch die Referenzpräparate der Maxilla entstandenen Ergebnisse kritisch, aber als bestmögliche Annäherung zu bewerten.

Nachteilig ist bei Hunden im Vergleich zum Menschen, dass sie ein Wundgebiet nicht verlässlich schonen. Die Ruhe des Augmentats ist aber Voraussetzung für die knöcherne Regeneration. Möglicherweise sind hier festgestellte Verschiebungen des Augmentats sowie Wundheilungsstörungen mit Augmentatverlust auf diese mangelnde Schonung zurïckzuführen.

Zur Auswertung der histologischen Präparate wurde die Histomorphometrie angewendet. Alternativ käme es in Betracht, die Defekte per Mikroradiographie oder Mikro-CT auszuwerten. Die Beurteilung von Knochenwachstum in Knochendefekten durch histologische Präparate wird aber als der klassische Goldstandard (SCHORTINGHUIS et al. 2003) beschrieben. Nachteilig ist, dass immer nur bestimmte Bereiche des Defekts ausgewertet werden können, die nicht zwingend den gesamten Defekt widerspiegeln. Notwendigerweise liegen zwischen den Präparaten nicht ausgewertete Lücken, weshalb Informationen verloren gehen (LINDE et al. 2012). Außerdem wird in der Regel nur eine bestimmte Anzahl an Schnitten untersucht.

Studien zum Vergleich von histologischer und mikroradiographischer Auswertung zeigten eine gute Übereinstimmung der Ergebnisse (SCHORTINGHUIS et al. 2003, THORWARTH et al. 2007). Per Mikroradiographie lassen sich auch akkurate Grenzen 
zwischen altem und neuem Knochen erkennen und als Fläche ausmessen (SCHORTINGHUIS et al. 2003). Außerdem müssen die Präparate nicht dekalzifiziert werden. THORWARTH et al. untersuchten unterschiedliche Augmentationsmaterialien mittels Mikroradiographie. Dabei zeigte sich je nach Augmentationsmaterial eine unterschiedliche Röntgenopazität. Anorganische Materialien ließen sich gut abgrenzen, wohingegen phykogenes HA ähnliche Grauwerte aufwies wie der umgebende Knochen. Das KEM war aufgrund seiner charakteristischen runden Form dennoch gut für den Untersucher zu identifizieren. Der Computer konnte die Unterschiede jedoch nicht automatisch erkennen, so dass der Untersucher manuell nachjustieren musste. Da die Histologie bei den phykogenen Materialien die Unterschiede deutlich besser darstellte, ist die Mikroradiographie für den Versuchsaufbau dieser Studie nicht gut geeignet (THORWARTH et al. 2007). Außerdem hätte bei ausschließlicher Auswertung per Mikroradiografie auf die Beobachtungen der zellulären Ebene verzichtet werden müssen, welche weitere interessante Erkenntnisse einbrachten.

Auswertungen per Micro-CT beinhalten den gesamten Defektbereich und lassen HA/TCP gut vom Knochen unterscheiden (LINDE et al. 2012, PLACHOKOVA et al. 2007). Nachteilig ist jedoch, dass Weichgewebe und vor allem auch Polymere nicht gut beurteilt werden können (LINDE et al. 2012). Die Beobachtungen bezüglich des verbliebenen Poloxamers wären somit nicht möglich gewesen Bei ausschließlicher Auswertung per Micro-CT fehlen zudem auch die zellulären Beobachtungen. Dafür wäre der Vorteil, dass man weitere Aussagen zur Qualität des Knochens treffen könnte. Da in dieser Studie die Stabilität des Poloxamers und die Reaktion des Körpers auf dieses Material eine wichtige Rolle spielt, war die Histomorphometrie die Methode der Wahl.

Problematisch für die statistische Auswertung war die aus ethischen Gründen eingeschränkte Anzahl an Versuchstieren. Diese geringe Anzahl schränkt die Interpretationsfähigkeit der Ergebnisse deutlich ein. Um trotzdem möglichst umfassende Ergebnisse zu erlangen, ohne eine große Anzahl an Tieren zu opfern, wurde einerseits mit dem SplitMouth-Design gearbeitet und andererseits eine zweite Studie gleichzeitig am Unterkiefer der Hunde durchgeführt.

Das Studiendesign macht es möglich, nicht nur interindividuell, sondern auch intraindividuell die Ergebnisse zu vergleichen. Die großen Streuung der Ergebnisse ließ es trotzdem nicht zu, weitere, statistische signifikante Unterschiede herauszuarbeiten. 


\subsection{Diskussion der Ergebnisse}

Ziel dieser Studie war es herauszufinden, ob ein in situ erhärtendes Poloxamerhydrogel partikuläres HA/TCP dreidimensional stabilisieren kann, ohne dabei die knöcherne Regeneration zu behindern. Partikuläres KEM ist schwierig zu verarbeiten, weshalb die Kombination mit Poloxamer 407 den grundsätzlichen Vorteil bietet, die intraoperative Handhabung zu verbessern (CLOKIE et al. 2002, ZHOU et al. 2007).

Zur Stabilisierung von partikulärem KEM und somit zur Unterstützung der knöchernen Regeneration wurden bereits andere Methoden wie Fibrinkleber, thrombozytenreiches Blutplasma (PRP) und weitere resorbierbare Polymere wie Polyethylenglykol untersucht. Membranen aus in situ erhärtendem Polyethylenglykol zeigten im Tierversuch genau wie das in dieser Studie untersuchte Poloxamer 407 eine gute Biokompatibilität und entsprechend gute Ergebnisse wie Kollagenmembranen (HERTEN et al. 2009, JUNG et al. 2009).

Der Einsatz von Fibrinkleber in Kombination mit einem xenogenen Ersatzmaterial an der Mandibula von Hunden zeigte eher nachteilige Wirkungen (CARMAGNOLA et al. 2002).

Thrombozytenreiches Plasma wird durch Zentrifugalprozesse aus dem Blut des Patienten gewonnen. So soll eine lokal erhöhte Konzentration der in den Thrombozyten angereicherten Wachstumsfaktoren wie TGF- $\beta$ oder PDGF erzielt werden, welche die knöcherne Regeneration fördern sollen (MARX et al. 1998). 2003 publizierten WILTFANG et al. eine prospektive, klinisch randomisierte Studie zur Sinusbodenaugmentation mit $\beta$-TCP oder $\beta$-TCP in Kombination mit PRP. In der Kombination mit PRP ergab sich 8-10 \% mehr Knochenneubildung (WILTFANG et al. 2003).

Im folgendes Jahr veröffentlichte dieselbe Arbeitsgruppe jedoch eine tierexperimentelle Studie, in der $\mathrm{zu}$ einem xenogenen KEM hinzugefügtes PRP keine Vorteile aufwies (WILTFANG et al. 2004). Dieses Ergebnis konnte in einer weiteren tierexperimentellen Studie mit HA/TCP und PRP bestätigt werden (PLACHOKOVA et al. 2007).

Kollagenmembranen werden zur „Guided Bone Regeneration“ eingesetzt. Dabei soll verhindert werden, dass die schnell proliferierenden Bindegewebszellen der relativ langsamen Knochenneubildung durch Osteoblasten Konkurrenz machen (HÄMMERLE und JUNG 2003).

Fibrös umschlossende KEM-Partikel bedeuten einen Misserfolg, da sie nicht zur Stabilisierung beitragen und auch nicht von Osteoklasten abgebaut werden können. 
Aufgrund der etwa gleichen Menge an neu gebildetem Knochen und der in beiden Versuchsgruppen nur geringen Menge an bindegewebig umschlossenem KEM, ist davon auszugehen, dass das Poloxamer 407 auch als längerfristige Barriere gegenüber Fibroblasten geeignet ist. Aus dieser Untersuchung lässt sich bezüglich der Barrierefunktion keine Überlegenheit der Kollagenmembran oder des Poloxamers erkennen.

Es ist neben der Abschottungsfunktion gegenüber den Fibroblasten auch Voraussetzung, dass das eingesetzte Poloxamer eine gewisse Porösität bietet um den Sauerstoff und Nährstofftransport, sowie die Zellimmigration und Vaskularisierung zu gewährleisten. LIPPENS et al. berichteten 2010, dass Poloxamer 407 sehr permeabel für Wirkstoffe sei.

Bisherige Studien an Kleintieren, zum Beispiel zur Blutstillung am Femur der Ratte (WANG et al. 2001), in Verbindung mit mesenchymalen Stammzellen an der Tibia von Ziegen (LIPPENS et al. 2010), oder in Kombination mit allogenem oder alloplastischem KEM an der Calvaria von Ratten (FOWLER et al. 2002) ergaben keine Beeinträchtigung der Osteogenese durch Poloxamer 407. Vermehrte Knochenneubildung konnte jedoch auch nicht beobachtet werden. Wie bereits erläutert, war die durchschnittlich neu regenerierten Knochenfläche bei den mit Poloxamer und KEM gefüllten Knochendefekten zwar etwas größer als bei den beiden anderen Defektgruppen, der Unterschied war jedoch nicht signifikant. Folglich hat das KEM in Verbindung mit dem Poloxamer zwar die knöcherne Regeneration nicht behindert, der Einsatz des osteokonduktiven KEM im Vergleich zu den ungefüllten Kontrolldefekten aber auch nicht zu signifikant mehr Knochen geführt. Obwohl HA/TCP bekanntermaßen osteokonduktiv ist (EWERS 2005, SCHOPPER et al. 2005), konnte es in dieser Studie seine Vorzüge nicht zeigen.

Dafür implizieren die Ergebnisse dieser Studie, dass das KEM dazu beigetragen hat, die Verteilung des Knochens im Defektbereich zu verändern. So liegt die maximal gemessene Knochenhöhe beider augmentierter Gruppen signifikant näher an der ursprünglichen Defekthöhe als bei den KEM-freien Kontrolldefekten. Hierbei machte es jedoch keinen signifikanten Unterschied, ob zusätzlich das Poloxamer oder die konventionelle Kollagenmembran eingesetzt wurde.

Deutlich sichtbar war in allen augmentierten Defekten, dass nach den 14 Wochen Versuchszeit nur etwa ein Drittel des augmentierten Volumens mit neu formiertem 
Knochen durchsetzt war. Vor allem die bukkalen und palatinalen Bereiche des Augmentats waren kaum knöchern durchbaut.

Genauso bestand auch kein signifikanter Unterschied zwischen den beiden augmentierten Gruppen bezüglich der Menge des KEM innerhalb des Regenerationsbereiches. Folglich lässt sich nicht belegen, dass mit Hilfe des Poloxamers mehr KEM im Defektbereich gehalten werden konnte. Die Kollagenmembran hatte den gleichen Effekt. Möglicherweise ist aber auch die sattelförmigen Defektmorphologie durch ihre gute Auflagefläche besonders gut für den Einsatz von Kollagenmembranen geeignet.

Interessant wäre es, den Einsatz des Poloxamers an irregulär geformten Defekten zu untersuchen, da möglicherweise bei komplizierten Defektmorphologien die Vorteile des Poloxamers deutlich werden.

Die besondere Schwierigkeit vertikaler sattelförmiger Knochendefekte besteht darin, die gewünschte Form des Augmentats langfristig lagestabil zu erhalten, damit die knöcherne Regeneration entlang dieser Leitstruktur entstehen kann. Sowohl die Höhe, als auch die Breite der Augmentationsfläche wurden daher mit den Originalausmaßen des Defektbereiches verglichen. Da die operativ geschaffenen Defekte vollständig mit dem KEM aufgefüllt wurden, entsprach die Augmentatausdehnung initial den Maßen des Defektes. Im Vergleich zur ursprünglichen Höhe stellte sich die Kombination von HA/TCP und Poloxamer 407 als etwas weniger formstabil heraus $(65,22 \%)$, als die mit Kollagenmembran abgedeckten Defekte (72,7 \%). Der Unterschied war jedoch statistisch nicht signifikant.

Auffällig ist jedoch die Veränderung der Breite der Augmentationsfläche im Vergleich zur ermittelten Originalbreite. Hier entsprach die Breite des Augmentats nach 14 Wochen mehr als $100 \%$ der ermittelten Originalbreite. Die mit Kollagenmembran stabilisierten Defekte wiesen eine leicht erhöhte Breite von 108,57 \% im Vergleich zum Referenzpräparat auf. Die mit HA/TCP und Poloxamer augmentierten Defekte wiesen sogar eine Breite von 142,64 \% auf! Da die Standardabweichung hierbei 43,71 betrug, konnte trotzdem keine Signifikanz festgestellt werden. Es ist jedoch nicht nur anhand der histomorphometrischen Ergebnisse, sondern auch schon bei der qualitativen Betrachtung der histologischen Präparate auffällig, dass besonders bei den KEM und Poloxamer gefüllten Defekten eine Verschiebung des Augmentats in die Breite stattgefunden haben muss. Das Augmentat ragte in einigen Defekten über die Seiten der ursprünglich 
geschaffenen Knochenkante hinaus (siehe Abbildung 25). Die mit HA/TCP und Poloxamer augmentierten Defekte scheinen dem Druck des aufliegenden Weichgewebes schlechter standgehalten zu haben und sich leichter zu verformen.

So lässt sich zusammenfassen, dass die augmentierte Fläche bei den mit Kollagenmembran bedeckten Defekten in etwa ihre Originalbreite erhalten hat und ungefähr ein Viertel der Originalhöhe einbüßen musste. Die mit HA/TCP sowie Poloxamer gefüllten Defekte hielten ihre Originalhöhe im Verhältnis dazu um etwa $7 \%$ geringer und zeigten zudem eine deutliche Zunahme im Vergleich zur Originalbreite um circa ein Drittel. Dieser große Unterschied war aufgrund der hohen Standardabweichung jedoch nicht signifikant, was wiederum erkennen lässt, dass die Ergebnisse aus der Poloxamergruppe sehr unterschiedlich ausfielen.

Folglich war das Poloxamer nicht in der Lage, die gewünschte Form des Augmentats besser zu stabilisieren als die konventionelle Methode mittels Kollagenmembran.

Ein interessanter Forschungsansatz ist es, osteoinduktive BMPs in ein Hydrogel zu inkorporieren, um sie langfristig in geeigneter Dosis an die Umgebung abzugeben.

URIST beschrieb 1965 erstmals die BMPs, welche im organischen Anteil des Knochens von Menschen und Tieren vorkommen und definitionsgemäß in der Lage sind, eine ektopische Knochenbildung zu induzieren (URIST 1965). Inzwischen können diese Faktoren synthetisch hergestellt werden (rhBMPs) (DUCY und KARSENTY 2000). Aufgrund der synthetischen Herstellung sind diese Materialien nun auch in größerem Ausmaß verfügbar und es besteht keine Gefahr der Übertragung von Infektionskrankheiten oder allergischer Reaktionen (RENGACHARY 2002).

Die Schwierigkeit hierbei ist es, die Wachstumsfaktoren an ein geeignetes gewebeverträgliches Trägermaterial zu binden oder zu inkorporieren, um sie kontrolliert an die Umgebung abgeben zu können und auch um ein Wegdiffundieren zu verhindern. Die verwendete Konzentration sollte die gewünschten Effekte erzielen können, jedoch auch nicht zu hoch sein, um unerwünschte Nebeneffekte zu verhindern (BOYAN et al. 1999, HOLLINGER J. O. et al. 1998). Wird ein Carriersystem einfach in eine Lösung der Proteine getaucht, so führt dies zu einer sehr schnellen Freigabe dieser adsorbierten Wachstumsfaktoren. Diese schnelle Verpuffung der biologischen Wirkung wird „burst release" genannt. Eine langanhaltende Freisetzung kann so nicht erreicht werden (ULUDAG et al. 1999). Daher müssen diese Wirkstoffe grundsätzlich entweder an das 
Trägermaterial gebunden werden oder gar in eine Matrix inkorporiert werden, je nach Degradationsfähigkeit des Materials (SCHLIEPHAKE 2010).

Die Idee ist daher, einen Wirkstoff wie die BMPs in ein wasserlösliches Hydrogel als „Speicher“ zu integrieren, der diesen Wirkstoff nach und nach freigibt. Aufgrund der amphiphilen Eigenschaften des Poloxamer 407 können auch hydrophobe Wirkstoffe gut von diesem Polymer gebunden werden (NIE et al. 2011, TIAN und MAO 2012).

Die Mizellen, welche sich in Größen von 10 bis $100 \mathrm{~nm}$ ausbilden, können in ihrem hydrophoben Kern Wirkstoffe fassen (BATRAKOVA und KABANOV 2008). Die Freigabe erfolgt durch Diffusion über die außerhalb der Mizellen gelegenen wässrigen Kanäle der Gelmatrix (XUAN et al. 2011).

In einigen Studien wurde erfolgreich versucht, die Freisetzungskinetik dieser Verbindungen zu modifizieren. Dies erfolgte z.B. durch Zugabe anderer Polymere und Proteine oder über die Wirkung von Ultraschall (FRISMAN et al. 2012, HUSSEINI et al. 2009, LEE et al. 2004).

Daraus ergibt sich die Möglichkeit, ein KEM wie das Trikalziumphosphat-HydroxylapatitKomposit durch das Poloxamer nicht nur dreidimensional zu stabilisieren, sondern gleichzeitig eine definierte osteoinduktive Wirkung zu erlangen (DUCY und KARSENTY 2000).

2000 veröffentlichten CLOKIE und URIST eine Studie an Mäusen, in welcher sie unter anderem das Poloxamer 407 alleine oder in Kombination mit BMPs einsetzten (CLOKIE und URIST 2000). Histomorphometrisch konnten sie feststellen, dass das Poloxamer 407 alleine keine Knochenneubildung induzierte. Die Kombination des Poloxamers mit BMPs führte jedoch zu signifikant mehr Knochenneubildung, auch im Vergleich zu den anderen untersuchten Trägersubstanzen wie allogenem, demineralisiertem Knochen, HA, oder Kollagen in Kombination mit BMP.

Auch phykogene KEM wurden bereits in Kombination mit BMPs erforscht.

SCHOPPER et al. stellten im Tierversuch an der Ratte fest, dass die Kombination von phykogenem HA/TCP und rhBMP-2 signifikant mehr Knochenneubildung induzierte als HA/TCP ohne Zusatz osteoinduktiver Proteine (2008).

ZHOU et al. kombinierten sogar bereits ein phykogenes HA/TCP mit dem Poloxamer 407 und BMP-7 an der Schädelkalotte von Kaninchen. Nach 6 Wochen Einheilzeit wurde die neu gebildete Knochenmenge evaluiert. Die alleinige Kombination von HA/TCP und dem Poloxamer ergab nicht mehr Knochen als das reine KEM. Dieses Ergebnis stimmt mit 
meiner Untersuchung überein. Nach Zugabe von BMP bildete sich jedoch in der Studie von ZHOU et al. signifikant mehr Knochen. Die Zugabe von BMPs zu dem TCP/HAPoloxamer-Gemisch wäre ein interessanter Anknüpfungspunkt für weitere Forschung analog zum Versuchsaufbau dieser Studie. Dabei wäre es nicht nur wichtig herauszufinden wie lange das Poloxamergel in vivo stabil bleibt, sondern auch, wie lange es osteoinduktive Wirkstoffe freisetzen könnte.

In der Literatur wird angegeben, dass ein Poloxamer-Hydrogel je nach Zusammensetzung etwa 1-15 Tage stabil ist (FRISMAN et al. 2012). Die Abbaurate der einzelnen Mizellen wird als sehr unterschiedlich bezeichnet (BATRAKOVA und KABANOV 2008). PARK et al. konnte durch Änderungen der chemischen Zusammensetzung die Stabilität des Gels von wenigen Tagen bis auf mehrere Monate ausdehnen (2012).

In der hier vorliegenden Studie konnte histologisch nach 14 Wochen noch verbliebenes Hydrogel beobachtet werden. Unklar ist, ob das Poloxamer zu diesem Zeitpunkt noch osteoinduktive Wirkstoffe freisetzen würde.

Deshalb muss der Einsatz eines Hydrogels als Speicher für osteoinduktive Wirkstoffe zukünftig hinsichtlich der Abbaugeschwindigkeit, des Abbaumechanismus und der Freisetzungskinetik genauer untersucht werden.

Ein kritisch zu bedenkender Aspekt beim Einsatz von Poloxameren ist die Tatsache, dass die Poloxamermoleküle aus sich wiederholenden Ethergruppen bestehen, welche dem Abbau und Zerfall in vivo standhalten (PARK M. H. et al. 2012).

Im Tierversuch entsteht nach parenteraler Gabe von hohen Dosen Poloxamer 407 eine Hyperlipidämie, d.h. die Blutplasmakonzentrationen von Cholesterin und Triglyceriden steigen beträchtlich (JOHNSTON 2004, JOHNSTON und PALMER 1993). Als Ursache hierfür werden zwei Wirkungsweisen des Poloymers angenommen:

Einerseits die direkte Inhibierung der Lipoproteinlipase (LPL), eines auf der Oberfläche von Blutkapillarendothelzellen sitzenden Enzyms, das Triacylglyceride spaltet (JOHNSTON 2004, JOHNSTON 2010).

Andererseits beeinflusst das Poloxamer 407 auch die Sinusendothelzellen der Leber, deren Poren sich nach Gabe des Poloxamers verkleinern. Dadurch wird der Transport von Lipoproteinen aus dem Sinuslumen zu den Hepatozyten beeinträchtigt. Entsprechend verbleiben mehr Lipoproteine in der Blutbahn (COGGER et al. 2006).

Infolge dieser beider Wirkungsweisen entsteht eine Hypertriglyceridämie. 
Nach Gabe von Poloxamer 407 konnten WARREN et al. morphologische Veränderungen der Kupffer-Zellen und der Sinusendothelzellen in der Leber von Mäusen beobachten. Sie stellten durch Endozytose aufgenommene Vakuolen in diesen Zellen fest. Demzufolge wird das Poloxamer von der Leber hauptsächlich durch Endozytose der Sinusendothelzellen und Kupffer-Zellen aufgenommen. Die Hepatozyten hingegen sind aufgrund der Defenestration der Sinusendothelzellen eher unbeeinflusst. Sie nehmen zwar auch das Poloxamer und Lipoproteine durch Endozytose auf, es gelangt aber nur ein kleiner Anteil über die Barriere der Sinusendothelzellen zu ihnen (WARREN et al. 2011). Wird die Gabe dieses Poloxamers an Nagetieren wiederholt durchgeführt, so kommt es zu artheriosklerotischen Läsionen der Gefäße. Daher handelt es sich dabei um ein etabliertes Studienmodell für die Pathogenese und Therapie der Artheriosklerose (PALMER et al. 1998).

Die koronare Herzerkrankung (KHK), welche die Manifestation der Artheriosklerose in den Herzkranzgefäßen dastellt, ist bekanntermaßen die häufigste Todesursache in den Industrienationen. Risikofaktoren hierfür sind unter anderem Nikotinabusus, die arterielle Hypertonie und Diabetes mellitus. Aber auch Lipidstoffwechselstörungen wie die Hypertriglyceridämie gehören zu den Risikofaktoren der KHK (ROBERT-KOCHINSTITUT 2012).

In Anbetracht der noch nicht abschließend geklärten möglichen Nebenwirkungen sollte der Einsatz von Poloxamer 407 in Kombination mit einem Knochenersatzmaterial zur Alveolarkammaugmentation kritisch abgewogen werden.

Anhand der histologischen Präparate dieser Studie lässt sich nicht genau feststellen, wie der Abbau des Hydrogels im Knochengewebe vonstatten geht. Auffällig ist aber die nahe topografische Beziehung zwischen dem nach 14 Wochen verbliebenen Poloxamer und einer großen Menge nah angrenzender Gefäßneubildungen. Möglicherweise finden Teile des Transportes der nicht abbaubaren Mizellen vaskulär statt, was zu Akkumulation in der Leber führen könnte. Die Frage der Degradation kann anhand dieser Studie jedoch nicht abschließend beantwortet werden.

Zwar hat der Einsatz des hier getesteten Poloxamers die Knochenneubildung in sattelförmigen Alveolarkammdefekten nicht beeinträchtigt, das Material hat aber auch keine Vorteile in Bezug auf den erwünschten Erhalt des Alveolarkammes im Vergleich zur 
Kollagenmembran gezeigt. Der Einsatz einer Kollagenmembran zur längerfristigen Lagestabilisierung des Augmentats stellte sich als effektiver heraus.

Die Möglichkeit, andere Wirkstoffe wie z.B. Wachstumsfaktoren mit in das Hydrogel zu integrieren, um die Knochenregeneration zu fördern, könnte zukünftig interessant sein, vorab müssen jedoch noch einige Fragestellungen wie die genaue Abbaugeschwindigkeit des Hydrogels, die Freisetzungskinetik und mögliche Nebenwirkungen beantwortet werden. 


\section{$5 \quad$ Zusammenfassung}

Ziel der hier vorliegenden Untersuchung war es, die knöcherne Regeneration von Alveolarfortsatzdefekten unter Anwendung eines Knochenersatzmaterials aus Trikalziumphosphat und Hydroxylapatit in Kombination mit einem Polymergel (Poloxamer 407) histomorphometrisch und histologisch zu untersuchen. Als Vergleich wurden sowohl ungefüllte Kontrolldefekte als auch das partikuläre Trikalziumphosphat-HydroxylapatitKomposit in Verbindung mit einer Kollagenmembran eingesetzt.

Dazu wurden in der Maxilla von sechs Hunden jeweils drei Alveolarfortsatzdefekte geschaffen und mit den genannten Methoden versorgt.

Nach 14 Wochen Einheilzeit wurde untersucht, ob das hinzugefügte Polymergel eine verbesserte dreidimensionale Stabilität des Augmentats erreichen konnte, ohne dabei die knöcherne Regeneration zu hemmen.

Die Auswertung ergab hierbei keinen signifikanten Unterschied bezüglich der absoluten Menge an neu gebildetem Knochen.

Die durchschnittliche maximal erreichte Höhe der knöchernen Regeneration war in den mit KEM und Kollagenmembran oder Poloxamer gefüllten Defekten zwar signifikant höher im Vergleich zu den ungefüllten Kontrolldefekten, unterschied sich aber nicht signifikant zwischen den beiden augmentierten Gruppen.

Wie die Messungen zum Erhalt der Breite und Höhe des augmentierten Bereiches gezeigt haben, konnte das Poloxamer im Gegensatz zur Kollagenmembran die Form des Alveolarkammes nicht besser erhalten.

Somit lässt sich feststellen, dass die Zugabe eines erhärtenden Poloxamer-407-Hydrogels zu einem Trikalziumphosphat-Hydroxylapatit-Komposit in dieser Studie keinen Vorteil gegenüber einer konventionell eingesetzten Kollagenmembran hatte. 


\section{Abbildungsverzeichnis}

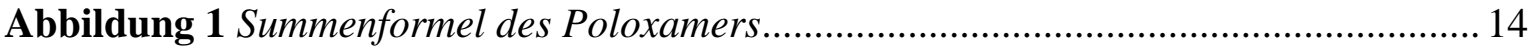

Abbildung 2 Versuchsablauf dieser tierexperimentellen Studie ....................................... 18

Abbildung 3 Verhalten der Poloxamer 407-Moleküle bei Temperaturänderung ..............21

Abbildung 4 Intraoperative Aufnahme mit aufgelegter Kollagenmembran .....................23

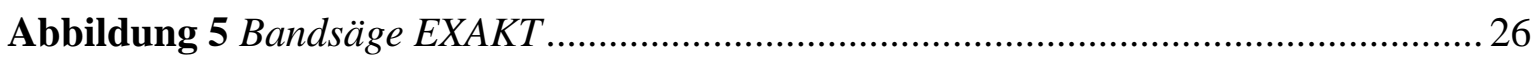

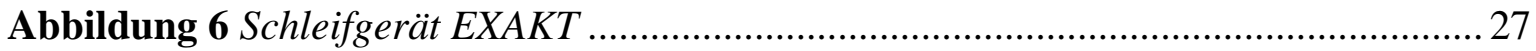

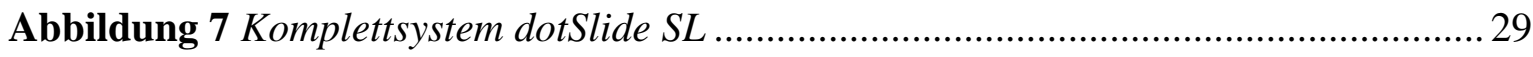

Abbildung 8 Ein digitalisiertes Präparat (Übersichtsaufnahme) .................................... 31

Abbildung 9 Markierung der Defektgrenze mit dem Instrument "magnetisches Lasso" ... 32

Abbildung 10 Die ausgeschnittene Regenerationsfläche ................................................32

Abbildung 11 Knochenersatzmaterial innerhalb des Regenerationsbereiches ................. 33

Abbildung 12 Knochenersatzmaterial außerhalb des Regenerationsbereiches ................ 33

Abbildung 13 Die reine Knochenfläche ohne Knochenersatzmaterial .............................33

Abbildung 14 Der ausgeschnittene Augmentationsbereich .............................................34

Abbildung 15 Der Beginn, ein beispielhafter Zwischenschritt und das Ende des "Region Growing" mit dem jeweiligen Histogramm ................................................................ 35

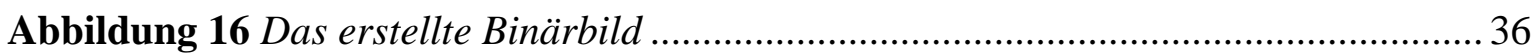

Abbildung 17 Messung der maximalen Defektausdehnung in Axiovision ......................... 37

Abbildung 18 Regeneration in der Kontrollgruppe …................................................... 39

Abbildung 19 Regeneration in der Kontrollgruppe ...................................................... 40

Abbildung 20 Regeneration nach Anwendung von TCP/HA und Kollagenmembran ....... 40

Abbildung 21 Regeneration nach Anwendung von TCP/HA und Kollagenmembran ....... 41

Abbildung 22 Regeneration bei Anwendung von TCP/HA eingebettet in eine

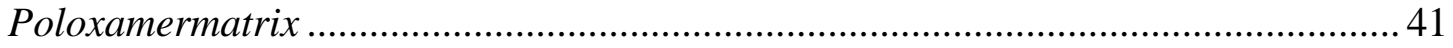

Abbildung 23 Regeneration bei TCP/HA und Poloxamer ............................................... 41

Abbildung 24 TCP/HA und Poloxamer ....................................................................... 42

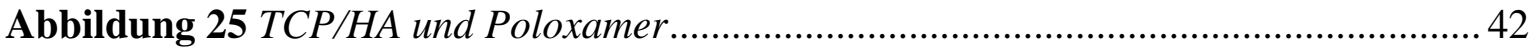


Abbildung 26 Gefäße sowie Poloxamer zwischen den TCP/HA-Partikeln in der Übersicht

Abbildung 27 Auschnitt aus Abbildung 26

Abbildung 28 Abgekapselte TCP/HA-Partikel .43

Abbildung 29 Osseointegrierte TCP/HA-Partikel 44

Abbildung 30 Osseointegrierte TCP/HA-Partikel 44

Abbildung 31 Osteoblastensäume um neu gebildeten Knochen .44

Abbildung 32 Osteoblastensaum. 44

Abbildung 33 Mehrkernige Riesenzellen an einem TCP/HA-Partikel. 45

Abbildung 34 Ansicht einer mehrkernigen Riesenzelle am KEM .45

Abbildung 35 Boxplot der neu gebildeten Knochenfläche 46

Abbildung 36 Knochenersatzmaterial im Regenerationsbereich 47

Abbildung 37 Flächenanteil der knöchernen Regeneration .48

Abbildung 38 Knochenhöhe im Vergleich zur Originalhöhe .49

Abbildung 39 Erhalt der augmentierten Höhe .51

Abbildung 40 Erhalt der augmentierten Breite .52

Abbildung 41 Knochendichte 53

Abbildung 42 Kombinierte Dichte aus neuem Knochen und KEM .54 


\section{$7 \quad$ Literaturverzeichnis}

Al-Nawas B, Gellrich N, Klein M, Palm F, Rothamel D, Schlee M, Schultze-Mosgau S, Schwarz F, Sommer M (2012): Deutsche Gesellschaft für Zahn-, Mund- und Kieferheilkunde S2-k-Leitlinie: Implantologische Indikationen für die Anwendung von Knochenersatzmaterialien

Amecke B, Bendix D, Entenmann G (1992): Resorbable polyesters: composition, properties, applications. Clin Mater $\underline{10}, 47-50$

Amler MH (1969): The time sequence of tissue regeneration in human extraction wounds. Oral Surg Oral Med Oral Pathol 27, 309-318

Arrington ED, Smith WJ, Chambers HG, Bucknell AL, Davino NA (1996): Complications of iliac crest bone graft harvesting. Clin Orthop Relat Res 300-309

Aubin JE, Liu F, Malaval L, Gupta AK (1995): Osteoblast and chondroblast differentiation. Bone $\underline{17}, 77 \mathrm{~S}-83 \mathrm{~S}$

Barichello JM, Morishita M, Takayama K, Chiba Y, Tokiwa S, Nagai T (1999): Enhanced rectal absorption of insulin-loaded Pluronic F-127 gels containing unsaturated fatty acids. Int J Pharm $\underline{183}, 125-132$

BASF-Laboratories (2004): Technical Bulletin Pluronic Block Copolymers NF Grades heruntergeladen am 23.09.2011

http://worldaccountbasfcom/wa/NAFTA/Catalog/ChemicalsNAFTA/pi/BASF/Brand/pluro nic

BASF-Laboratories (2007): Safety Data Sheet Pluronic F 127 NF PRILL Poloxamer 401 heruntergeladen am 23.09.2011

http://worldaccountbasfcom/wa/NAFTA/Catalog/ChemicalsNAFTA/pi/BASF/Brand/pluro nic

Batrakova EV, Kabanov AV (2008): Pluronic block copolymers: evolution of drug delivery concept from inert nanocarriers to biological response modifiers. J Control Release 130, 98-106

Baud'huin M, Lamoureux F, Duplomb L, Redini F, Heymann D (2007): RANKL, RANK, osteoprotegerin: key partners of osteoimmunology and vascular diseases Cellular and molecular life sciences. CMLS $\underline{64}, 2334-2350$ 
Bauer TW, Muschler GF (2000): Bone graft materials. An overview of the basic science. Clin Orthop Relat Res 10-27

Becker J (2006): Deutsche Gesellschaft für Zahn,- Mund- und Kieferheilkunde: Zahnärztliche Mitteilung zum Risiko der Krankheitsübertragung durch enogene Knochenersatzmaterialien in der Implantologie und Parodontologie

Becker J, Terheyden H (2006): Wissenschaftliche Stellungnahme der Deutschen Gesellschaft für Zahn-, Mund- und Kieferheilkunde: Osteoinduktive Substanzen und Faktoren in der Zahn-, Mund- und Kieferheilkunde

Bodner L (1996): Effect of decalcified freeze-dried bone allograft on the healing of jaw defects after cyst enucleation. J Oral Maxillofac Surg 노, 1282-1286

Bolander ME (1992): Regulation of fracture repair by growth factors. Proc Soc Exp Biol Med 200, 165-170

Bosch C, Melsen B, Vargervik K (1998): Importance of the critical-size bone defect in testing bone-regenerating materials. J Craniofac Surg $\underline{9}$, 310-316

Bowen JA, Mellonig JT, Gray JL, Towle HT (1989): Comparison of decalcified freezedried bone allograft and porous particulate hydroxyapatite in human periodontal osseous defects. J Periodontol $\underline{60}, 647-654$

Boyan BD, Lohmann CH, Somers A, Niederauer GG, Wozney JM, Dean DD, Carnes DL, Jr., Schwartz Z (1999): Potential of porous poly-D,L-lactide-co-glycolide particles as a carrier for recombinant human bone morphogenetic protein-2 during osteoinduction in vivo. J Biomed Mater Res $\underline{46}$, 51-59

Boyle WJ, Simonet WS, Lacey DL (2003): Osteoclast differentiation and activation. Nature $\underline{423}, 337-342$

Budras K, Nöller C: Atlas der Anatomie des Hundes: Lehrbuch für Tierärzte und Studierende. Schlütersche Verlagsgesellschaft, Hannover 2010

Campion CR, Chander C, Buckland T, Hing K (2011): Increasing strut porosity in silicate-substituted calcium-phosphate bone graft substitutes enhances osteogenesis. J Biomed Mater Res B Appl Biomater 97, 245-254

Cardaropoli G, Araujo M, Lindhe J (2003): Dynamics of bone tissue formation in tooth extraction sites. An experimental study in dogs. J Clin Periodontol 30, 809-818

Cardaropoli G, Araujo M, Hayacibara R, Sukekava F, Lindhe J (2005): Healing of extraction sockets and surgically produced - augmented and non-augmented - defects in the alveolar ridge. An experimental study in the dog. J Clin Periodontol $\underline{32}, 435-440$ 
Carmagnola D, Berglundh T, Lindhe J (2002): The effect of a fibrin glue on the integration of Bio-Oss with bone tissue. A experimental study in labrador dogs. J Clin Periodontol $\underline{29}, 377-383$

Chen WJ, Huang JW, Niu CC, Chen LH, Yuan LJ, Lai PL, Yang CY, Lin SS (2009): Use of fluorescence labeled mesenchymal stem cells in pluronic F127 and porous hydroxyapatite as a bone substitute for posterolateral spinal fusion. J Orthop Res 27, 16311636

Chen-Chow PC, Frank SG (1981): In vitro release of lidocaine from pluronic F-127 gels. Int J Pharm $\underline{8}, 89-99$

Clavero J, Lundgren S (2003): Ramus or chin grafts for maxillary sinus inlay and local onlay augmentation: comparison of donor site morbidity and complications. Clin Implant Dent Relat Res $\underline{5}, 154-160$

Clokie CM, Urist MR (2000): Bone morphogenetic protein excipients: comparative observations on poloxamer. Plast Reconstr Surg $\underline{105}$, 628-637

Clokie CM, Moghadam H, Jackson MT, Sandor GK (2002): Closure of critical sized defects with allogenic and alloplastic bone substitutes. J Craniofac Surg 13, 111-121; discussion 122-113

Cogger VC, Hilmer SN, Sullivan D, Muller M, Fraser R, Le Couteur DG (2006): Hyperlipidemia and surfactants: the liver sieve is a link. Atherosclerosis $\underline{189}, 273-281$

Cohen G, Campbell PM, Rossouw PE, Buschang PH (2010): Effects of increased surgical trauma on rates of tooth movement and apical root resorption in foxhound dogs. Orthod Craniofac Res $\underline{13}$, 179-190

Cornell CN, Lane JM (1998): Current understanding of osteoconduction in bone regeneration. Clin Orthop Relat Res S267-273

Cunha C, Panseri S, Villa O, Silva D, Gelain F (2011): 3D culture of adult mouse neural stem cells within functionalized self-assembling peptide scaffolds. Int J Nanomedicine $\underline{6}$, 943-955

Daculsi G, LeGeros RZ, Nery E, Lynch K, Kerebel B (1989): Transformation of biphasic calcium phosphate ceramics in vivo: ultrastructural and physicochemical characterization. J Biomed Mater Res $\underline{23}$, 883-894

Dahl LK (1952): A simple and sensitive histochemical method for calcium. Proc Soc Exp Biol Med $\underline{80}, 474-479$ 
Dahlin C, Gottlow J, Linde A, Nyman S (1990): Healing of maxillary and mandibular bone defects using a membrane technique. An experimental study in monkeys. Scand $\mathbf{J}$ Plast Reconstr Surg Hand Surg 24, 13-19

Damien CJ, Parsons JR (1991): Bone graft and bone graft substitutes: a review of current technology and applications. J Appl Biomater 2 , 187-208

Davies JE (2003): Understanding peri-implant endosseous healing. J Dent Educ 67, 932949

de Vicente JC, Recio O, Martin-Villa L, Junquera LM, Lopez-Arranz JS (2006): Histomorphometric evaluation of guided bone regeneration around implants with SLA surface: an experimental study in beagle dogs. Int J Oral Maxillofac Surg 35, 1047-1053

Desai SD, Blanchard J (1998): Evaluation of pluronic F127-based sustained-release ocular delivery systems for pilocarpine using the albino rabbit eye model. J Pharm Sci $\underline{87}$, 1190-1195

Devlin H, Horner K, Ledgerton D (1998): A comparison of maxillary and mandibular bone mineral densities. J Prosthet Dent $\underline{79}$, 323-327

Dogan A, Yalvac ME, Sahin F, Kabanov AV, Palotas A, Rizvanov AA (2012): Differentiation of human stem cells is promoted by amphiphilic pluronic block copolymers. Int J Nanomedicine $\underline{7}, 4849-4860$

Donath K, Breuner G (1982): A method for the study of undecalcified bones and teeth with attached soft tissues. The Sage-Schliff (sawing and grinding) technique. J Oral Pathol $\underline{11}, 318-326$

Ducy P, Karsenty G (2000): The family of bone morphogenetic proteins. Kidney Int 57 , 2207-2214

Dumortier G, Grossiord JL, Zuber M, Couarraze G, Chaumeil JC (1991): Rheological study of a thermoreversible morphine gel Drug. Dev Ind Pharm 17, 1255-1265

Dumortier G, Grossiord JL, Agnely F, Chaumeil JC (2006): A review of poloxamer 407 pharmaceutical and pharmacological characteristics. Pharm Res $\underline{23}$, 2709-2728

Edsman K, Carlfors J, Petersson R (1998): Rheological evaluation of poloxamer as an in situ gel for ophthalmic use. Eur J Pharm Sci $\underline{6}, 105-112$

Eitel F, Klapp F, Jacobson W, Schweiberer L (1981): Bone regeneration in animals and in man. A contribution to understanding the relative value of animal experiments to human pathophysiology. Archives of orthopaedic and traumatic surgery Archiv fur orthopadische und Unfall-Chirurgie 99, 59-64 
Endres S, Kratz M, Heinz M, Herzberger C, Reichel S, von Garrel T, Gotzen L, Wilke A (2005): Biocompatibility testing of different sterilised or disinfected allogenous bone grafts in comparison to the gold standard of autologous bone grafts--an "in vitro" analysis of immunomodulation. Z Orthop Ihre Grenzgeb 143, 660-668

Ewers R (2005): Maxilla sinus grafting with marine algae derived bone forming material: a clinical report of long-term results. J Oral Maxillofac Surg $\underline{63}$, 1712-1723

Ewers R: Phycodene hydoxyapatite material; in: Bone Augmentation in Oral Implantology. Hrsg. v. Khoury F, Antoun H, Missika P; Quintessence Publ. Co, London, Berlin, Chicago 2007, 348-351

Fisher M, Hyzy S, Guldberg RE, Schwartz Z, Boyan BD (2010): Regeneration of bone marrow after tibial ablation in immunocompromised rats is age dependent. Bone $\underline{46}, 396-$ 401

Fowler EB, Cuenin MF, Hokett SD, Peacock ME, McPherson JC, 3rd, Dirksen TR, Sharawy M, Billman MA (2002): Evaluation of pluronic polyols as carriers for grafting materials: study in rat calvaria defects. J Periodontol $\underline{73}$, 191-197

Franz-Odendaal TA, Hall BK, Witten PE (2006): Buried alive: how osteoblasts become osteocytes. Dev Dyn 235, 176-190

Frisman I, Seliktar D, Bianco-Peled H (2012): Nanostructuring biosynthetic hydrogels for tissue engineering: a cellular and structural analysis. Acta Biomater $\underline{8}, 51-60$

Froum S, Cho SC, Rosenberg E, Rohrer M, Tarnow D (2002): Histological comparison of healing extraction sockets implanted with bioactive glass or demineralized freeze-dried bone allograft: a pilot study. J Periodontol $\underline{73}, 94-102$

Geistlich Biomaterials (2013): heruntergeladen am 29.3.13

http://wwwgeistlichde/?dom=1017\&rub=2040

Gilbert JC, Hadgraft J, Bye A, Brookes LG (1986): Drug release from Pluronic F-127 gels. Int J Pharm $\underline{32}$, 223-228

Gosain AK, Persing JA (1999): Biomaterials in the face: benefits and risks. J Craniofac Surg $\underline{10}, 404-414$

Guzman M, Aberturas MR, Garcia F, Molpeceres J (1994): Gelatine Gels and Polyoxyethylene-Polyoxypropylene Gels: Comparative Study of Their Properties Drug. Dev Ind Pharm 20, 2041-2048

Habibovic P, Yuan H, van der Valk CM, Meijer G, van Blitterswijk CA, de Groot K (2005): 3D microenvironment as essential element for osteoinduction by biomaterials. Biomaterials $\underline{26}, 3565-3575$ 
Hämmerle CH, Jung RE (2003): Bone augmentation by means of barrier membranes. Periodontol $2000 \underline{33}, 36-53$

Hansson S, Halldin A (2012): Alveolar ridge resorption after tooth extraction: A consequence of a fundamental principle of bone physiology. J Dent Biomech $\underline{3}$, 1758736012456543

Hashimoto-Uoshima M, Ishikawa I, Kinoshita A, Weng HT, Oda S (1995): Clinical and histologic observation of replacement of biphasic calcium phosphate by bone tissue in monkeys. Int J Periodontics Restorative Dent 15, 205-213

Heary RF, Schlenk RP, Sacchieri TA, Barone D, Brotea C (2002): Persistent iliac crest donor site pain: independent outcome assessment. Neurosurgery $\underline{50}, 510-516$; discussion 516-517

Hench LL, Wilson J (1984): Surface-active biomaterials. Science 226, 630-636

Herten M, Jung RE, Ferrari D, Rothamel D, Golubovic V, Molenberg A, Hammerle CH, Becker J, Schwarz F (2009): Biodegradation of different synthetic hydrogels made of polyethylene glycol hydrogel/RGD-peptide modifications: an immunohistochemical study in rats. Clin Oral Implants Res $\underline{20}, 116-125$

Hokett SD, Cuenin MF, O'Neal RB, Brennan WA, Strong SL, Runner RR, McPherson JC, Van Dyke TE (2000): Pluronic polyol effects on human gingival fibroblast attachment and growth. J Periodontol 71, 803-809

Hollinger J, Wong ME (1996): The integrated processes of hard tissue regeneration with special emphasis on fracture healing. Oral Surg Oral Med Oral Pathol Oral Radiol Endod $\underline{82}, 594-606$

Hollinger JO, Kleinschmidt JC (1990): The critical size defect as an experimental model to test bone repair materials. J Craniofac Surg $\underline{1}$, 60-68

Hollinger JO, Uludag H, Winn SR (1998): Sustained release emphasizing recombinant human bone morphogenetic protein-2. Adv Drug Deliv Rev 31, 303-318

Howell TH, Fiorellini JP, Blackburn P, Projan SJ, de la Harpe J, Williams RC (1993): The effect of a mouthrinse based on nisin, a bacteriocin, on developing plaque and gingivitis in beagle dogs. J Clin Periodontol 20, 335-339

Huang JW, Chen WJ, Liao SK, Yang CY, Lin SS, Wu CC (2006): Osteoblastic differentiation of rabbit mesenchymal stem cells loaded in A carrier system of Pluronic F127 and Interpore. Chang Gung Med J 29, 363-372 
Huh JY, Choi BH, Kim BY, Lee SH, Zhu SJ, Jung JH (2005): Critical size defect in the canine mandible. Oral Surg Oral Med Oral Pathol Oral Radiol Endod 100, 296-301

Husseini GA, Pitt WG, Christensen DA, Dickinson DJ (2009): Degradation kinetics of stabilized Pluronic micelles under the action of ultrasound. J Control Release 138, 45-48

Ibrahim el SA, Ismail S, Fetih G, Shaaban O, Hassanein K, Abdellah NH (2012): Development and characterization of thermosensitive pluronic-based metronidazole in situ gelling formulations for vaginal application. Acta Pharm $\underline{62}, 59-70$

Iezzi G, Degidi M, Piattelli A, Mangano C, Scarano A, Shibli JA, Perrotti V (2012): Comparative histological results of different biomaterials used in sinus augmentation procedures: a human study at 6 months. Clin Oral Implants Res $\underline{23}$, 1369-1376

Iglhaut G, Schwarz F, Grundel M, Mihatovic I, Becker J, Schliephake H (2014): Shell technique using a rigid resorbable barrier system for localized alveolar ridge augmentation. Clin Oral Implants Res $\underline{25}$, e149-154

Im GI, Lee JH (2010): Repair of osteochondral defects with adipose stem cells and a dual growth factor-releasing scaffold in rabbits. J Biomed Mater Res B Appl Biomater 92, 552560

Implantologie DGf (2010): Implantatversorgung - die Rolle der DGI in Wissenschaft und Praxis. heruntergeladen am 21.01.2014

http://wwwdginetde/web/dgi/informationen?p_p_id=dgijournallatestarticles_WAR_dgijour nallatestarticlesportlet_INSTANCE_1gjY\&p_p_lifecycle=0\&p_p_state=maximized\&p_p_ mode=view\&p_p_col_id=column-

1\&p_p_col_pos=1\&p_p_col_count=2\&_dgijournallatestarticles_WAR_dgijournallatestarti clesportlet_INSTANCE_1gjY_articleID=22896

Jansen MM, Verzijl JM, Burger DM, Hekster YA (2013): Controlled release of morphine from a poloxamer 407 gel. Int J Pharm $\underline{452}$, 266-269

Jarcho M (1986): Biomaterial aspects of calcium phosphates. Properties and applications. Dent Clin North Am $\underline{30}$, 25-47

Jensen SS, Yeo A, Dard M, Hunziker E, Schenk R, Buser D (2007): Evaluation of a novel biphasic calcium phosphate in standardized bone defects: a histologic and histomorphometric study in the mandibles of minipigs. Clin Oral Implants Res $\underline{18}, 752-760$

Johnston TP (2004): The P-407-induced murine model of dose-controlled hyperlipidemia and atherosclerosis: a review of findings to date. J Cardiovasc Pharmacol $\underline{43}$, 595-606

Johnston TP (2010): Poloxamer 407 as a general lipase inhibitor: its implications in lipid metabolism and atheroma formation in C57BL/6 mice. J Pharm Pharmacol 62, 1807-1812 
Johnston TP, Palmer WK (1993): Mechanism of poloxamer 407-induced hypertriglyceridemia in the rat. Biochem Pharmacol $\underline{46}, 1037-1042$

Jung RE, Lecloux G, Rompen E, Ramel CF, Buser D, Hammerle CH (2009): A feasibility study evaluating an in situ formed synthetic biodegradable membrane for guided bone regeneration in dogs. Clin Oral Implants Res $\underline{20}, 151-161$

Jung RE, Fenner N, Hämmerle CH, Zitzmann NU (2012): Long-term outcome of implants placed with guided bone regeneration (GBR) using resorbable and non-resorbable membranes after 12-14 years. Clin Oral Implants Res

Kabanov AV, Batrakova EV, Alakhov VY (2002): Pluronic block copolymers for overcoming drug resistance in cancer. Adv Drug Deliv Rev 54, 759-779

Kainer MA, Linden JV, Whaley DN, Holmes HT, Jarvis WR, Jernigan DB, Archibald LK (2004): Clostridium infections associated with musculoskeletal-tissue allografts. N Engl J Med 350, 2564-2571

Kanekawa M, Shimizu N (1998): Age-related changes on bone regeneration in midpalatal suture during maxillary expansion in the rat. Am J Orthod Dentofacial Orthop 114, 646653

Karageorgiou V, Kaplan D (2005): Porosity of 3D biomaterial scaffolds and osteogenesis. Biomaterials 26, 5474-5491

Klein M, Goetz H, Pazen S, Al-Nawas B, Wagner W, Duschner H (2009): Pore characteristics of bone substitute materials assessed by microcomputed tomography. Clin Oral Implants Res $\underline{20}, 67-74$

Koerten HK, van der Meulen J (1999): Degradation of calcium phosphate ceramics. J Biomed Mater Res 44, 78-86

Kumari N, Pathak K (2012): Dual controlled release, in situ gelling periodontal sol of metronidazole benzoate and serratiopeptidase: statistical optimization and mechanistic evaluation. Curr Drug Deliv $\underline{9}, 74-84$

Laurencin C, Khan Y, El-Amin SF (2006): Bone graft substitutes. Expert Rev Med Devices $\underline{3}, 49-57$

Lee JB, Chun KW, Yoon JJ, Park TG (2004): Controlling degradation of acidhydrolyzable pluronic hydrogels by physical entrapment of poly(lactic acid-co-glycolic acid) microspheres. Macromol Biosci 4, 957-962

Lenaerts V, Triqueneaux C, Quartern M, Rieg-Falson Fo, Couvreur P (1987): Temperature-dependent rheological behavior of Pluronic F-127 aqueous solutions. Int $\mathbf{J}$ Pharm $\underline{39}, 121-127$ 
Leszczynska K, Namiot A, Cruz K, Byfield FJ, Won E, Mendez G, Sokolowski W, Savage PB, Bucki R, Janmey PA (2011): Potential of ceragenin CSA-13 and its mixture with pluronic F-127 as treatment of topical bacterial infections. J Appl Microbiol 110, 229238

Lian JB, Stein GS (1993): The developmental stages of osteoblast growth and differentiation exhibit selective responses of genes to growth factors (TGF beta 1) and hormones (vitamin D and glucocorticoids). J Oral Implantol 19, 95-105; discussion 136107

Linde A, Alberius P, Dahlin C, Bjurstam K, Sundin Y (1993): Osteopromotion: a softtissue exclusion principle using a membrane for bone healing and bone neogenesis. $\mathrm{J}$ Periodontol $\underline{64}, 1116-1128$

Linde D, Diebowski S, Greiner-Petter C, Schneider G (2012): Evaluation of bone replacement materials in a rabbit cranial defect model using micro $\mathrm{CT}$ and hard tissue histology. Biomed Tech (Berl) $\underline{57}, 557-560$

Lippens E, Vertenten G, Girones J, Declercq H, Saunders J, Luyten J, Duchateau L, Schacht E, Vlaminck L, Gasthuys F et al (2010): Evaluation of bone regeneration with an injectable, in situ polymerizable Pluronic F127 hydrogel derivative combined with autologous mesenchymal stem cells in a goat tibia defect model. Tissue Eng Part A $\underline{16}$, 617-627

Lu J, Descamps M, Dejou J, Koubi G, Hardouin P, Lemaitre J, Proust JP (2002): The biodegradation mechanism of calcium phosphate biomaterials in bone. J Biomed Mater Res $\underline{63}, 408-412$

Lu JX, Flautre B, Anselme K, Hardouin P, Gallur A, Descamps M, Thierry B (1999): Role of interconnections in porous bioceramics on bone recolonization in vitro and in vivo. J Mater Sci Mater Med 10, 111-120

Lüllmann-Rauch R (2006): Binde- und Stützgewebe; in: Histologie, hrsg. v. LüllmannRauch R; Georg Thieme Verlag KG, Stuttgart New York, 112-162

Lundgren D, Lundgren AK, Sennerby L (1995): The effect of mechanical intervention on jaw bone density. Clin Oral Implants Res $\underline{6}, 54-59$

Maiorana C, Beretta M, Salina S, Santoro F (2005): Reduction of autogenous bone graft resorption by means of bio-oss coverage: a prospective study. Int $\mathrm{J}$ Periodontics Restorative Dent 25, 19-25

Manjubala I, Sastry TP, Kumar RV (2005): Bone in-growth induced by biphasic calcium phosphate ceramic in femoral defect of dogs. J Biomater Appl 19, 341-360 
Marx RE, Carlson ER, Eichstaedt RM, Schimmele SR, Strauss JE, Georgeff KR (1998): Platelet-rich plasma: Growth factor enhancement for bone grafts. Oral Surg Oral Med Oral Pathol Oral Radiol Endod 85, 638-646

Meikle MC, Papaioannou S, Ratledge TJ, Speight PM, Watt-Smith SR, Hill PA, Reynolds JJ (1994): Effect of poly DL-lactide--co-glycolide implants and xenogeneic bone matrix-derived growth factors on calvarial bone repair in the rabbit. Biomaterials $\underline{15}$, 513-521

Melcher AH, Dreyer CJ (1962): Protection of the blood clot in healing corcumscribed bone defects. J Bone Joint Surg Br 44-B, 424-430

Miyazaki S, Yokouchi C, Nakamura T, Hashiguchi N, Hou WM, Takada M (1986): Pluronic F-127 gels as a novel vehicle for rectal administration of indomethacin. Chem Pharm Bull (Tokyo) 34, 1801-1808

Monchau F, Lefevre A, Descamps M, Belquin-myrdycz A, Laffargue P, Hildebrand HF (2002): In vitro studies of human and rat osteoclast activity on hydroxyapatite, betatricalcium phosphate, calcium carbonate. Biomol Eng $\underline{19}$, 143-152

Moore WR, Graves SE, Bain GI (2001): Synthetic bone graft substitutes. ANZ J Surg $\underline{71}, 354-361$

Morikawa K, Okada F, Hosokawa M, Kobayashi H (1987): Enhancement of therapeutic effects of recombinant interleukin 2 on a transplantable rat fibrosarcoma by the use of a sustained release vehicle, pluronic gel. Cancer Res $\underline{47}, 37-41$

Nery EB, LeGeros RZ, Lynch KL, Lee K (1992): Tissue response to biphasic calcium phosphate ceramic with different ratios of HA/beta TCP in periodontal osseous defects. $\mathbf{J}$ Periodontol $\underline{63}, 729-735$

Nie S, Hsiao WL, Pan W, Yang Z (2011): Thermoreversible Pluronic F127-based hydrogel containing liposomes for the controlled delivery of paclitaxel: in vitro drug release, cell cytotoxicity, and uptake studies. Int J Nanomedicine $\underline{6}, 151-166$

Niedhart C, Pingsmann A, Jurgens C, Marr A, Blatt R, Niethard FU (2003): Complications after harvesting of autologous bone from the ventral and dorsal iliac crest a prospective, controlled study. Z Orthop Ihre Grenzgeb 141, 481-486

Nkenke E, Stelzle F (2009): Clinical outcomes of sinus floor augmentation for implant placement using autogenous bone or bone substitutes: a systematic review. Clin Oral Implants Res 20 Suppl 4, 124-133

Nkenke E, Schultze-Mosgau S, Radespiel-Troger M, Kloss F, Neukam FW (2001): Morbidity of harvesting of chin grafts: a prospective study. Clin Oral Implants Res $\underline{12}$, 495-502 
Oh TJ, Meraw SJ, Lee EJ, Giannobile WV, Wang HL (2003): Comparative analysis of collagen membranes for the treatment of implant dehiscence defects. Clin Oral Implants Res $\underline{14}, 80-90$

Padilla M, Clark GT, Merrill RL (2000): Topical medications for orofacial neuropathic pain: a review. J Am Dent Assoc 131, 184-195

Palmer WK, Emeson EE, Johnston TP (1998): Poloxamer 407-induced atherogenesis in the C57BL/6 mouse. Atherosclerosis $\underline{136}, 115-123$

Pang S (1993): Final report on the safety assessment of polyethylene glycols (PEGs) -6, 8, -32, -75, -150, -14M, -20M. J Am Coll Toxicol 12, 429-457

Park H, Park K (1996): Biocompatibility issues of implantable drug delivery systems. Pharm Res $\underline{13}, 1770-1776$

Park MH, Joo MK, Choi BG, Jeong B (2012): Biodegradable thermogels. Acc Chem Res $\underline{45}, 424-433$

Pfeilschifter J, Wolf O, Naumann A, Minne HW, Mundy GR, Ziegler R (1990): Chemotactic response of osteoblastlike cells to transforming growth factor beta. $\mathbf{J}$ Bone Miner Res $\underline{5}, 825-830$

Piattelli A, Scarano A, Mangano C (1996): Clinical and histologic aspects of biphasic calcium phosphate ceramic (BCP) used in connection with implant placement. Biomaterials $\underline{17}, 1767-1770$

Pistner H, Gutwald R, Ordung R, Reuther J, Muhling J (1993): Poly(L-lactide): a long-term degradation study in vivo. I. Biological results Biomaterials $\underline{14}$, 671-677

Plachokova AS, van den Dolder J, Stoelinga PJ, Jansen JA (2007): Early effect of platelet-rich plasma on bone healing in combination with an osteoconductive material in rat cranial defects. Clin Oral Implants Res $\underline{18}, 244-251$

Price TO, Farr SA, Yi X, Vinogradov S, Batrakova E, Banks WA, Kabanov AV (2010): Transport across the blood-brain barrier of pluronic leptin. J Pharmacol Exp Ther $\underline{333}, 253-263$

Rakhmatia YD, Ayukawa Y, Furuhashi A, Koyano K (2013): Current barrier membranes: titanium mesh and other membranes for guided bone regeneration in dental applications. J Prosthodont Res 57, 3-14

Ramel CF, Wismeijer DA, Hammerle CH, Jung RE (2012): A randomized, controlled clinical evaluation of a synthetic gel membrane for guided bone regeneration around dental implants: clinical and radiologic 1- and 3-year results. Int J Oral Maxillofac Implants 27, 435-441 
Reid CA, McCarthy JG, Kolber AB (1981): A study of regeneration in parietal bone defects in rabbits. Plast Reconstr Surg 67, 591-596

Reis EC, Borges AP, del Carlo RJ, Oliveira PM, Sepulveda RV, Fernandes NA, Martins LM, Carvalho TB (2013): Guided tissue regeneration using rigid absorbable membranes in the dog model of chronic furcation defect. Acta Odontol Scand 71, 372-380

Rengachary SS (2002): Bone morphogenetic proteins: basic concepts. Neurosurg Focus $\underline{13}, \mathrm{e} 2$

Reynolds MA, Aichelmann-Reidy ME, Branch-Mays GL, Gunsolley JC (2003): The efficacy of bone replacement grafts in the treatment of periodontal osseous defects. A systematic review. Ann Periodontol $\underline{8}, 227-265$

Robert Koch-Institut (2012): Daten und Fakten: Ergebnisse der Studie »Gesundheit in Deutschland aktuell 2010«. Beiträge zur Gesundheitsberichterstattung des Bundes. RKI, Berlin

Rothamel D, Schwarz F, Sager M, Herten M, Sculean A, Becker J (2005): Biodegradation of differently cross-linked collagen membranes: an experimental study in the rat. Clin Oral Implants Res $\underline{16}, 369-378$

Rousselle AV, Heymann D (2002): Osteoclastic acidification pathways during bone resorption. Bone $\underline{30}, 533-540$

Scarano A, Degidi M, Perrotti V, Piattelli A, Iezzi G (2012): Sinus augmentation with phycogene hydroxyapatite: histological and histomorphometrical results after 6 months in humans. A case series. Oral Maxillofac Surg 16, 41-45

Schell H, Epari DR, Kassi JP, Bragulla H, Bail HJ, Duda GN (2005): The course of bone healing is influenced by the initial shear fixation stability. J Orthop Res $\underline{23}, 1022-$ 1028

Schenk RK, Buser D, Hardwick WR, Dahlin C (1994): Healing pattern of bone regeneration in membrane-protected defects: a histologic study in the canine mandible. Int J Oral Maxillofac Implants $\underline{9}, 13-29$

Schliephake H (2010): Application of bone growth factors--the potential of different carrier systems. Oral Maxillofac Surg $\underline{14}, 17-22$

Schmolka IR (1972): Artificial skin. I. Preparation and properties of pluronic F-127 gels for treatment of burns. J Biomed Mater Res $\underline{6}, 571-582$

Schopper C, Ziya-Ghazvini F, Goriwoda W, Moser D, Wanschitz F, Spassova E, Lagogiannis G, Auterith A, Ewers R (2005): HA/TCP compounding of a porous CaP 
biomaterial improves bone formation and scaffold degradation--a long-term histological study. J Biomed Mater Res B Appl Biomater 74, 458-467

Schopper C, Moser D, Spassova E, Goriwoda W, Lagogiannis G, Hoering B, Ewers R, Redl H (2008): Bone regeneration using a naturally grown HA/TCP carrier loaded with rh BMP-2 is independent of barrier-membrane effects. J Biomed Mater Res A $\underline{85}$, 954-963

Schortinghuis J, Ruben JL, Meijer HJ, Bronckers AL, Raghoebar GM, Stegenga B (2003): Microradiography to evaluate bone growth into a rat mandibular defect. Arch Oral Biol $\underline{48}, 155-160$

Schratt HE, Regel G, Kiesewetter B, Tscherne H (1996): HIV infection caused by cold preserved bone transplants. Unfallchirurg $\underline{99}, 679-684$

Schwartz Z, Somers A, Mellonig JT, Carnes DL, Jr., Dean DD, Cochran DL, Boyan BD (1998): Ability of commercial demineralized freeze-dried bone allograft to induce new bone formation is dependent on donor age but not gender. J Periodontol $\underline{69}, 470-478$

Schwartz Z, Weesner T, van Dijk S, Cochran DL, Mellonig JT, Lohmann CH, Carnes DL, Goldstein M, Dean DD, Boyan BD (2000): Ability of deproteinized cancellous bovine bone to induce new bone formation. J Periodontol 71, 1258-1269

Schwartz-Arad D, Levin L (2005): Intraoral autogenous block onlay bone grafting for extensive reconstruction of atrophic maxillary alveolar ridges. J Periodontol $\underline{76}$, 636-641

Shindo M, Fong BP, Funk GF, Karnell LH (2000): The fibula osteocutaneous flap in head and neck reconstruction: a critical evaluation of donor site morbidity. Arch Otolaryngol Head Neck Surg 126, 1467-1472

Simion M, Rocchietta I, Kim D, Nevins M, Fiorellini J (2006): Vertical ridge augmentation by means of deproteinized bovine bone block and recombinant human platelet-derived growth factor-BB: a histologic study in a dog model. Int J Periodontics Restorative Dent 26, 415-423

Smith LG, Karagianes MT (1974): Histological preparation of bone to study ingrowth into implanted materials. Calcif Tissue Res 14, 333-337

Sogal A, Tofe AJ (1999): Risk assessment of bovine spongiform encephalopathy transmission through bone graft material derived from bovine bone used for dental applications. J Periodontol $\underline{70}$, 1053-1063

Spassova E, Gintenreiter S, Halwax E, Moser D, Schopper C, Ewers R (2007): Chemistry, ultrastructure and porosity of monophasic and biphasic bone forming materials derived from marine algae. Materialwissenschaft und Werkstofftechnik $\underline{38}$, 1027-1034 
Stein GS, Lian JB (1993): Molecular mechanisms mediating proliferation/differentiation interrelationships during progressive development of the osteoblast phenotype. Endocr Rev $\underline{14}, 424-442$

Svanberg GK, Syed SA, Scott BW, Jr. (1982): Differences between gingivitis and periodontitis associated microbial flora in the beagle dog. Relationship of plaque parameters to histological parameters of periodontal disease. J Periodontal Res $\underline{17}, 1-11$

Swennen I, Vermeersch V, Hornof M, Adriaens E, Remon JP, Urtti A, Schacht EH (2006): In-situ crosslinkable thermo-responsive hydrogels for drug delivery. J Control Release $\underline{116}$, e21-24

Tatsumi S, Ishii K, Amizuka N, Li M, Kobayashi T, Kohno K, Ito M, Takeshita S, Ikeda K (2007): Targeted ablation of osteocytes induces osteoporosis with defective mechanotransduction. Cell Metab $\underline{5}, 464-475$

Terheyden H (2010): Knochenaugmentationen in der Implantologie. Dtsch Zahnarztl Z $\underline{65}, 320-331$

Thorwarth M, Wehrhan F, Srour S, Schultze-Mosgau S, Felszeghy E, Bader RD, Schlegel KA (2007): Evaluation of substitutes for bone: comparison of microradiographic and histological assessments. Br J Oral Maxillofac Surg 45, 41-47

Tian Y, Mao S (2012): Amphiphilic polymeric micelles as the nanocarrier for peroral delivery of poorly soluble anticancer drugs. Expert Opin Drug Deliv $\underline{9}, 687-700$

Tsuruga E, Takita H, Itoh H, Wakisaka Y, Kuboki Y (1997): Pore size of porous hydroxyapatite as the cell-substratum controls BMP-induced osteogenesis. J Biochem $\underline{121}$, 317-324

Turhani D, Cvikl B, Watzinger E, Weissenbock M, Yerit K, Thurnher D, Lauer G, Ewers R (2005): In vitro growth and differentiation of osteoblast-like cells on hydroxyapatite ceramic granule calcified from red algae. J Oral Maxillofac Surg 63, 793 799

Uludag H, D'Augusta D, Palmer R, Timony G, Wozney J (1999): Characterization of rhBMP-2 pharmacokinetics implanted with biomaterial carriers in the rat ectopic model. $\mathbf{J}$ Biomed Mater Res $\underline{46}$, 193-202

Urist MR (1965): Bone: formation by autoinduction. Science 150, 893-899

Urist MR, DeLange RJ, Finerman GA (1983): Bone cell differentiation and growth factors. Science 220, 680-686

Valentini P, Abensur DJ (2003): Maxillary sinus grafting with anorganic bovine bone: a clinical report of long-term results. Int J Oral Maxillofac Implants $\underline{18}, 556-560$ 
Vashi AV, Keramidaris E, Abberton KM, Morrison WA, Wilson JL, O'Connor AJ, Cooper-White JJ, Thompson EW (2008): Adipose differentiation of bone marrowderived mesenchymal stem cells using Pluronic F-127 hydrogel in vitro. Biomaterials 29, 573-579

Vignoletti F, Abrahamsson I (2012): Quality of reporting of experimental research in implant dentistry. Critical aspects in design, outcome assessment and model validation. $\mathbf{J}$ Clin Periodontol 39 Suppl 12, 6-27

Viinikainen AK, Goransson H, Huovinen K, Kellomaki M, Tormala P, Rokkanen P (2009): Bioabsorbable poly-L/D-lactide (PLDLA) 96/4 triple-stranded bound suture in the modified Kessler repair: an ex vivo static and cyclic tensile testing study in a porcine extensor tendon model. J Mater Sci Mater Med 20, 1963-1969

von Arx T, Cochran DL, Hermann JS, Schenk RK, Buser D (2001): Lateral ridge augmentation using different bone fillers and barrier membrane application. A histologic and histomorphometric pilot study in the canine mandible. Clin Oral Implants Res $\underline{12}, 260$ 269

Waasdorp J, Reynolds MA (2010): Allogeneic bone onlay grafts for alveolar ridge augmentation: a systematic review. Int J Oral Maxillofac Implants $\underline{25}, 525-531$

Wang MY, Armstrong JK, Fisher TC, Meiselman HJ, McComb GJ, Levy ML (2001): A new, pluronic-based, bone hemostatic agent that does not impair osteogenesis. Neurosurgery $\underline{49}, 962-967$; discussion 968

Warren A, Benseler V, Cogger VC, Bertolino P, Le Couteur DG (2011): The impact of poloxamer 407 on the ultrastructure of the liver and evidence for clearance by extensive endothelial and kupffer cell endocytosis. Toxicol Pathol 39, 390-397

Welsch U: Knochengewebe; in: Lehrbuch Histologie, hrsg. v. Welsch U; Urban \& Fischer Verlag, München 2006, 131-146

Weng D, Hurzeler MB, Quinones CR, Ohlms A, Caffesse RG (2000): Contribution of the periosteum to bone formation in guided bone regeneration. A study in monkeys. Clin Oral Implants Res $\underline{11}, 546-554$

Wenz B, Oesch B, Horst M (2001): Analysis of the risk of transmitting bovine spongiform encephalopathy through bone grafts derived from bovine bone. Biomaterials $\underline{22}, 1599-1606$

Wiltfang J, Schlegel KA, Schultze-Mosgau S, Nkenke E, Zimmermann R, Kessler P (2003): Sinus floor augmentation with beta-tricalciumphosphate (beta-TCP): does plateletrich plasma promote its osseous integration and degradation? Clin Oral Implants Res $\underline{14}$, 213-218 
Wiltfang J, Kloss FR, Kessler P, Nkenke E, Schultze-Mosgau S, Zimmermann R, Schlegel KA (2004): Effects of platelet-rich plasma on bone healing in combination with autogenous bone and bone substitutes in critical-size defects. An animal experiment. Clin Oral Implants Res $\underline{15}$, 187-193

Wozney JM (1998): The bone morphogenetic protein family: multifunctional cellular regulators in the embryo and adult. Eur J Oral Sci 106 Suppl 1, 160-166

Xuan JJ, Yan YD, Oh DH, Choi YK, Yong CS, Choi HG (2011): Development of thermo-sensitive injectable hydrogel with sustained release of doxorubicin: rheological characterization and in vivo evaluation in rats. Drug Deliv $\underline{18}, 305-311$

Yamada S, Heymann D, Bouler JM, Daculsi G (1997): Osteoclastic resorption of calcium phosphate ceramics with different hydroxyapatite/beta-tricalcium phosphate ratios. Biomaterials $\underline{18}, 1037-1041$

Zhou AJ, Peel SA, Clokie CM (2007): An evaluation of hydroxyapatite and biphasic calcium phosphate in combination with Pluronic F127 and BMP on bone repair. J Craniofac Surg $\underline{18}, 1264-1275$

Zitzmann NU, Naef R, Scharer P (1997): Resorbable versus nonresorbable membranes in combination with Bio-Oss for guided bone regeneration. Int J Oral Maxillofac Implants $\underline{12}, 844-852$ 


\section{Anhang}

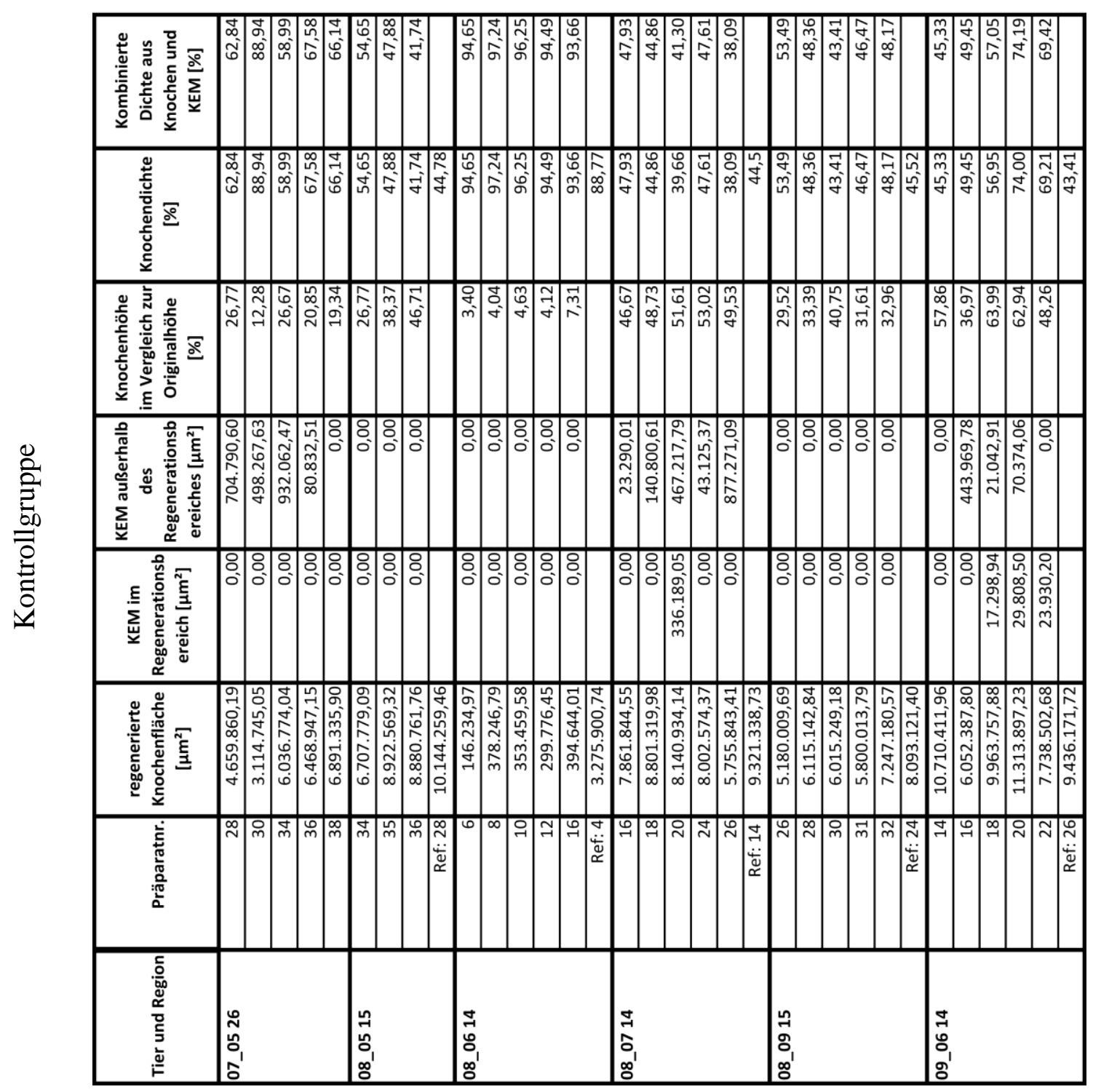




\begin{tabular}{|c|c|c|c|c|c|c|c|c|c|c|c|c|c|c|c|c|c|c|}
\hline 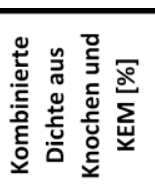 & 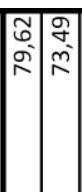 & & \begin{tabular}{|l|}
$\infty$ \\
0 \\
0 \\
\end{tabular} & 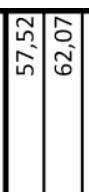 & 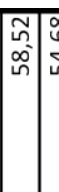 & & 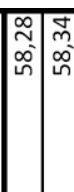 & 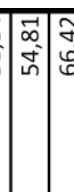 & 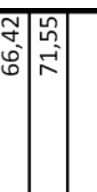 & 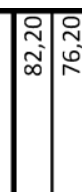 & 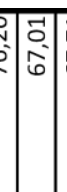 & 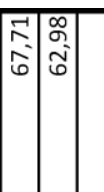 & 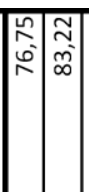 & 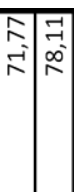 & \begin{tabular}{|l|} 
\\
$\overrightarrow{0}$ \\
\end{tabular} & 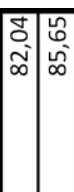 & & \\
\hline 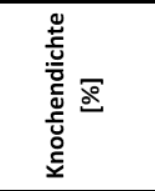 & 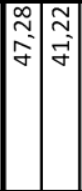 & 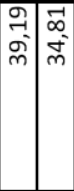 & 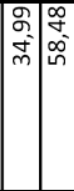 & 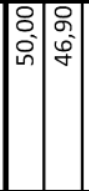 & 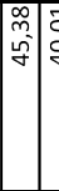 & $\begin{array}{l}n \\
\end{array}$ & 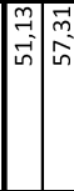 & $\begin{array}{l}0 \\
\vdots \\
\\
0\end{array}$ & 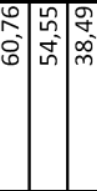 & 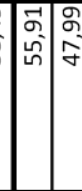 & $\begin{array}{ll}n \\
\hat{f}\end{array}$ & 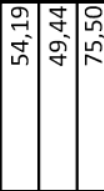 & 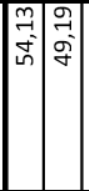 & \begin{tabular}{l|l}
0 \\
\multirow{2}{*}{} \\
\end{tabular} & \begin{tabular}{|l|l} 
& $\vec{N}$ \\
0 \\
$\infty$ \\
$m$
\end{tabular} & 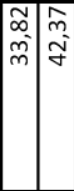 & \begin{tabular}{|c|} 
\\
0 \\
0 \\
0
\end{tabular} \mid & 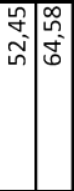 \\
\hline 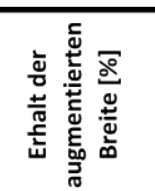 & 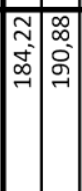 & 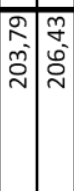 & 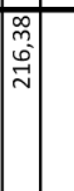 & 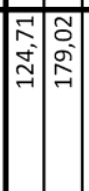 & 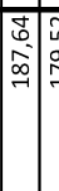 & 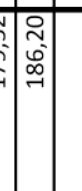 & 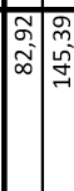 & 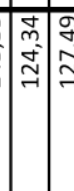 & 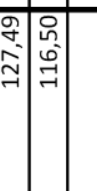 & 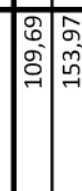 & 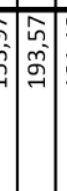 & 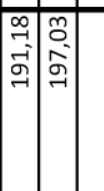 & 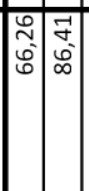 & 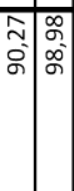 & $\mid \begin{array}{l}\mid \begin{array}{l}0 \\
\vdots \\
0 \\
0\end{array} \\
\end{array}$ & 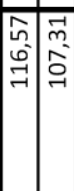 & $\mid$ & $\begin{array}{l}\text { न्वे } \\
\text { के }\end{array}$ \\
\hline 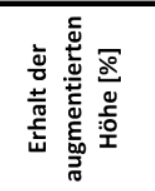 & 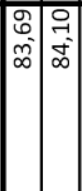 & 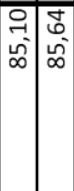 & \begin{tabular}{|l|}
$\begin{array}{l}0 \\
n \\
n \\
n\end{array}$ \\
\end{tabular} & 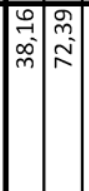 & 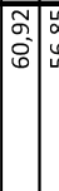 & 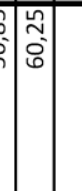 & 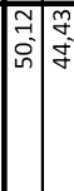 & 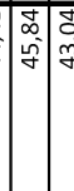 & 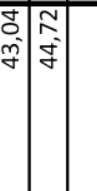 & 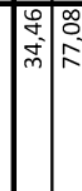 & 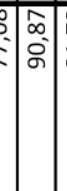 & 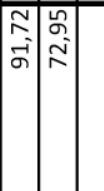 & 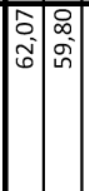 & 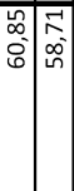 & \begin{tabular}{|l|} 
\\
\\
in \\
\end{tabular} & 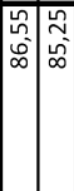 & \begin{tabular}{|l|} 
\\
9 \\
0 \\
0
\end{tabular} & 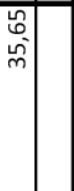 \\
\hline 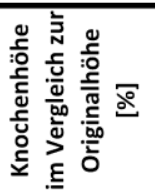 & 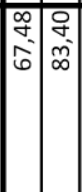 & 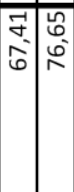 & 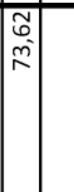 & 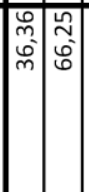 & 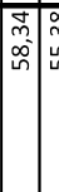 & 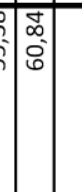 & 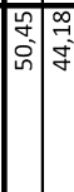 & 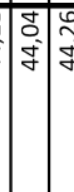 & 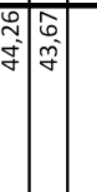 & 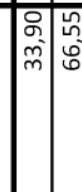 & مُ & 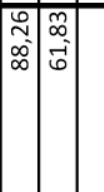 & 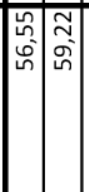 & 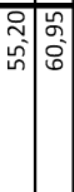 & \begin{tabular}{|l|} 
\\
\\
0 \\
0 \\
0
\end{tabular} & 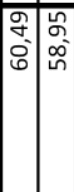 & 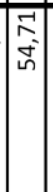 & 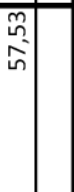 \\
\hline 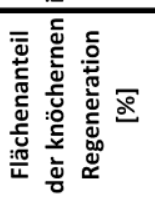 & 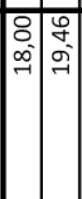 & 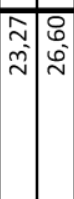 & 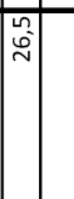 & 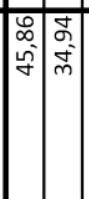 & & ș & 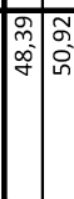 & \begin{tabular}{l|l}
$\bar{\alpha}$ & $\bar{\alpha}$ \\
$\bar{m}$ & $\bar{m}$
\end{tabular} & 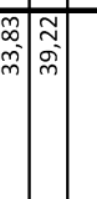 & 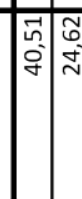 & 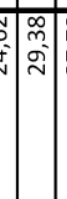 & 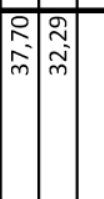 & 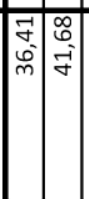 & 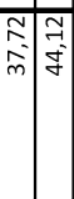 & \begin{tabular}{|l|}
0 \\
0 \\
0 \\
$m$
\end{tabular} \mid & 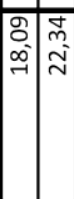 & \begin{tabular}{|l|}
$\infty$ \\
$\stackrel{-}{A}$
\end{tabular} & $\begin{array}{l}\text { J } \\
\substack{n \\
m}\end{array}$ \\
\hline 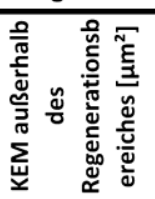 & 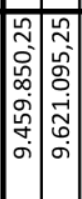 & 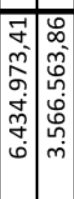 & 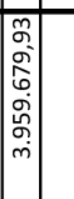 & 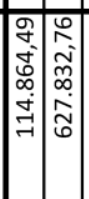 & 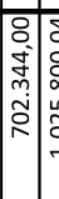 & 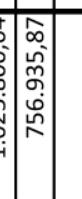 & 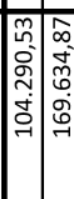 & 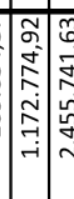 & 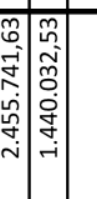 & 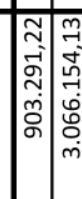 & 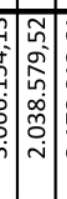 & 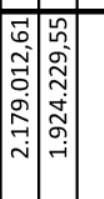 & 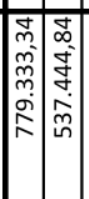 & 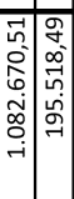 & 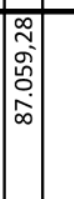 & 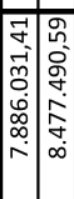 & 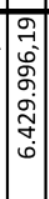 & 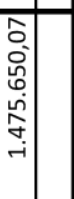 \\
\hline 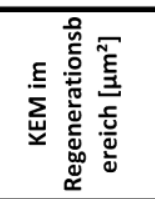 & 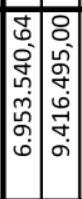 & 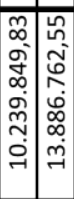 & 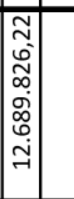 & 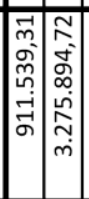 & 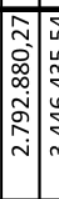 & 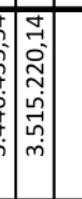 & 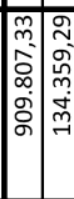 & 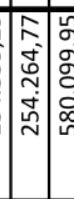 & 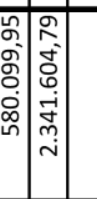 & 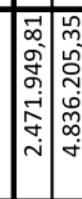 & 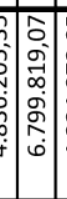 & 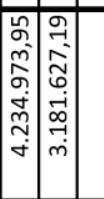 & 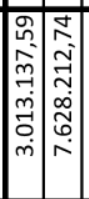 & 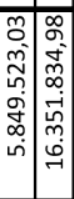 & 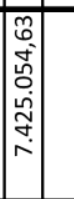 & 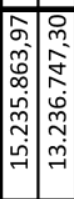 & 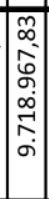 & 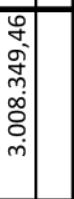 \\
\hline 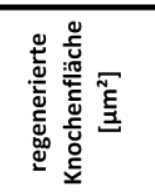 & 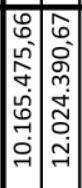 & 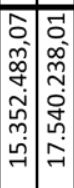 & 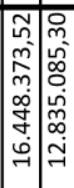 & 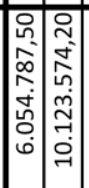 & 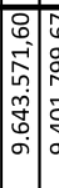 & 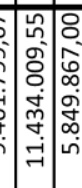 & 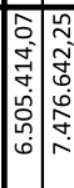 & 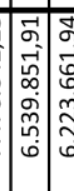 & 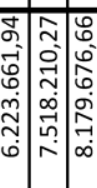 & 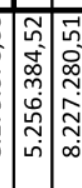 & 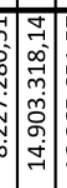 & 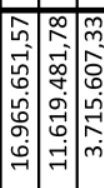 & 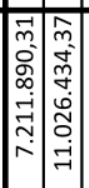 & 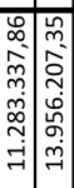 & 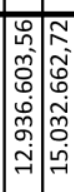 & 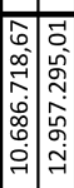 & 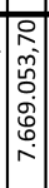 & 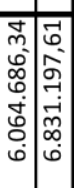 \\
\hline 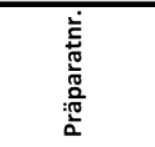 & ৯ & \begin{tabular}{|l|l|} 
m \\
\end{tabular} & 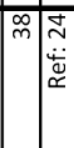 & $\stackrel{-\infty}{\oplus}$ & & 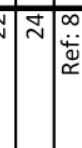 & & $\sim$ & ৯ & ক্ল & & 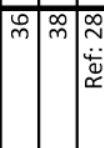 & ${ }^{\infty}$ 어 & ন্ন & 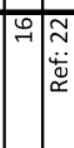 & & 6 & व) \\
\hline 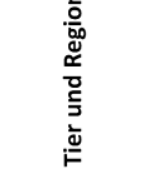 & & $\begin{array}{l}0 \\
0 \\
n_{0} \\
0 \\
0\end{array}$ & & & $\begin{array}{l}\text { J } \\
\text { n̆ }^{\prime} \\
\infty^{\prime}\end{array}$ & & & $\begin{array}{l}\text { J̃ } \\
\mathscr{L}^{\prime} \\
\infty^{\prime}\end{array}$ & & & $\begin{array}{l}\stackrel{2}{1} \\
0 \\
\text { o }\end{array}$ & a & & $\begin{array}{l}\text { J } \\
\sigma_{1} \\
\infty^{\prime}\end{array}$ & & & 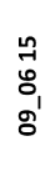 & \\
\hline
\end{tabular}




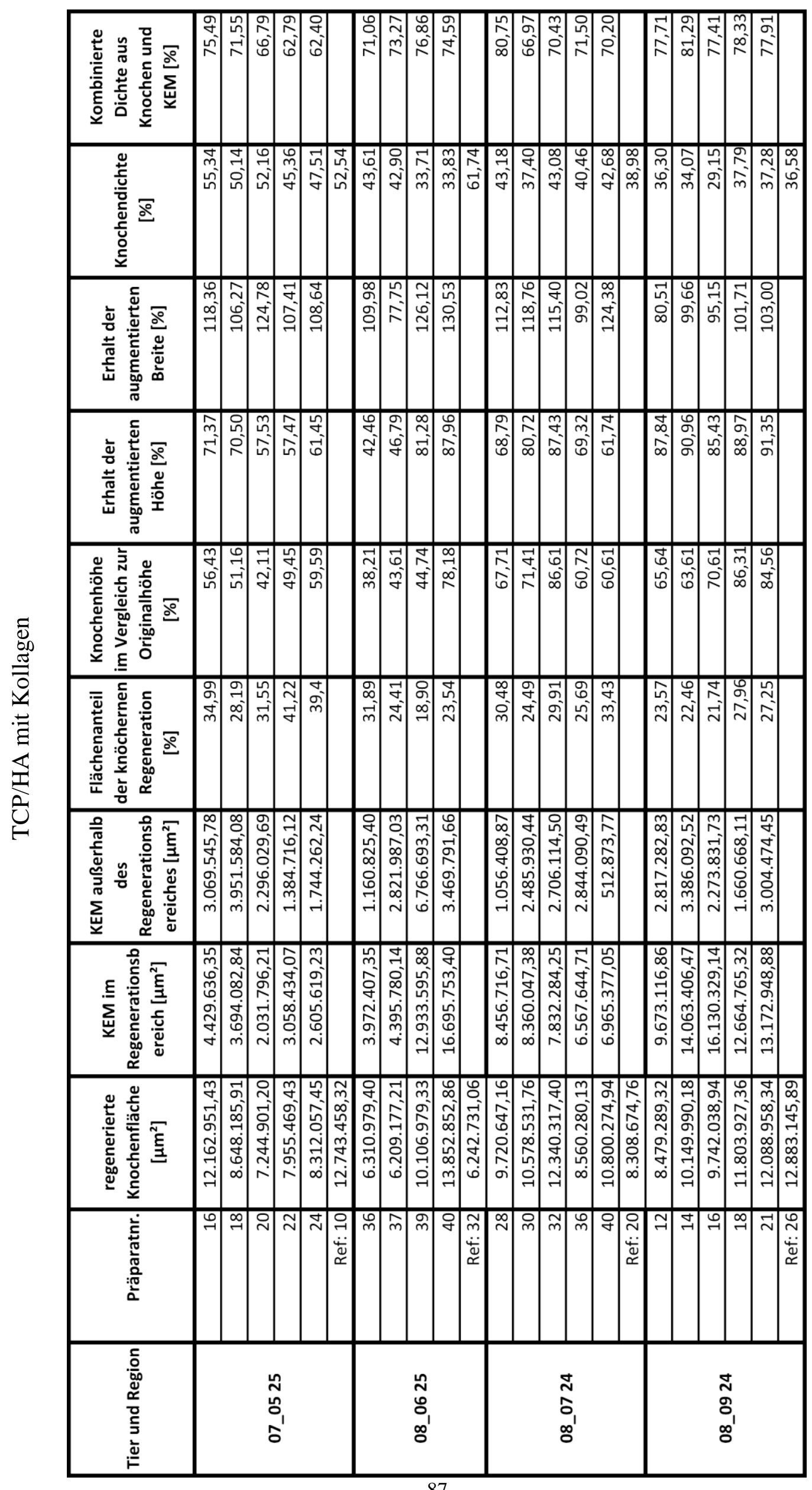




\section{Danksagung:}

Herrn Prof. Dr. med. Dr. med. dent H. Schliephake gilt mein besonderer Dank für die Überlassung dieses Promotionsthemas und die hervorragende wissenschaftliche Betreuung dieser Arbeit.

Ebenso gilt mein Dank allen wissenschaftlichen und technischen Mitarbeiterinnen der Klinik für Mund-, Kiefer- und Gesichtschirurgie für die umfassende Einarbeitung in die Labortätigkeit.

Sehr herzlich möchte ich mich auch bei Herrn Markus Harden für die Unterstützung bei der statistischen Auswertung der Ergebnisse bedanken. 


\section{Lebenslauf:}

Am 26.04.1987 wurde ich als Tochter von Regina Drewes und Gerhard Hase in Hannover geboren. Von 1993 bis 1997 besuchte ich die Grundschule Tegelweg in Hannover, von der ich für ein Jahr auf die Orientierungsschule Sahlkamp wechselte. Anschließend besuchte ich für ein Schuljahr die Gottfried-Keller-Schule in Hannover. Die Allgemeine Hochschulreife erlangte ich 2006 an der Ricarda-Huch-Schule in Hannover.

Zum Sommersemester 2007 begann ich das Studium der Zahnmedizin an der GeorgAugust-Universität in Göttingen, das ich im Juli 2012 mit dem Staatsexamen beendete.

Vom 15.10.2012 bis zum 28.02.2014 war ich in der Poliklinik für Präventive Zahnmedizin, Parodontologie und Kariologie der Universitätsmedizin Göttingen tätig.

Seit dem 01.03.2014 arbeite ich in der Praxis für Kieferorthopädie Dr. Buken in Gehrden und befinde mich im NEBEOP-Programm, der Weiterbildung zur Fachzahnärztin für Kieferorthopädie an der Medizinischen Hochschule Hannover. 